UNIVERSIDADE DE SÃO PAULO

ESCOLA DE ENGENHARIA DE SÃO CARLOS

DEPARTAMENTO DE ENGENHARIA DE ESTRUTURAS

FERNANDO HENRIQUE SANTANA GILIO

Terças de aço formadas a frio com

continuidade nos apoios por meio de luvas

SÃO CARLOS 



\title{
Terças de aço formadas a frio com continuidade nos apoios por meio de luvas
}

\author{
VERSÃO CORRIGIDA \\ A versão original encontra-se na escola de Engenharia de São Carlos
}

Dissertação apresentada à Escola de Engenharia de São Carlos da Universidade de São Paulo, como parte dos requisitos necessários para obtenção do título de Mestre em Engenharia Civil (Estruturas).

Orientador: Prof. Dr. Maximiliano Malite 
AUTORIZO A REPRODUÇÃO TOTAL OU PARCIAL DESTE TRABALHO, POR QUALQUER MEIO CONVENCIONAL OU ELETRÔNICO, PARA FINS DE ESTUDO E PESQUISA, DESDE QUE CITADA A FONTE.

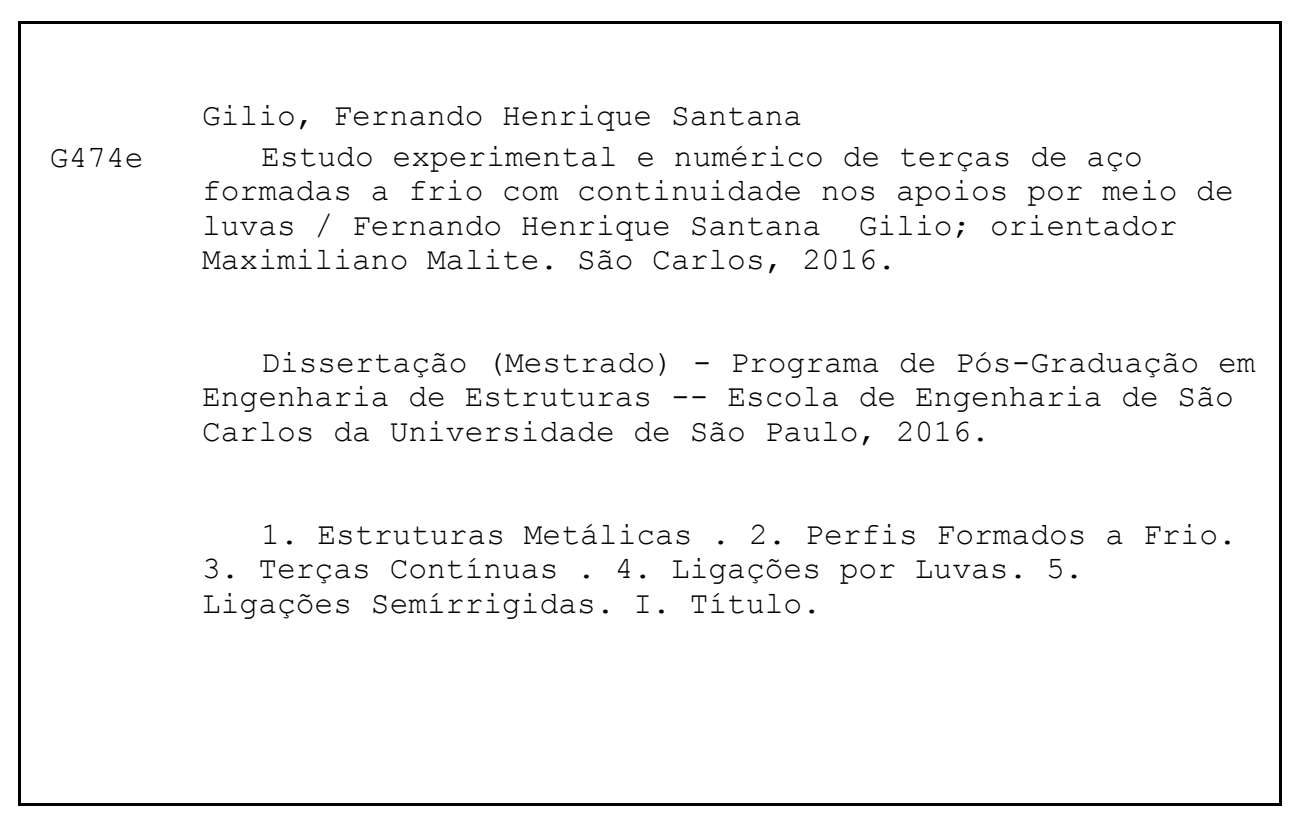




\section{FOLHA DE JULGAMENTO}

Candidato: Engenheiro FERNANDO HENRIQUE SANTANA GILIO.

Título da dissertação: "Terças de aço formadas a frio com continuidade nos apoios por meio de luvas".

Data da defesa: 24/03/2016

Comissão Julgadora:

Prof. Associado Maximiliano Malife (Orientador)

(Escola de Engenharia de São Carlos/EESC)

Prof. Dr. Luiz Carlos Marcos Vieira Júnior

(Universidade Estadual de Campinas/UNICAMP)

Prof. Dr. Wanderson Fernando Maia

(Universidade Federal de São Carlos/UFSCar)
Resultado:

APROVADO

APROVADO

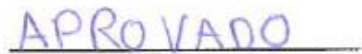

Coordenador do Programa de Pós-Graduação em Engenheira Civil (Engenharia de Estruturas):

Prof. Titular Humberto Breves Coda

Presidente da Comissão de Pós-Graduação:

Prof. Associado Paulo Sergio Lima Segantine 

Dedico este trabalho ao meu pai, Wilson Gilio. 



\section{AGRADECIMENTOS}

A Deus e a minha família por todas as conquistas em minha vida.

Ao Prof. Maximiliano Malite pela excelente orientação, confiança, paciência e as valiosas contribuições dadas a este trabalho.

À Modular Sistemas Construtivos pelo apoio à pesquisa e fornecimento de todos os protótipos do programa experimental.

À equipe do Laboratório de Estruturas: Amaury, Douglas, Fabiano, Fernando, Jorge Mario, Mauri, Romeu e Vareda.

A todos os meus amigos pelo companheirismo, conselhos e momentos de descontração.

Aos professores e funcionários do Departamento de Engenharia de Estruturas e da Escola de Engenharia de São Carlos.

Ao CNPq (Conselho Nacional de Desenvolvimento Científico e Tecnológico) pela bolsa concedida. 



\section{RESUMO}

GILIO, F. H. S. Terças de aço formadas a frio com continuidade nos apoios por meio de luvas. 2016. 120 p. Dissertação (Mestrado em Engenharia de Estruturas) - Departamento de Engenharia de Estruturas, Escola de Engenharia de São Carlos, Universidade de São Paulo. São Carlos, 2016.

Há basicamente dois sistemas empregados para promover a continuidade das terças de múltiplos vãos: transpasse e luva. Do ponto de vista do transporte e da montagem, o sistema de luvas é vantajoso em relação ao sistema de transpasse, uma vez que conduz a barras de menor comprimento. Entretanto, o emprego de luvas tem sido pouco explorado, devido principalmente ao pouco conhecimento sobre o comportamento estrutural do sistema e, consequentemente, pela ausência de recomendações de projeto disponibilizadas pelas normas e manuais técnicos. Neste trabalho foram analisadas a rigidez e a resistência de terças de seção transversal $\mathrm{Z}$ contínuas por meio de luvas. Para tanto, uma série de quinze protótipos de terças de aço formadas a frio foi submetida a ensaios de flexão, variando-se a altura do perfil, espessura e comprimento da luva e o vão. Foi conduzida uma análise da viabilidade do método da resistência direta (MRD) ao dimensionamento de terças contínuas por meio de luvas. Em relação à rigidez, curvas momento-rotação calibradas experimentalmente foram implementadas em modelos numéricos por meio de molas rotacionais, buscando simular o comportamento não linear da ligação. Posteriormente, uma análise paramétrica foi realizada, resultando na expressão momentorotação proposta com base nas variáveis investigadas. Essa expressão representa a rigidez da ligação, que aliada a um modelo simples barra-mola, permite a avaliação mais precisa dos esforços solicitantes e deslocamentos de terças com luvas.

Palavras-chave: Estruturas Metálicas. Perfis Formados a Frio. Terças Contínuas. Ligações por Luvas. Ligações Semirrígidas. 



\begin{abstract}
GILIO, F. H. S. Cold-formed steel purlins with sleeved bolted connection. 2016. 120 p. Dissertation (M. Sc. in Structural Engineering) - Department of Structural Engineering, School of Engineering of São Carlos, University of São Paulo. São Carlos, 2016.
\end{abstract}

There are basically two systems employed to promote the continuity of multi-span purlins: overlap and sleeve. From the point of view of transport and assemblage, the sleeve system is advantageous in relation to the overlap system since it leads to shorter length bars. However, the use of sleeves has not been hardly explored mainly due to lack of knowledge about the system structural behavior and, therefore, the absence of design recommendations provided by standards and technical manuals. This study analyzed the stiffness and strength of continuous Z-section purlins with sleeved bolted connection. In order to develop the study a series of fifteen prototype were tested in bending; their cross-section height, thickness, sleeve length and span were varied. A viability analysis of the Direct Strength Method (DSM) for design of continuous sleeve purlins was conducted. In relation to stiffness, moment-rotation curves were calibrated experimentally and implemented in numerical models through rotational springs to simulate the nonlinear behavior of the connection. Afterwards, a moment-rotation expression based on the studied variables and a parametric analysis was proposed. This expression represents the connection stiffness and, when implemented in a simple spring-beam model, allows a more accurate prediction of the internal efforts and displacements in the purlin-sleeve system.

Keywords: Steel Structures. Cold-formed Steel Members. Continuous Purlins. Sleeved Connections. Semi-Rigid Connections. 



\section{SUMÁRIO}

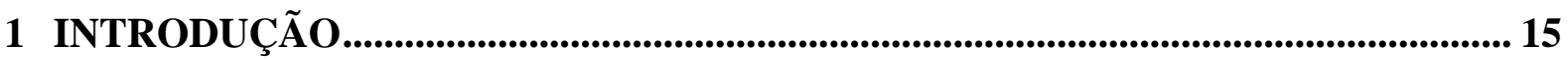

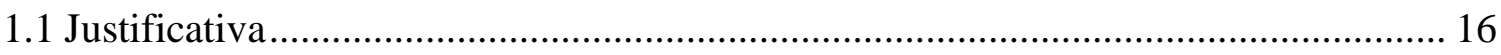

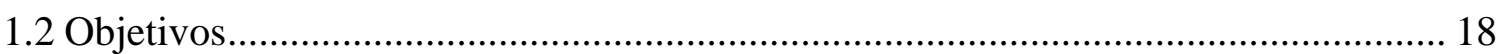

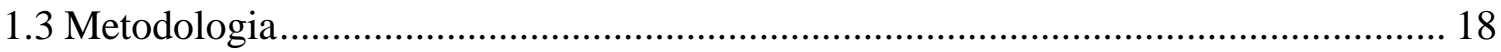

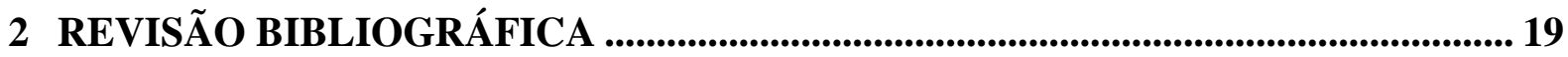

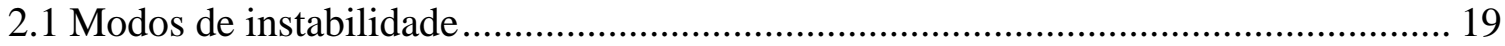

2.2 Ligações parafusadas em chapas finas e perfis formados a frio............................... 22

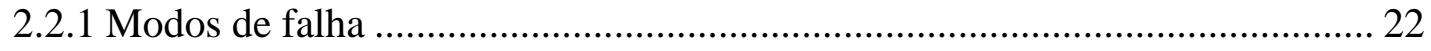

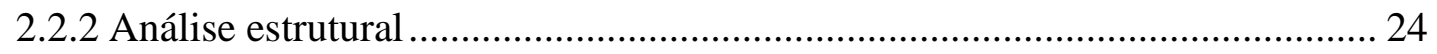

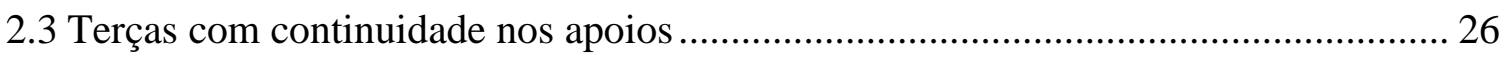

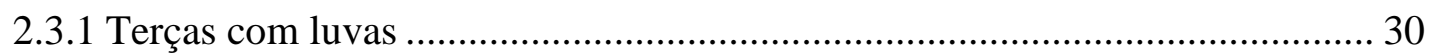

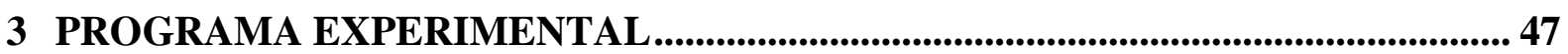

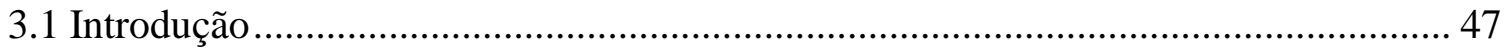

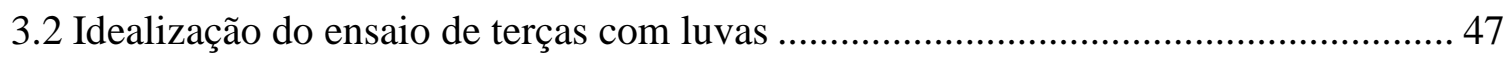

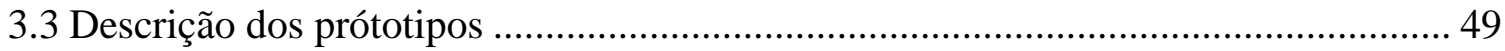

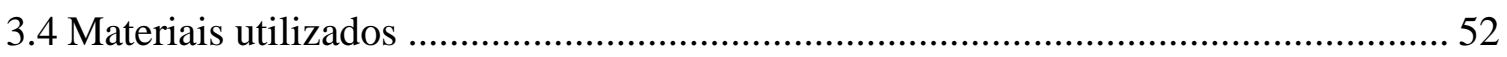

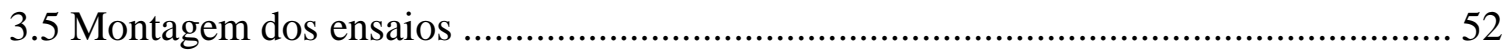

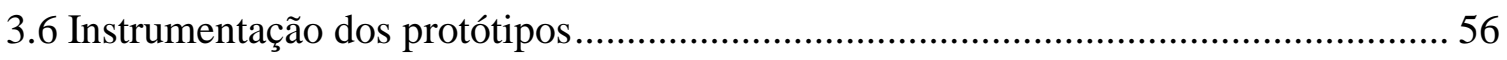

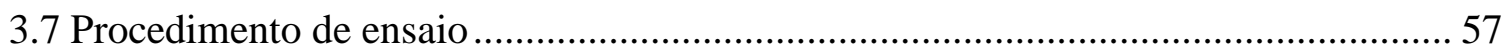

4 RESULTADOS DA ANÁLISE EXPERIMENTAL E NÚMERICA ........................... 59

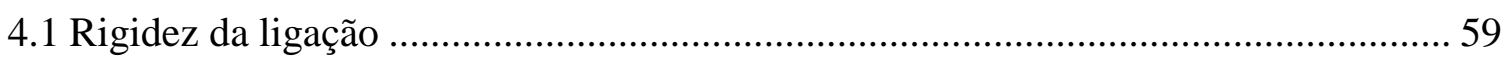

4.1.1 Avaliação das curvas força versus deslocamento .......................................... 59

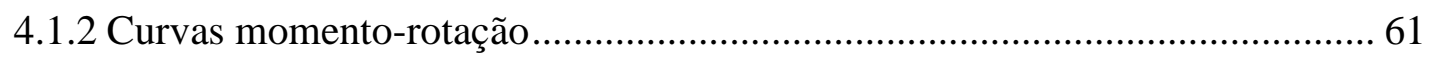

4.1.3 Parametrização das curvas momento-rotação.................................................. 70

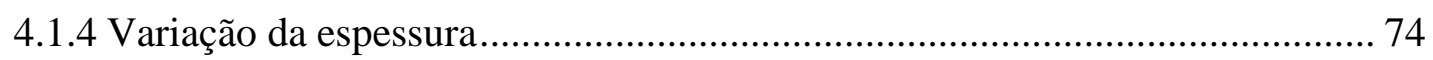

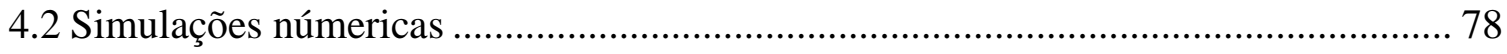

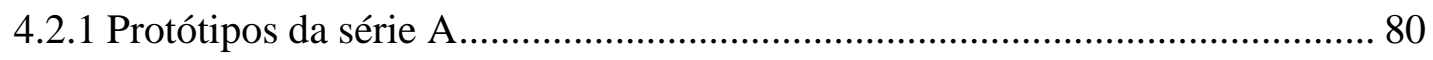

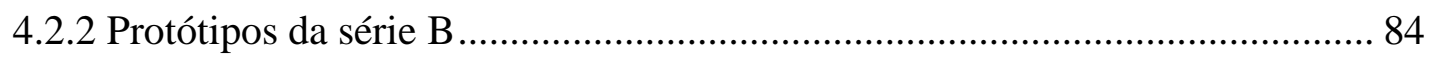

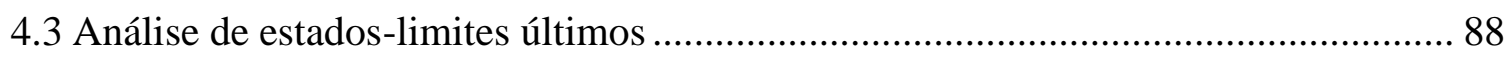

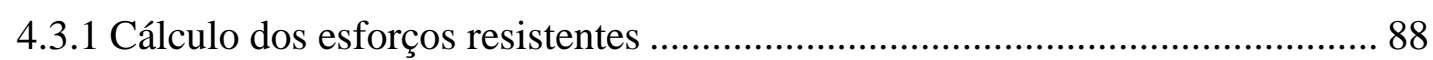

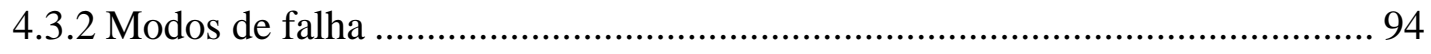

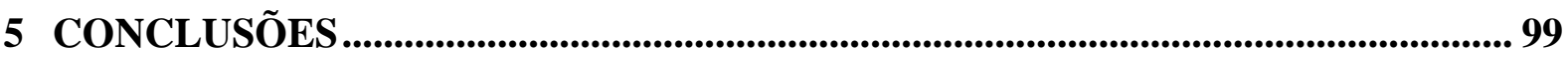

REFERÊNCIAS BIBLIOGRÁFICAS.................................................101

APÊNDICE A-MODELO MECÂNICO PARA TERÇAS COM LUVAS......................105

APÊNDICE B-DIMENSÕES DOS PROTÓTIPOS......................................107

APÊNDICE C-CARACTERIZAÇÃO MECÂNICA DO AÇO DOS PROTÓTIPOS..109

APÊNDICE D-INSTRUMENTAÇÃO DOS PROTÓTIPOS.....................................113

APÊNDICE E-ANÁLISE DE DEFORMAÇÕES NAS MESAS DAS TERÇAS........117 



\section{INTRODUÇÃO}

A ideia central dos perfis formados a frio consiste na simples alteração geométrica de chapas finas, permitindo otimizar a seção transversal sob o ponto de vista estrutural e econômico, obtendo-se consequentemente perfis com elevada relação inércia/peso. Por outro lado, a pequena espessura das chapas utilizadas na fabricação desses perfis favorece a ocorrência dos fenômenos de instabilidade, que devem ser cuidadosamente avaliados.

Atualmente, a grande maioria das terças e longarinas empregadas em sistemas de cobertura e fechamento é constituída por perfis formados a frio. Esses componentes estruturais apoiam-se na estrutura principal com a função de suportar as telhas. Em condições adversas, outros sistemas podem ser mais vantajosos, como os sistemas de treliças planas (joists) e treliças multiplanares. Esta última, apesar de ser pouco utilizada, apresenta bom desempenho estrutural para grandes vãos (VIEIRA, 2009).

Direcionando-se ao tema específico desta pesquisa, os sistemas estruturais empregados para terças podem ser divididos em quatro categorias em função do grau de continuidade oferecido pela ligação: (i) biapoiado, (ii) contínuo com dois vãos, (iii) múltiplos vãos com luvas e (iv) múltiplos vãos com transpasse (CHUNG; HO, 2005).

Terças biapoiadas são muito utilizadas para pequenos vãos (até $10 \mathrm{~m}$ ), pois permitem a fácil padronização e ligações simples com os demais elementos, proporcionando benefícios na fabricação, transporte e montagem. Entretanto, o dimensionamento destas terças depende, dentre outros aspectos, do momento fletor solicitante e dos deslocamentos. Assim sendo, os sistemas contínuos mostram-se vantajosos para grandes vãos, visto que a continuidade (total ou parcial) possibilita a redução dos picos de momentos fletores, bem como dos deslocamentos em relação ao sistema biapoiado, representando significativa economia de material.

Terças contínuas fisicamente ou com emendas soldadas acarretam problemas de transporte e montagem, sobretudo, devido aos elevados comprimentos e as dificuldades de execução da solda em campo. Logo, esses elementos estruturais são frequentemente segmentados e conectados por meio de ligações parafusadas em campo.

Atualmente, as formas mais utilizadas para promover a continuidade em terças de múltiplos vãos são por meio de transpasse ou luva. No primeiro sistema, as terças adjacentes são superpostas de certo comprimento na região do apoio e parafusadas na alma (Figura 1.1a). No segundo sistema, a luva (perfil com geometria similar à da terça) é responsável pela conexão 
entre as terças justapostas no apoio por meio de ligações parafusadas na alma dos perfis (Figura $1.1 b)$.

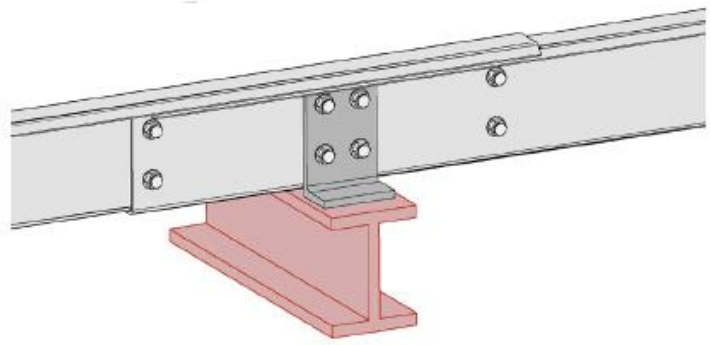

a) Transpasse

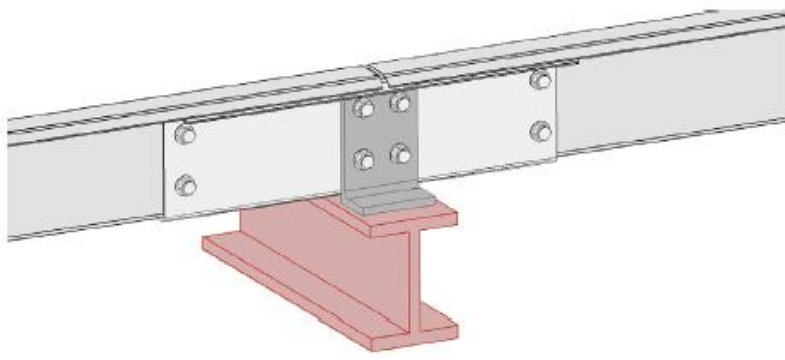

b) Luvas

Figura 1.1 - Sistemas de terças contínuas (adaptada de MODULAR SISTEMAS CONSTRUTIVOS, 2016).

Entretanto, o dimensionamento seguro de terças contínuas por meio de luvas é dependente da análise prévia do comportamento estrutural da ligação, ou seja, a determinação da rigidez e dos esforços solicitantes e resistentes desenvolvidos para cada configuração de ligação. Entretanto, conforme apresentado no trabalho de Tan et al. (2002), a rigidez rotacional das conexões terça-luva e terça-suporte tem influência significativa no desempenho global do sistema.

\subsection{JUSTIFICATIVA}

A participação da EESC-USP (Escola de Engenharia de São Carlos da Universidade de São Paulo) no desenvolvimento de pesquisas relacionadas ao tema de terças de aço com continuidade nos apoios teve início com o trabalho do mestrando Fávero Neto (2013). Esse primeiro estudo investigou o comportamento estrutural de terças contínuas por meio de transpasse e luvas para alguns casos usuais na construção civil.

Dando sequência ao referido trabalho, a presente pesquisa focalizou o estudo de terças contínuas nos apoios por meio de luvas, por apresentarem vantagens em relação ao armazenamento, transporte e montagem, quando comparadas aos sistemas de transpasse. Para um mesmo vão de cobertura, as terças conectadas com luvas resultam menores que as conectadas por transpasse, otimizando o espaço de armazenamento e a seleção do veículo de transporte. No processo de montagem, Gutierrez et. al. (2011) destacam como principais 
vantagens a redução do tempo e custos proporcionados por esse sistema estrutural, fatores de grande interesse ao setor da construção.

Em relação ao projeto, as normas em geral não apresentam recomendações específicas para o caso de terças com continuidade conferida por transpasse ou luva. O AISI Design Guide D111-09 (2009) apresenta recomendações e exemplos de cálculo de terças com transpasse, onde mediante determinadas condições, admite-se que o sistema tenha continuidade total nos apoios (terça calculada como viga contínua). Entretanto, nada apresenta sobre o sistema de terças com luvas.

As ligações parafusadas geram uma mudança brusca nas propriedades geométricas da seção transversal, devido à presença do transpasse ou da luva, além da descontinuidade na transmissão das tensões longitudinais devido à interrupção das mesas e à introdução de esforços localizados nas almas dos perfis. O comportamento mecânico dessas ligações e as peculiaridades descritas anteriormente não são abordados nos textos normativos, que contém apenas recomendações gerais. Desse modo, a determinação dos esforços solicitantes e resistentes dos perfis ficam comprometidas.

Pesquisas têm sido realizadas para entender o comportamento de terças com continuidade nos apoios por meio de luvas ou transpasse e, assim, desenvolver critérios mais seguros de cálculo. Entretanto, a interdependência de diversas variáveis aumenta a complexidade do problema, que dificulta o desenvolvimento de modelos teóricos e numéricos. Consequentemente, ensaios em laboratório são fundamentais para o avanço científico, importantes para suprir a carência básica de informações técnicas sobre o assunto e servir de base para novas pesquisas.

As pesquisas referentes aos sistemas de transpasse foram exploradas no sentido de complementar as informações técnicas sobre terças contínuas por meio de luvas, uma vez que ambos os sistemas apresentam suas particularidades. As terças com transpasse são exploradas pela indústria da construção civil, com várias configurações desenvolvidas pelas empresas do ramo. Além disso, existem diversas pesquisas, relacionadas na revisão da literatura (capítulo 02), que definem parâmetros para o dimensionamento de uma ampla gama de casos corriqueiros na engenharia.

Dessa maneira, torna-se interessante e oportuno o estudo da continuidade por meio de luvas, face à carência de pesquisas e recomendações para projeto. 


\subsection{OBJETIVOS}

O objetivo fundamental desta pesquisa foi o estudo do comportamento estrutural de terças de aço formadas a frio com continuidade nos apoios por meio de luvas. A carência de especificações de projeto direcionou o foco principal do trabalho na caracterização da rigidez da ligação. Assim, buscou-se uma expressão parametrizada capaz de estimar as curvas momento-rotação dessas ligações parafusadas, bem como um modelo simples de barra-mola para uso nas previsões de deslocamentos e esforços solicitantes de sistemas de terças de múltiplos vãos contínuos por meio de luvas. Por fim, foi empregado o método da resistência direta a terças com luvas, com o propósito de verificar sua viabilidade nas estimativas dos esforços resistentes.

\subsection{METODOLOGIA}

A metodologia empregada para atender os propósitos supracitados correspondeu a um estudo experimental e numérico dos sistemas de terças contínuas nos apoios por meio de luvas. Primeiramente, a revisão da literatura (capítulo 02) foi fundamental para o suporte teórico e científico nesta pesquisa.

A campanha experimental foi elaborada para o estudo específico da região da ligação. Por meio de ensaios de flexão, a rigidez e a resistência desses sistemas foram quantificadas de forma eficiente. $\mathrm{O}$ detalhamento do programa experimental está apresentado no capítulo 03.

Os resultados experimentais foram analisados em relação ao comportamento forçadeslocamento, força-deformação e momento-rotação. Outro ponto importante diz respeito à identificação e documentação dos modos de falha desses sistemas.

Os modelos numéricos barra-mola foram desenvolvidos no programa de elementos finitos ANSYSTM. Para determinação dos esforços resistentes via método da resistência direta, foi empregado o programa CU-FSMv4.05 nas análises de estabilidade elástica. 


\section{REVISÃO BIBLIOGRÁFICA}

\subsection{MODOS DE INSTABILIDADE}

A reduzida espessura das chapas utilizadas na produção dos perfis formados a frio leva a seções com elevadas relações largura/espessura. Essa característica intrínseca dos perfis formados a frio favorece a ocorrência dos fenômenos de instabilidade, bem como de fenômenos locais associados às ligações.

A estabilidade de uma estrutura está associada ao conceito de equilíbrio, ou seja, à capacidade de uma estrutura de permanecer próxima à sua configuração de equilíbrio após a aplicação de uma força externa. Em uma análise de estabilidade é importante observar as trajetórias de equilíbrio da estrutura, ou seja, as curvas que relacionam os acréscimos de cargas aos valores de deslocamentos de seus pontos.

A transição entre configurações de equilíbrio estáveis e instáveis corresponde à instabilidade de uma estrutura, sendo associada aos chamados pontos críticos. A depender das características, tais pontos podem receber as denominações de pontos de bifurcação do equilíbrio ou ponto limite.

O ponto de bifurcação (instabilidade bifurcacional) marca o final de uma trajetória de equilíbrio fundamental estável, que se inicia na origem do diagrama força-deslocamento. A partir desse ponto, as possíveis configurações de equilíbrio caracterizam a trajetória fundamental instável e de pós-flambagem (estável). Diferentemente, o ponto limite (instabilidade por snap-through ou snap-back) encerra uma sucessão de configurações com certa característica de equilíbrio, sem o aparecimento de bifurcação do equilíbrio. A partir desse ponto, se a força for aumentada, a estrutura passa dinamicamente para uma configuração de equilíbrio afastada.

Considerando ambas as interpretações do ponto crítico, o termo flambagem é empregado para designar problemas de bifurcação do equilíbrio (instabilidade de primeira espécie), presente em sistemas ideais (sem imperfeições) e com carregamento centrado.

Entretanto, problemas ideais (como, por exemplo, a clássica coluna de Euler) não acontecem na prática, ocorrendo um fenômeno mais amplo de instabilidade, com apenas uma trajetória e sem a ocorrência da bifurcação do equilíbrio.

As normas destinadas ao projeto de estruturas em perfis de aço formados a frio apresentam o clássico Método da Largura Efetiva, o qual permite considerar a instabilidade 
local (instabilidade de chapa) por meio de propriedades geométricas reduzidas (ou efetivas) da seção. Tal método consiste em calcular larguras efetivas dos elementos (chapas) por meio da fórmula de Winter, a qual considera o comportamento pós-crítico das chapas.

O Método da Resistência Direta (MRD) é uma alterativa recentemente adotada para a determinação dos esforços resistentes, considerando todos os modos de instabilidade envolvidos (global, local e/ou distorcional). Tal método requer uma análise de estabilidade elástica da barra para identificar todos os modos de instabilidade envolvidos e os respectivos esforços críticos elásticos. Atualmente existem dois softwares livres para as análises de estabilidade elástica, o CUFSM e o GBTUL, baseados em faixas finitas e teoria generalizada de viga, respectivamente.

Para exemplificar, na Figura 2.1 apresenta-se a análise de estabilidade elástica do perfil Z enrijecido (ZB63-L126) submetido à flexão restringida (em torno do eixo perpendicular à alma). Tal análise relaciona a tensão crítica de flambagem elástica de cada modo de instabilidade (local, distorcional e global) com o respectivo comprimento de meia onda.

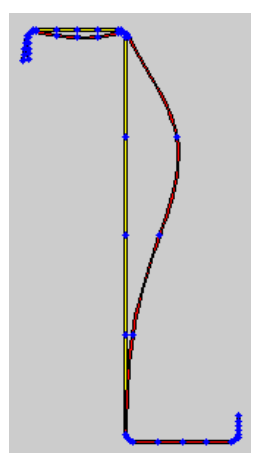

- Fambagem local

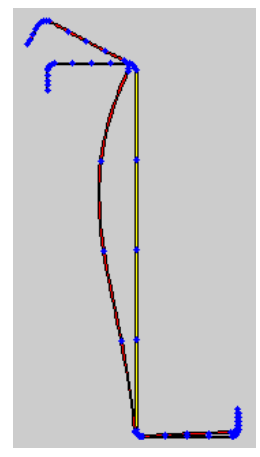

$\checkmark$ Flambagem distorcional

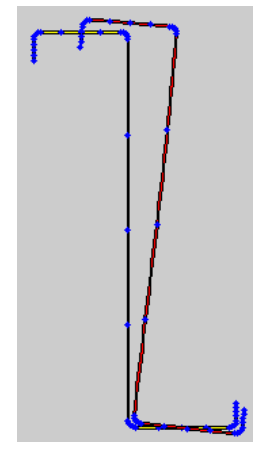

- Flambagem lateral com torção

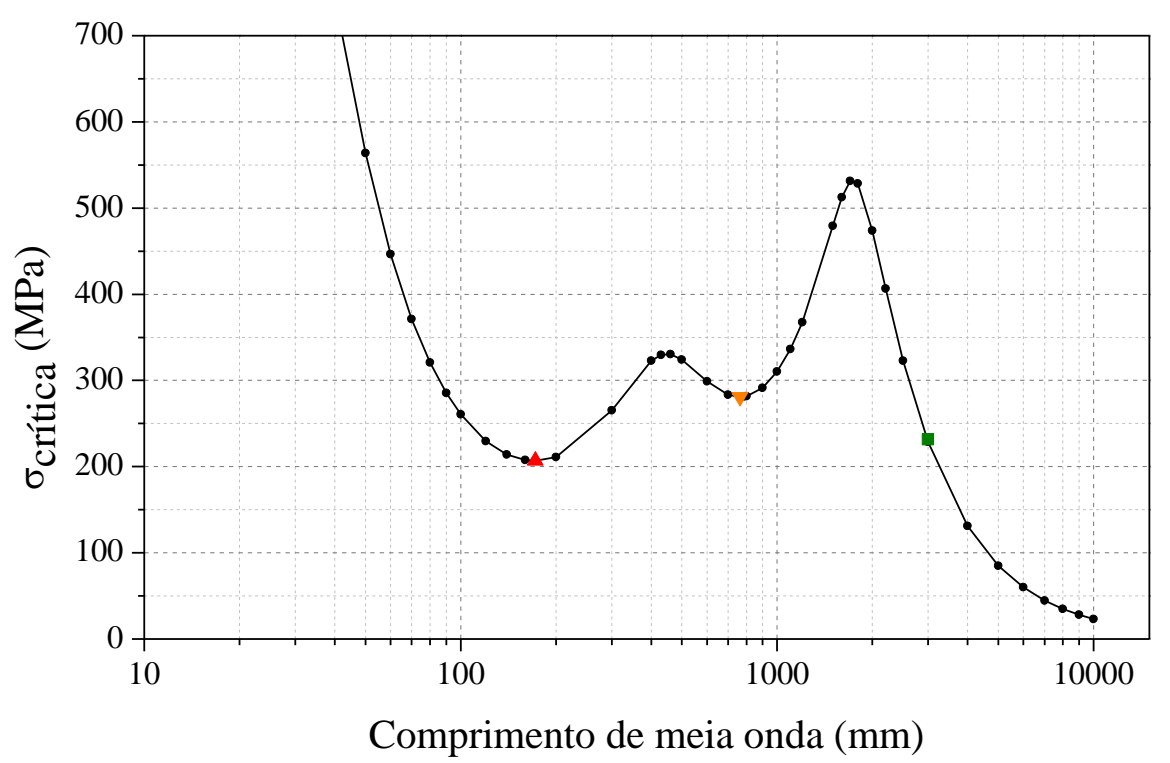

Figura 2.1 - Análise de estabilidade elástica do perfil ZB63-L126. 
Em suma, os modos de instabilidade observados nessa análise são três:

i. Instabilidade local: está associada à instabilidade de chapa, com deslocamentos de flexão fora do plano dos elementos do perfil (mesa, alma ou enrijecedor), cujas linhas de intersecção bem como o ângulo entre os elementos mantém-se inalterados;

ii. Instabilidade distorcional: é caracterizada pela abertura ou fechamento do conjunto mesa-enrijecedor com consequente flexão da alma do perfil;

iii. Instabilidade global (no caso, flambagem lateral com torção): configura a posição deslocada do eixo da barra, com seção transversal inalterada.

Uma vez obtidos os momentos críticos elásticos (associados aos pontos de mínimo da curva apresentada na Figura 2.1 para os modos local e distorcional) os momentos fletores resistentes são determinados para os respectivos modos de instabilidades, por meio de curvas de dimensionamento específicas, como as apresentadas nas normas ABNT NBR 14762:2010 e ANSI/AISI S100-12. O valor característico do momento fletor resistente $M_{R k}$ deve ser tomado como o menor valor calculado para a instabilidade (i) global, (ii) local e (iii) distorcional por meio das expressões 2.1 a 2.10 :

i. Instabilidade global (FLT)

$$
\begin{array}{ll}
M_{R e}=W f_{y} & \text { para } \lambda_{0} \leq 0,6 \\
M_{R e}=1,11\left(1-0,278 \lambda_{0}^{2}\right) W f_{y} & \text { para } 0,6<\lambda_{0}<1,336 \\
M_{R e}=\frac{W f_{y}}{\lambda_{0}^{2}} & \text { para } \lambda_{0} \geq 1,336 \\
\lambda_{0}=\left(\frac{W f_{y}}{M_{e}}\right)^{0,5} &
\end{array}
$$

ii. Instabilidade local

$$
\begin{array}{ll}
M_{R l}=M_{\mathrm{Re}} & \text { para } \lambda_{l} \leq 0,776 \\
M_{R l}=\left(1-\frac{0,15}{\lambda_{l}^{0,8}}\right) \frac{M_{\mathrm{Re}}}{\lambda_{l}^{0,8}} & \text { para } \lambda_{l}>0,776 \\
\lambda_{l}=\left(\frac{M_{\mathrm{Re}}}{M_{l}}\right)^{0,5} &
\end{array}
$$


iii. Instabilidade distorcional

$$
\begin{array}{ll}
M_{\text {Rdist }}=W f_{y} & \text { para } \lambda_{\text {dist }} \leq 0,673 \\
M_{\text {dist }}=\left(1-\frac{0,22}{\lambda_{\text {dist }}}\right) \frac{W f_{y}}{\lambda_{\text {dist }}} & \text { para } \lambda_{\text {dist }}>0,673 \\
\lambda_{\text {dist }}=\left(\frac{W f_{y}}{M_{\text {dist }}}\right)^{0,5} &
\end{array}
$$

Onde:

$f_{y}$ é a resistência ao escoamento do aço;

$M_{e}, M_{l}$ e $M_{\text {dist }}$ são os momentos fletores de flambagem elástica global, local e distorcional, respectivamente.

W é o módulo de resistência elástico da seção bruta em relação ao eixo de flexão.

\subsection{LIGAÇÕES PARAFUSADAS EM CHAPAS FINAS E PERFIS FORMADOS A FRIO}

\subsubsection{Modos de falha}

Anteriormente a 1980, as especificações do AISI no tocante às ligações eram baseadas nas pesquisas do professor George Winter, da universidade americana de Cornell (YU; LABOUBE, 2010).

Por meio de ensaios de cisalhamento em ligações, Winter (1956) ensaiou 574 corpos de prova de ligações parafusadas em chapas finas, cujo programa experimental cobriu algumas variáveis pertinentes, como por exemplo: o diâmetro do parafuso, a espessura da chapa, as propriedades mecânicas das chapas e parafusos, a distância entre o furo e a borda, entre outras considerações.

Em suma, Winter (1956) objetivou atender à carência de informações técnicas relacionadas à resistência de ligações entre elementos de chapas finas, uma vez que a resposta estrutural destas ligações é diferente em relação aos perfis de chapa grossa (laminado e soldado).

Para os parâmetros estudados por Winter (1956), os resultados experimentais mostraram quatro diferentes modos (ou tipos) de falha (Figura 2.2): 


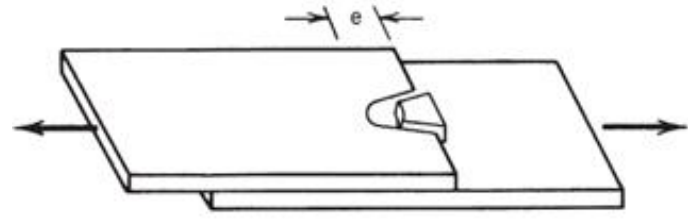

(a)

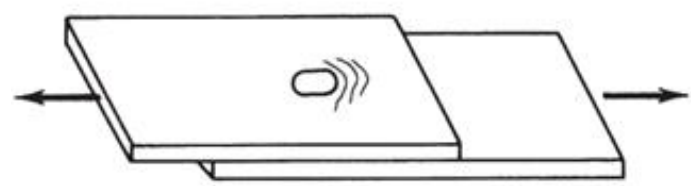

(b)

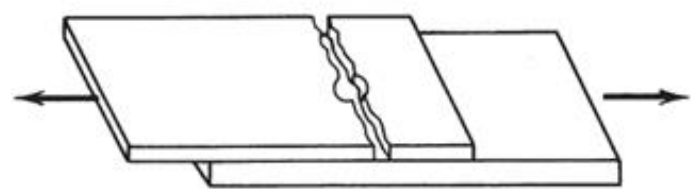

(c)

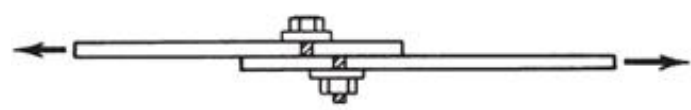

(d)

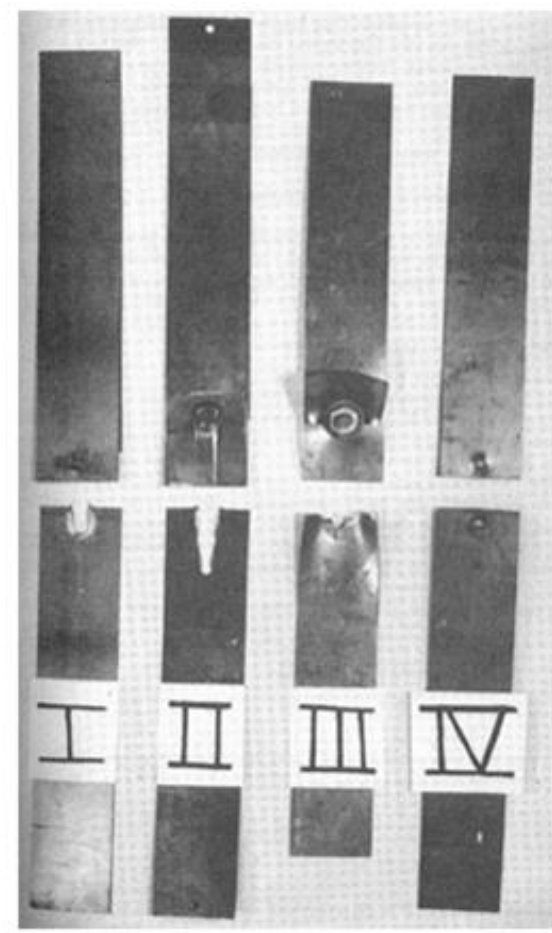

(e)

Figura 2.2 - Modos de falha em ligações parafusadas: (a) rasgamento entre furos e entre furo e borda (Tipo I), (b) deformação ou esmagamento do material junto ao furo (Tipo II), (c) ruptura da seção líquida (Tipo III) e (d) cisalhamento do parafuso (Tipo IV), (YU; LABOUBE, 2010). (e) Corpos de prova ensaiados por WINTER (1956).

a) Falha por rasgamento longitudinal da chapa (Tipo I): acontece com o enrugamento da chapa em frente ao parafuso, seguido do rasgamento de duas linhas longitudinais por cisalhamento. Essa falha ocorre em ligações com pequenas distâncias $(e)$ entre furos ou entre furo e borda (aproximadamente um diâmetro do parafuso).

b) Falha por esmagamento (Tipo II): ocorre com a deformação excessiva ou enrugamento do material junto ao furo (borda em contato com o parafuso).

c) Falha da seção líquida (Tipo III): é identificada pela estricção da seção, seguida da ruptura do material. Essa falha tem origem junto às bordas do furo central (ou furos centrais), propagando-se para as extremidades da chapa.

d) Ruptura por cisalhamento do parafuso (Tipo IV): ocorre quando a resistência ao cisalhamento do parafuso for inferior às resistências associadas aos tipos I, II e III, ou seja, o parafuso foi subdimensionado. 


\subsubsection{Análise estrutural}

A presente pesquisa tratará da continuidade de terças por meio de luvas, ou seja, ligações parafusadas entre a almas dos perfis adjacentes. Em ligações parafusadas, os esforços podem agir perpendicularmente à superfície de contato entre as partes ligadas, paralelamente a essa superfície ou de modo combinado. O mecanismo de resistência da região da ligação ocorre por meio do contato entre as chapas de ligação e o corpo do parafuso, sendo estes solicitados ao cisalhamento e/ou à tração.

Os esforços aqui estudados serão, predominantemente, paralelos à superfície de contato, estando os parafusos submetidos ao cisalhamento. Para ligações em chapas grossas, a ruptura por cisalhamento do parafuso é uma ruptura em potencial. Entretanto, a espessura da chapa em perfis dobrados corresponde a uma pequena fração do diâmetro do parafuso. Assim sendo, a resistência desse tipo de ligação é determinada pela deformação da parede do furo (esmagamento do material - Figura 2.2b), partindo do pressuposto que foram respeitadas as distâncias mínimas entre furos, furos e bordas, e o número de parafusos necessários. Portanto, o esmagamento do material durante o contato entre o parafuso e a parede do furo é o modo de falha mais provável e sua consideração é indispensável. Esse comportamento da ligação influencia na distribuição dos esforços internos e nos deslocamentos de toda a estrutura ou em regiões localizadas.

As principais normas utilizadas para projetos de estruturas constituídas por perfis formados a frio apresentam apenas recomendações gerais para o dimensionamento de ligações. Pouca informação é fornecida para avaliar o comportamento estrutural de ligações entre os elementos de chapas finas para o assunto específico deste trabalho. Geralmente, essas especificações são voltadas para meios de ligações individuais, desenvolvidas para uma limitada faixa de propriedades de materiais e dimensões geométricas. Portanto, tais recomendações devem ser utilizadas com precaução no desenvolvimento de projetos e na execução de construções.

As normas ABNT NBR 14762:2010 e ANSI/AISI S100-12 disponibilizam a mesma expressão para o cálculo da força resistente ao esmagamento $\left(F_{R d}\right)$, dadas pelas expressões 2.11a e 2.11b:

$$
\begin{array}{ll}
F_{R d}=\alpha_{e} d t f_{u} / \gamma & (\mathrm{NBR} 14762: 2010) \\
F_{R d}=\phi \alpha_{e} d t f_{u} & (\text { AISI S100-12) }
\end{array}
$$


Onde:

$d$ é o diâmetro nominal do parafuso;

$t$ é a espessura do elemento conectado analisado;

$f_{u}$ é a resistência à ruptura do aço (metal base);

$\alpha_{e}$ é o fator igual a $(0,183 t+1,53)$, com $t$ em $\mathrm{mm}(t \leq 4,75 \mathrm{~mm})$;

$\gamma$ é igual a 1,55

$\phi$ é igual a 0,65 (método dos estados limites);

No sentido de caracterizar as deformações da parede do furo, Zadanfarrokh e Bryan (1992) e Bryan (1993) realizaram 230 ensaios de cisalhamento (“Lap Shear Test”). A partir dos resultados experimentais (curvas força-deslocamento), os autores propuseram uma expressão que descreve a rigidez de contato da parede do furo $\left(K_{h}\right)$ :

$$
K_{h}=\frac{1000}{5 n\left(\frac{10}{t_{1}}+\frac{10}{t_{2}}-2\right)} \quad(\mathrm{kN} / \mathrm{mm})
$$

Onde:

$t_{1}$ e $t_{2}$ são as espessuras das chapas dos perfis conectados $\left(t_{1} \leq 8 \mathrm{~mm}\right.$ e $\left.t_{2} \leq 8 \mathrm{~mm}\right)$;

$n$ é um fator que depende da posição do plano de cisalhamento no parafuso, do número de parafusos, do tipo de solicitação (momento ou tração) e do tipo de ligação.

De posse da expressão da rigidez de contato da parede do furo $\left(K_{h}\right)$, Bryan (1993) desenvolveu alguns modelos mecânicos para a determinação das rigidezes rotacionais em ligações submetidas à flexão, devida exclusivamente à deformação dos furos. $\mathrm{O}$ autor analisou três configurações de furação: com dois, três e quatro parafusos. Esses modelos foram apoiados no clássico método vetorial, conforme apresentado por Salmon et al. (2008).

Posteriomente, Zaharia e Dubina (2006) modificaram a Expressão 2.12, resultando na Expressão 2.13 para previsão da rigidez de contato da parede do furo.

$$
K_{h}=6,8 \frac{\sqrt{d}}{\left(\frac{5}{t_{1}}+\frac{5}{t_{2}}-1\right)} \quad(\mathrm{kN} / \mathrm{mm})
$$


Onde:

$t_{1}$ e $t_{2}$ são as espessuras das chapas dos perfis conectados;

$d$ é o diâmetro nominal do parafuso.

A expressão é válida para parafusos com diâmetros entre 8 e 16 mm, espessuras de chapas entre 2 e $4 \mathrm{~mm}$ e uma folga entre o parafuso e a borda do furo de $1 \mathrm{~mm}$.

Como exposto anteriormente, certas ligações em perfis formados a frio com características semirrígidas não podem, naturalmente, ser consideradas como rígidas, pois as deformações nas paredes dos furos e outros fatores mencionados posteriormente reduzem a rigidez das ligações. Com isso, não ocorrem a "continuidade perfeita" e a transferência total do momento fletor.

Nesse sentido, uma alternativa de análise apresentada pela norma ANSI/AISC 360-10 é a caracterização das curvas momento-rotação (M- $\theta$ ) das ligações. Para curvas que seguem um comportamento não linear, mesmo em níveis baixos de solicitação, a rigidez inicial não é um parâmetro adequado para caracterizar a resposta da ligação. Logo, a norma ANSI/AISC 36010 propõe a rigidez secante $K_{\theta, s}$ (Expressão 2.14) como um parâmetro mais adequado para carregamentos em serviço:

$$
K_{\theta, s}=\frac{M_{s}}{\theta_{s}}
$$

A norma ANSI/AISC 360-10 também separa a análise da rigidez para situações de serviço e situações últimas. Com isso, algumas simplificações podem ser tomadas no desenvolvimento dos modelos analíticos.

\subsection{TERÇAS COM CONTINUIDADE NOS APOIOS}

Como já destacado na introdução, as terças contínuas por meio de transpasse têm sido frequentemente empregadas nos sistemas metálicos de cobertura e fechamento. Já as terças contínuas por meio de luvas têm seu emprego mais restrito, o que se justifica principalmente pela carência de informações sobre o comportamento estrutural e, consequentemente, pela escassez de recomendações técnicas e procedimentos de cálculo. 
As seções transversais mais exploradas para a fabricação de terças são: "Z", "U” e "Sigma" (Figura 2.3). Além disso, essas podem ser modificadas com o propósito de melhorar o comportamento estrutural frente aos fenômenos de instabilidades, como é o caso do perfil de seção transversal do tipo " $\mathrm{Z}$ modificado".

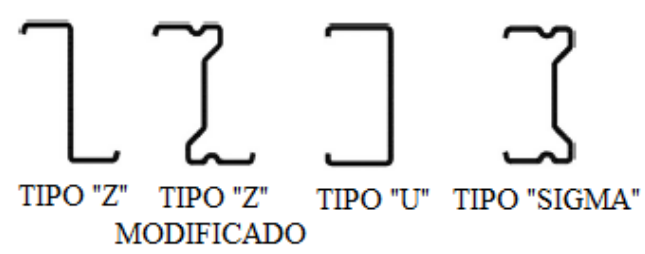

Figura 2.3 - Perfis de aço comuns na fabricação de terças (adaptada de YE, 2013).

Entre os trabalhos encontrados na literatura, as seções transversais do tipo "Z" são as mais utilizadas em sistemas de terças de múltiplos vãos. Estes perfis são fabricados com mesas de tamanhos ligeiramente diferentes, estabelecendo assim a continuidade pela simples superposição dos perfis adjacentes, combinando mesa maior com mesa menor. Dessa maneira, mantém-se o alinhamento ao longo de todo o comprimento da edificação. Para seções do tipo "U” e "Sigma" são necessárias adaptações nessas ligações, dificultando a padronização nos processos de fabricação e montagem.

A caracterização do comportamento estrutural de terças com continuidade nos apoios por meio de ligações parafusadas depende de diversos fatores: das propriedades mecânicas do aço, da configuração geométrica da estrutura, das restrições impostas pelas telhas e travamentos intermediários, dos suportes de fixação das terças na estrutura principal e do comportamento mecânico da ligação (HO; CHUNG, 2006b; ZHANG; TONG, 2008).

Todos esses fatores dificultam uma previsão teórica dos deslocamentos, dos esforços resistentes e solicitantes, sendo tais informações imprescindíveis para o adequado dimensionamento das terças.

Pesquisas relativas às terças com continuidade nos apoios por meio de transpasse tiveram início com o trabalho de Robertson e Kurt (1986). Apesar de limitado, o estudo mostrou a importância da investigação do comportamento da ligação, pois variações na relação entre o comprimento de transpasse e a altura do perfil conferiram diferentes graus de continuidade, indicando que a resistência e a rigidez total na ligação equivalente a uma viga contínua nem sempre são atingidas. Posteriormente, a atividade científica evoluiu com os trabalhos experimentais, teóricos e numéricos realizados por Ghosn e Sinno (1995 e 1996), Ho e Chung 
(2004, 2006a e 2006b), Chung e Ho (2005), Zhang e Tong (2008), Dubina e Ungureanu (2010), Pham et al. (2012 e 2014), Fávero Neto et al. (2013) e Liu et al. (2015a).

Conforme evidenciado pelas pesquisas na área, a relação entre comprimento de transpasse e altura do perfil $\left(2 \mathrm{~L}_{\mathrm{t}} / \mathrm{h}\right)$ é o parâmetro mais significativo no comportamento mecânico de terças contínuas por transpasse. Ho e Chung (2004, 2006a e 2006b) e Chung e Ho (2005) investigaram extensivamente terças com continuidade por transpasse e concluíram que para uma ampla faixa de ligações, o momento fletor resistente total é atingido para razões $2 \mathrm{~L}_{\mathrm{t}} / \mathrm{h}$ 22. A rigidez rotacional total é alcançada para relações iguais ou maiores que 4. Quanto aos modos de falha, os trabalhos apontam para instabilidades localizadas com consequentes mecanismos plásticos na seção simples da terça localizada no final do transpasse (ocorrência da instabilidade local na mesa comprimida e na alma, atribuída à ação combinada do momento fletor e força cortante).

No que diz respeito às terças com continuidade nos apoios por meio de luvas, pode-se citar o pioneirismo do trabalho de Moore (1990). Tal estudo foi iniciado após o desastre ocorrido durante o inverno de 1981 e 1982 no Reino Unido, onde fortes ventos e nevascas ocasionaram a destruição de várias coberturas leves em aço. Outros autores que deram sequência às pesquisas nesta área foram Tan et al. (2002), Gutierrez et al. (2011, 2015), Wang et al. (2012), Yang e Liu (2012 e 2015), Ye et al. (2013) e Fávero Neto (2013).

Os sistemas contínuos por meio de luvas podem ser formados com os mesmos perfis em todos os vãos. No entanto, torna-se mais vantajoso trabalhar com perfis mais espessos no primeiro e no último vão, uma vez que o momento fletor e os deslocamentos são maiores que nos tramos internos. Além disso, dois tipos de ligações são necessários: principais e secundárias. Ligações principais são utilizadas no segundo e penúltimo apoios, devido ao momento fletor nesses apoios ser superior ao momento nos apoios internos, os quais recebem as ligações ditas secundárias. Assim sendo, a luva da ligação principal apresenta um comprimento maior que a luva das ligações secundárias, que, por sua vez, conectam os perfis de mesma espessura nos demais apoios (Figura 2.4). 


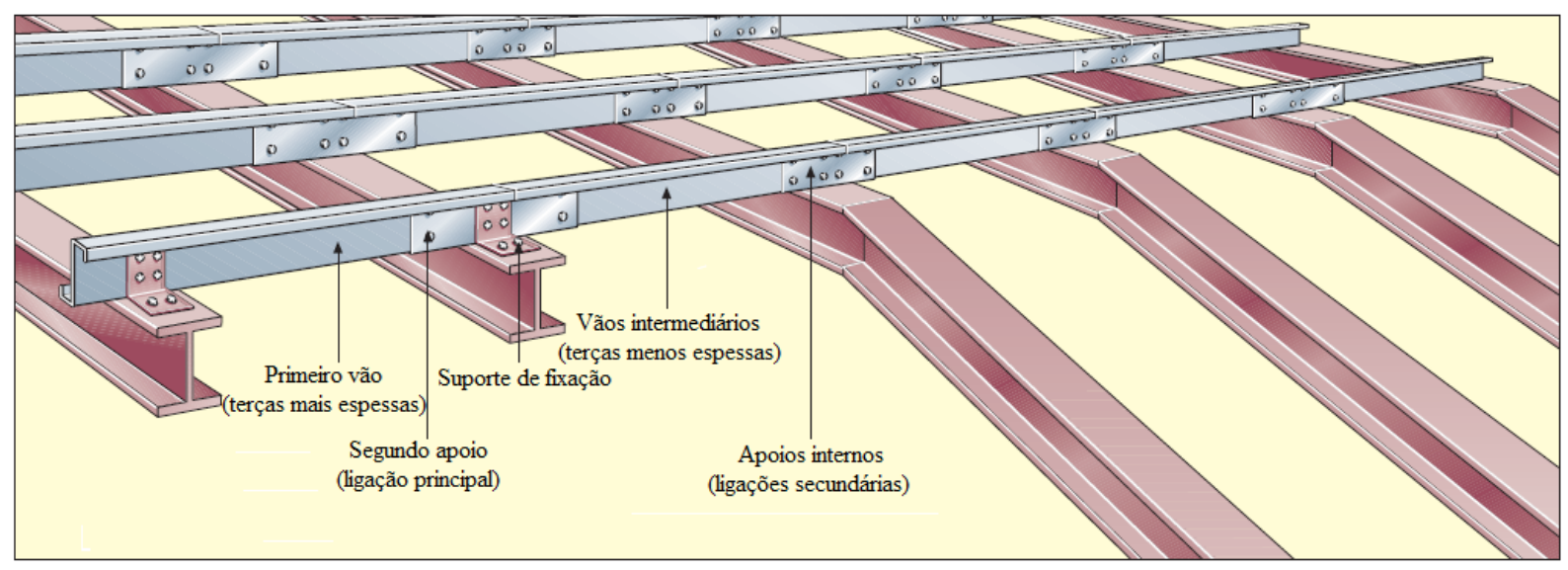

Figura 2.4 - Sistema típico de múltiplos vãos com luvas (adaptada de ALBION SECTIONS, 2016).

Basicamente, terças contínuas nos apoios por meio de luvas são constituídas por três componentes na região da ligação: terça, luva e suporte. A interação entre esses componentes influencia significativamente o desempenho mecânico do sistema.

Até o presente momento, as normas e manuais de cálculo e o conhecimento científico sobre terças com luvas são limitados. Assim sendo, esses sistemas de cobertura têm sido avaliados de maneira experimental ou numérica. A seguir será apresentada uma revisão da literatura existente e para um melhor entendimento das principais variáveis envolvidas nas pesquisas, adotou-se uma padronização apresentada na Figura 2.5.

\begin{tabular}{|c|c|c|c|c|c|}
\hline Terça & Luva & 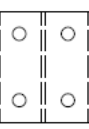 & \begin{tabular}{ll|} 
& 0 \\
$t_{s}$ & \\
\end{tabular} & $t_{p}$ & $\mathrm{D}$ \\
\hline मp & & $\begin{array}{l}\mathrm{L}_{\mathrm{p}} \\
\mathrm{L}_{\mathrm{s}} \\
\mathrm{L}_{\mathrm{t}}\end{array}$ & & & \\
\hline
\end{tabular}

Figura 2.5 - Padronização das variáveis nos modelos de terças com luvas.

Onde:

$L_{p}$ é o comprimento efetivo da luva;

$L_{s}$ é o comprimento da luva;

$L_{t}$ é o vão de ensaio;

$D$ é a altura do perfil;

$t_{s}$ é a espessura da luva;

$t_{p}$ é a espessura da terça. 


\subsubsection{Terças com luvas}

Como exposto anteriormente, a pesquisa de Moore (1990) foi a precursora na investigação estrutural de terças contínuas por meio de luvas. Tal estudo envolveu um programa experimental iniciado pelo Building Research Establishment, com a colaboração do grupo Cold Rolled Section Association (CRSA). O programa experimental abrangeu 33 sistemas de coberturas com diferentes concepções estruturais: sem luvas (terças contínuas apenas pelo suporte), com luvas e contínuas fisicamente.

Os perfis ensaiados apresentavam seções transversais dos tipos " $Z$ ” com enrijecedores

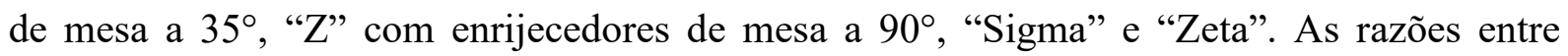
comprimento da luva e altura do perfil $\left(L_{s} / D\right)$ foram de 2,98; 2,98; 7,15 e 5,56; respectivamente. Para a mesma sequência de seções transversais descritas anteriormente, as relações entre o comprimento da luva e o vão de ensaio $\left(L_{s} / L_{t}\right)$ foram de 0,$21 ; 0,21 ; 0,5$ e 0,35 ; respectivamente.

Com base nos resultados experimentais, Moore (1990) concluiu que o comportamento estrutural de todos os sistemas ensaiados depende da rigidez rotacional da ligação. Destacou ainda a importância da correta caracterização do desempenho mecânico dessas ligações, almejando aferir acurácia aos modelos teóricos. Assim sendo, o objetivo principal de seu trabalho foi a caracterização das curvas momento-rotação dos sistemas mencionados anteriormente para o uso em estudos analíticos. As rotações foram quantificadas mediante a colocação de inclinômetros em pontos estratégicos.

De modo geral, as terças contínuas por meio de luvas apresentaram curvas momentorotação relativa não linear. Esse comportamento foi atribuído ao escorregamento entre a terça e a luva nos estágios iniciais do carregamento, ao esmagamento da parede do furo e à instabilidade local nas mesas comprimidas das terças (região da extremidade da luva). Para o perfil com seção do tipo "Z" com enrijecedores de mesa a 90', a Figura 2.6 mostra as curvas momento-rotação obtidas experimentalmente para as terças sem luva, com luva e contínua fisicamente. 


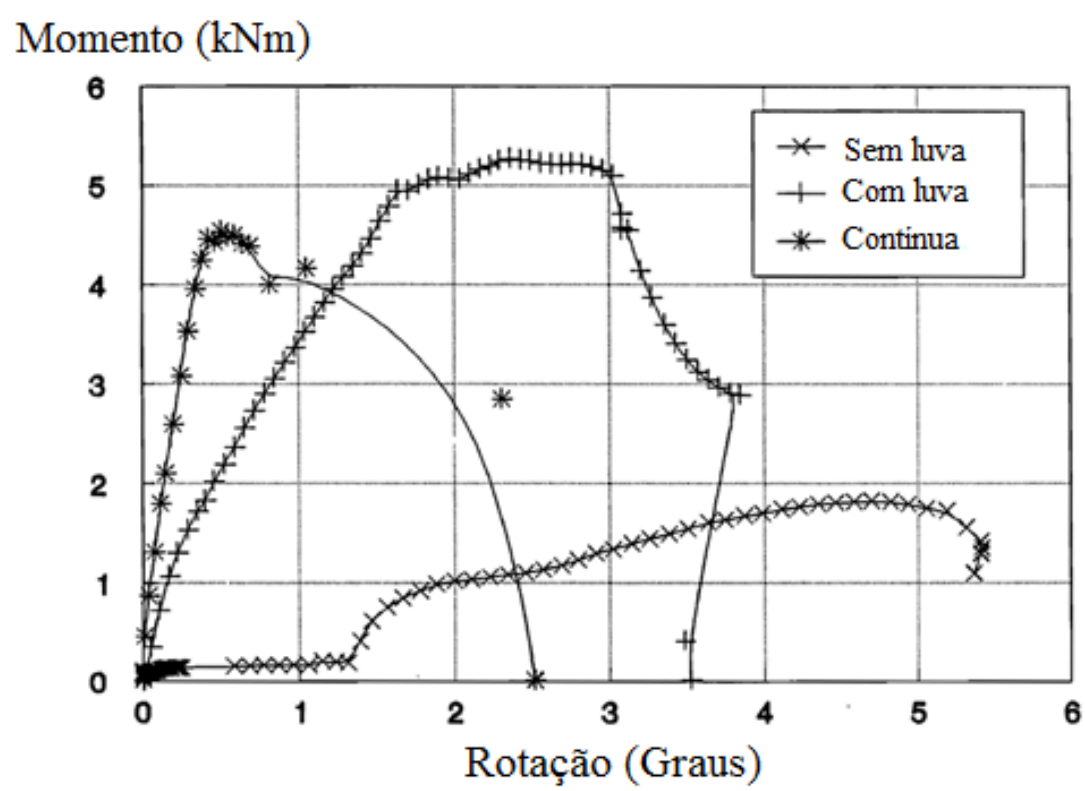

Figura 2.6 - Curvas momento-rotação dos protótipos deseção transversal do tipo “Z” enrijecido a 90" (adaptada de MOORE, 1990).

Essas curvas exemplificam as diferenças entre os sistemas estudados. Em comparação às terças contínuas fisicamente, verificam-se a queda na rigidez nos sistemas com luvas e a baixa continuidade propiciada apenas pelo suporte de fixação nos protótipos sem luvas. Para as terças contínuas apenas pelo suporte, Morre (1990) relata que, além da força de atrito e o contato entre o parafuso e a borda do furo, ocorreu o contato das mesas compridas no meio do vão nos estágios avançados de carregamento, justificando o ganho de rigidez desse sistema após certo avanço do carregamento.

No que diz respeito ao modo de falha para as configurações ensaiadas, observou-se a instabilidade local da mesa comprimida das terças (região da extremidade da luva) em todos os protótipos com luvas. Tal falha ocorreu para valores de momentos resistentes entre $12 \%$ e $58 \%$ maiores em relação às terças equivalentes com continuidade física. Para as rigidezes rotacionais secantes, os valores variaram entre $94 \mathrm{kNm} / \mathrm{rad}$ a $208 \mathrm{kNm} / \mathrm{rad}$.

Apesar dos resultados obtidos, o programa experimental não foi suficiente para o desenvolvimento de expressões analíticas, sobretudo devido à complexidade do comportamento estrutural da região da ligação e ao número reduzido de ensaios realizados (apenas quatro protótipos com luvas). Assim sendo, o desenvolvimento de expressões matemáticas necessitaria de mais ensaios para um desenvolvimento teórico consistente.

Mesmo assim, Moore (1990) propôs um modelo simples de análise do comportamento estrutural de terças contínuas nos apoios por meio de luvas, baseado nas curvas momentorotação obtidas experimentalmente. O modelo idealiza a região terça-luva, mediante a 
colocação de uma mola de rigidez rotacional com comportamento elastoplástico perfeito. A estratégia consiste na determinação da rigidez rotacional secante (primeiro trecho "linear" da curva momento-rotação) e o momento fletor máximo (segundo trecho "constante" da curva momento-rotação). O autor adotou uma rotação de 0,05 radianos para a determinação dos momentos últimos, ou seja, a região considerada importante da curva momento-rotação corresponde a rotações inferiores a 0,05 radianos $\left(2,86^{\circ}\right)$.

Tan et al. (2002) organizaram um estudo experimental e paramétrico de terças com perfis do tipo "Z" enrijecido a $90^{\circ}$ para caracterizar o comportamento estrutural das ligações terça-luva e terça-suporte. Esse estudo englobou outras variáveis não exploradas por Moore (1990). Nas ligações terça-luva, desenvolveu-se um programa experimental para a investigação das seguintes variáveis: a espessura e a altura da terça, a espessura, a altura e o comprimento da luva e a posição do parafuso localizado no final da luva (na posição próxima à mesa superior, intermediária ou próxima à mesa inferior). Nas ligações terça-suporte, estudou-se duas variáveis: a altura e a espessura da terça.

Entre as variáveis investigadas para as ligações terça-luva, o comprimento da luva exerceu forte influência na rigidez rotacional para relações $L_{S} / D$ entre 2 e 6 e $L_{s} / L_{t}$ entre 0,15 e 0,50. A respeito dos suportes de fixação das terças, a variação da altura dos perfis influenciou no comportamento destas ligações. Portanto, os autores recomendam suportes robustos para terças com alturas superiores a $200 \mathrm{~mm}$, com a finalidade de prevenir eventuais falhas nesses elementos.

Baseados no programa experimental desenvolvido, Tan et al. (2002) propuseram uma expressão para o cálculo da rigidez rotacional dessas ligações. Os autores utilizaram a Expressão 2.12, proposta por Bryan (1993), para calcular a rigidez de contato de um único parafuso. No entanto, essa expressão foi alterada para os parâmetros utilizados em seu trabalho. Posteriormente, essa rigidez de contato foi utilizada na expressão da rigidez rotacional da ligação. Porém, as pesquisas de Bryan (1993) e Tan et al. (2002) se assemelham ao trabalho de Moore (1990), uma vez que ambas as relações e procedimentos conduzem a uma curva momento-rotação relativa linear.

Gutierrez et al. (2011) propuseram trabalho numérico em elementos finitos, desenvolvido via Abaqus $^{\mathrm{TM}}$. Os modelos numéricos foram validados com resultados experimentais de dois protótipos contínuos por meio de luvas, com seções transversais do tipo “Z” enrijecidos a $90^{\circ}$ e relações geométricas $L_{p} / D$ e $L_{p} / L_{t}$ iguais a 2,1 e 0,139 , respectivamente. Uma peculiaridade desse trabalho refere-se aos furos alongados (14 mm x $23 \mathrm{~mm}$ ) existentes 
na região da ligação. Tal prática é comum na fabricação de estruturas metálicas e tem o objetivo de facilitar o processo de montagem.

Os protótipos estudados por Gutierrez et al. (2011), nomeados de "T1" e "T2", foram formados por duas terças paralelas (denominadas "viga frontal" e "viga posterior"). Os sistemas foram devidamente travados lateralmente, com a função de evitar a instabilidade global por flexo-torção (FLT).

Os resultados experimentais foram apresentados por meio de curvas forçadeslocamento no meio do vão (Figura 2.7) e momento fletor-rotação relativa (Figura 2.8). As rotações foram medidas diretamente por um par de inclinômetros fixados na alma do perfil da luva e da terça. Desse modo, a rotação relativa foi quantificada na linha de parafusos da extremidade da luva (nomeada de seção "L4"), região onde se encontravam os inclinômetros.

Os resultados experimentais foram comparados a um modelo elastoplástico perfeito de viga contínua teoricamente definido. Considerando essa continuidade idealizada, a rotação relativa entre as duas seções adjacentes é nula. Consequentemente, a rigidez rotacional é “infinita”. Todas as curvas (gráficos força-deslocamento ou momento fletor-rotação relativa) foram plotadas nos mesmos gráficos, Figura 2.7 e Figura 2.8, facilitando a visualização das diferenças de comportamento ocasionadas pela introdução das luvas.

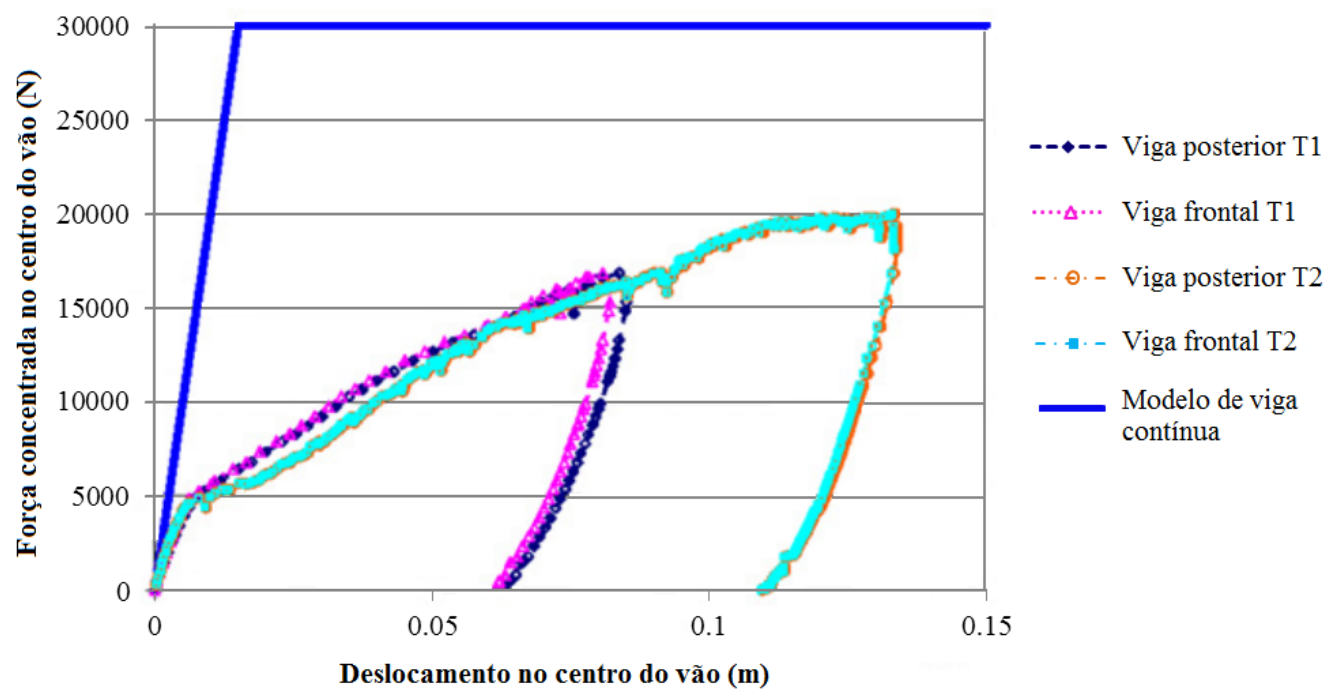

Figura 2.7 - Curvas força versus deslocamento no meio do vão (adaptada de GUTIERREZ et al., 2011). 


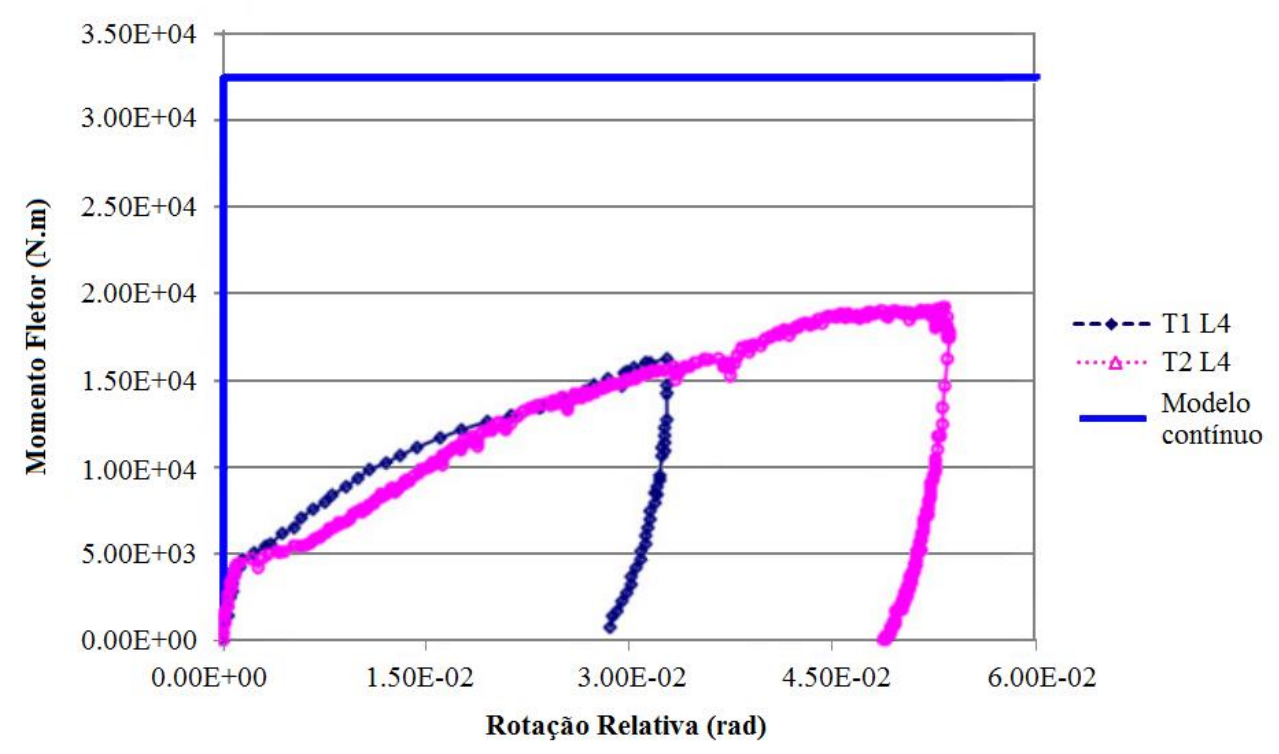

Figura 2.8 - Momento fletor versus rotação relativa (adaptada de GUTIERREZ et al., 2011).

Para os parâmetros estudados experimentalmente por Gutierrez (2011), percebe-se que o momento fletor resistente e a rigidez dos sistemas com luva são inferiores ao modelo teórico da viga contínua, mostrando que a hipótese de continuidade total na região da ligação, sem uma análise prévia do comportamento dessas ligações, pode conduzir ao dimensionamento inseguro. Portanto, esse comportamento semirrígido da ligação afeta substancialmente a resposta da estrutura.

Outra tendência observada nas curvas dos conjuntos T1 e T2 foi a queda significativa da rigidez no segundo trecho. Tal fenômeno é atribuído ao esmagamento dos furos, ou seja, à concentração de tensões introduzidas durante o contato entre o parafuso e a borda do furo, que pode levar a deformações excessivas nessa região. Para ligações com pequenas relações entre o comprimento efetivo da luva e altura do perfil $\left(L_{p} / D\right)$ têm-se maiores concentrações de tensões nos furos próximos ao meio do vão (Figura 2.9), consequentemente maiores deformações. Portanto, observa-se o aumento de flexibilidade da ligação. 


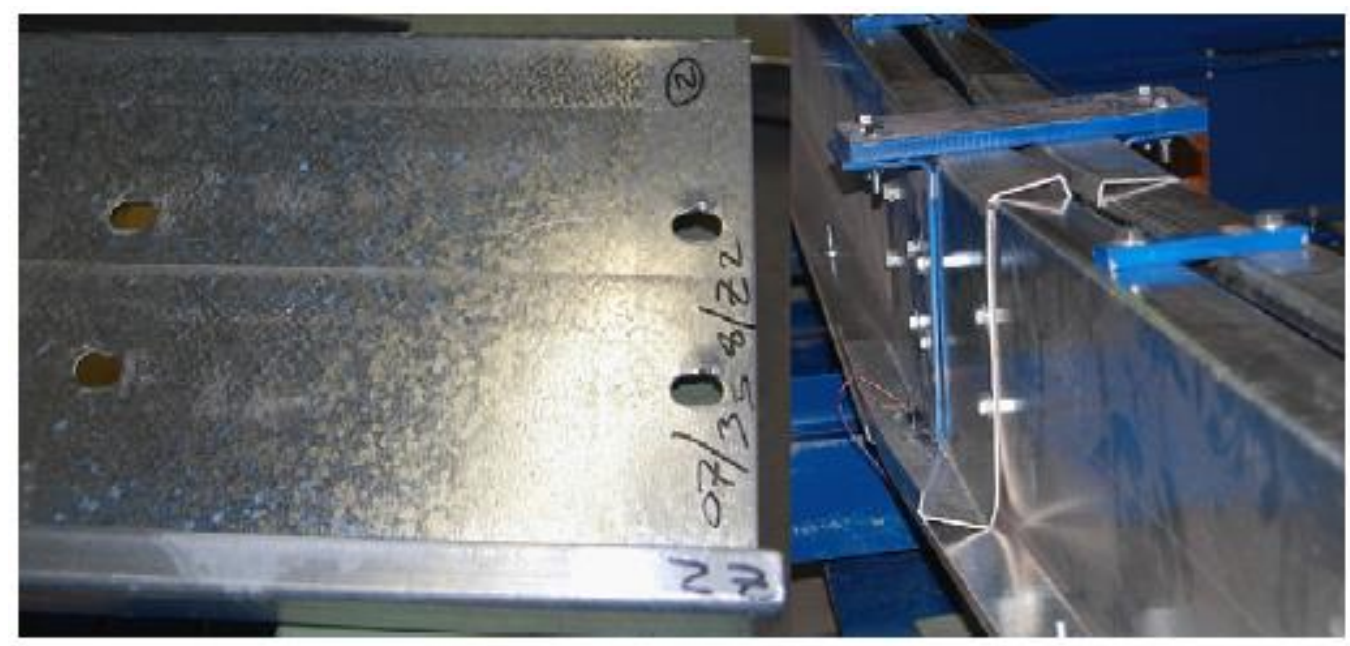

Figura 2.9 - Aspecto dos furos após ensaio (GUTIERREZ et al. , 2011).

Diferentemente da falha apontada por Moore (1990), nos estágios avançados de carregamento, o modo de falha observado por Gutierrez et al. (2011) foi a distorção com deformação excessiva ao longo da mesa da luva (Figura 2.9). Tal modo ocasiona o desprendimento da mesa da luva.

O trabalho apresentado por Gutierrez et al. (2011) englobou uma análise numérica, em que se idealizaram as condições impostas experimentalmente na modelagem via elementos finitos. Essa modelagem permitiu avaliar a distribuição de tensões de von Mises nas terças e nas luvas.

Para os protótipos com luvas, a distribuição de tensões foi avaliada em dois pontos das curvas força versus deslocamento (Figura 2.7). O primeiro ponto escolhido marca a primeira queda na rigidez e o segundo ponto representa o instante próximo à falha do sistema. Em relação à distribuição de tensões no primeiro ponto (Figura 2.10), observa-se na terça a concentração de tensões nos furos localizados na região do meio do vão e pequenas regiões nas mesas (linha de parafusos próxima ao final da luva) que atingiram a tensão de escoamento. No estágio final (Figura 2.11), constataram-se nas terças o escoamento completo na região em volta dos furos próximos da metade do vão e o escoamento do material nas mesas das luvas, culminando em um mecanismo de instabilidade distorcional nas luvas semelhante às verificações experimentais (Figura 2.9). 


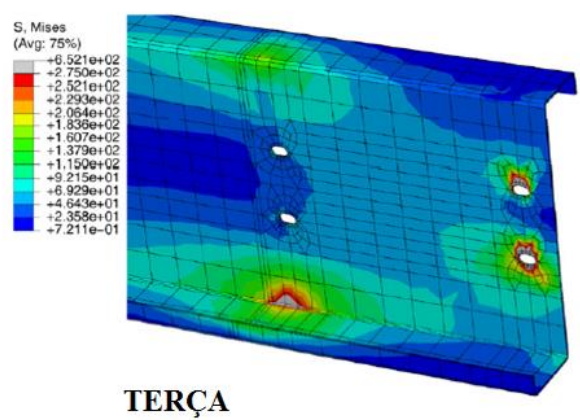

TERÇA

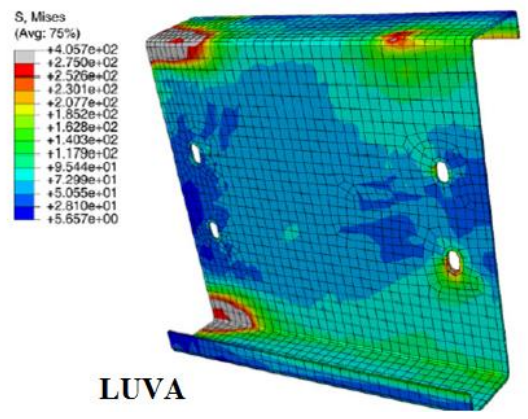

Figura 2.10 - Distribuição de tensões de von Mises na primeira queda de rigidez (adaptada de GUTIERREZ et al., 2011).
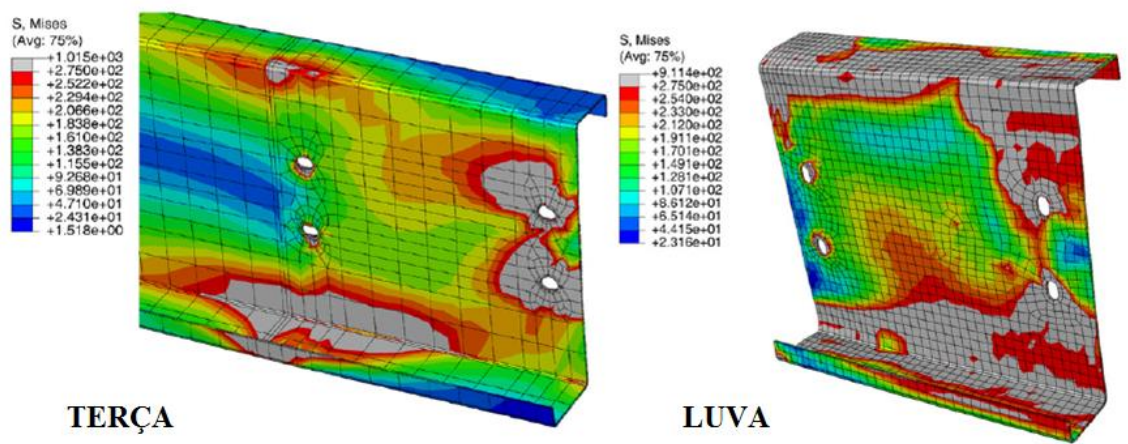

Figura 2.11 - Distribuição de tensões de von Mises no estágio final do sistema (adaptada de GUTIERREZ et al., 2011).

Fundamentado na campanha experimental de Gutierrez et al. (2011), Gutierrez et al. (2015) propõem um modelo simplificado para a avaliação dos sistemas de terças contínuas por meio de luvas. Esse modelo é composto por elementos de barras simples e molas rotacionais, que reproduzirem a rigidez e a resistência dessas ligações. Tais molas são concentradas nas linhas de parafusos da seção S1 e S2, conforme representado na Figura 2.12.

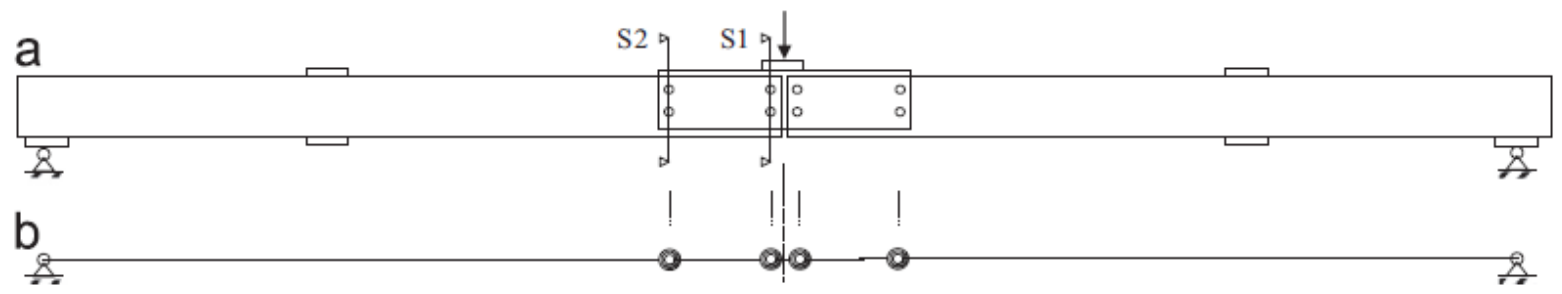

Figura 2.12 - Modelo de barras com molas de rotação (GUTIERREZ et al., 2015).

No trabalho de Gutierrez et al. (2015), o comportamento de cada mola foi extraído de simulações numéricas e descrito por curvas bilineares momento-rotação. Com isso, as rigidezes rotacionais secantes e os momentos fletores máximos de cada mola são determinados para os 
parâmetros estudados. A partir desses valores, os autores propuseram expressões para quantificar a rigidez rotacional secante $\left(K_{\theta}\right)$ (Expressão 2.15) e do momento fletor máximo na seção S1 $\left(M_{\max , S I}\right)$ (Expressão 2.16). O momento fletor na seção $1\left(M_{s 1}\right)$ é adotado igual a $75 \%$ do momento fletor máximo. Para a estimativa do momento fletor na seção $2\left(M_{s 2}\right)$, definiu-se uma relação entre $M_{s 1}$ e $M_{s 2}$ (Expressão 2.17)

$$
\begin{aligned}
& K_{\theta}=C_{1} e^{C_{2} \frac{L p}{D}} \\
& M_{\max , S 1}=1851\left(\frac{L p}{D}\right)+4197 \quad \text { (Luvas curtas) } \\
& \frac{M_{S 1}}{M_{S 2}}=C 3\left(\frac{L p}{D}\right)+C 4
\end{aligned}
$$

Onde:

Para luvas longas $M_{\max , S l}$ é maior ou igual ao momento fletor para terças contínuas equivalentes;

$L_{p}$ é o comprimento efetivo da luva;

$D$ é a altura do perfil;

$C_{1}, C_{2}, C_{3}$ e $C_{4}$ são constantes válidas para os paramentos estudados.

O modelo proposto é válido dentro do regime elástico para permitir o dimensionamento seguro, permitindo uma análise global em elementos finitos de barras com inserção de molas que idealizam o comportamento semirrígido da ligação.

Apoiados no modelo de barra proposto, Gutierrez et al. (2015) avaliaram um exemplo de terças com luvas de múltiplos vãos. A consideração do comportamento semirrígido da ligação aumentou os deslocamentos verticais e diminuiu os picos de momentos fletores ao longo dos vãos desse sistema. Apesar do ganho de resistência e rigidez para variações crescentes da relação $L_{p} / D$, os autores constataram que nenhum protótipo simulado numericamente atingiu a rigidez de uma terça fisicamente contínua, ao contrário do momento resistente, que foi atingido em algumas configurações. Portanto, esse estudo reforça que a hipótese de continuidade total na ligação pode conduzir ao dimensionamento contra a segurança.

Explorando os perfis do tipo "Sigma", Yang e Liu (2012) propuseram um método prático para o dimensionamento de terças contínuas por meio de luvas, baseados nos resultados e observações experimentais de 20 protótipos. Tais perfis apresentam enrijecedores 
intermediários na alma, que conferem maior resistência frente a fenômenos de instabilidade. Outra vantagem na utilização desse tipo de perfil está relacionada à posição do centro de cisalhamento (próximo à alma do perfil), diminuindo o efeito da instabilidade global por flexotorção.

Os protótipos propostos foram avaliados por curvas momento fletor no meio do vão versus rotação nos apoios. Posteriormente, essas curvas foram idealizadas em três estágios lineares (Figura 2.13): (i) o primeiro seguimento considera que o atrito entre a terça e a luva é suficiente para resistir ao momento fletor inicial, logo, a região de seção dupla (terça e luva) trabalha em conjunto; (ii) no trecho intermediário, considera-se que o momento fletor atuante ultrapassou o atrito das chapas em contato, assim o movimento de corpo rígido acrescenta rotação nos apoios devido ao escorregamento dos parafusos; e, por fim, (iii) a rotação no terceiro trecho é atribuída à flexão da terça e da luva e à deformação da borda do furo (Figura 2.14d), quando o corpo do parafuso entra em contato com a borda do furo.

Portanto, a rotação resultante no apoio é proveniente do momento fletor dos perfis (terça e luva) trabalhando em conjunto, do escorregamento entre os perfis e da deformação da borda do furo. Na Figura 2.13, essas três parcelas são denominados $\theta_{1}, \theta_{2}$ e $\theta_{3}$, respectivamente.

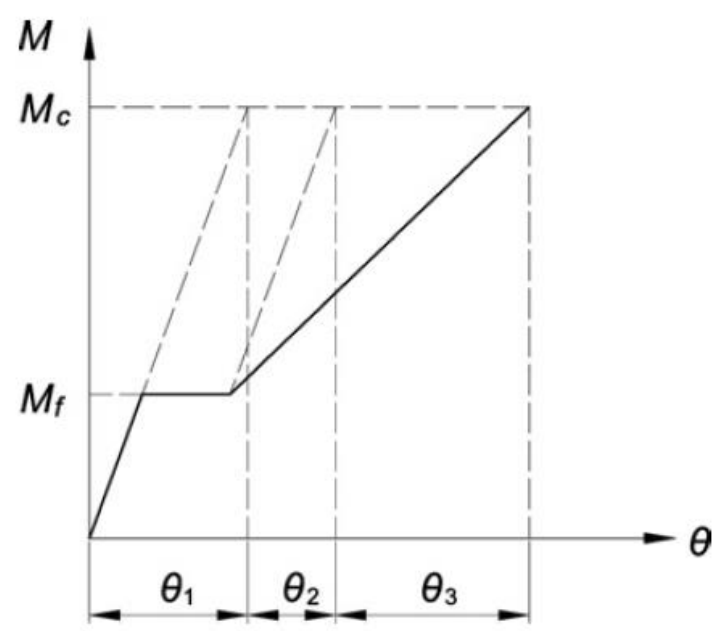

Figura 2.13 - Modelo idealizado das curvas momento-rotação (YANG; LIU, 2012).

O valor de $\theta_{1}$ foi obtido por meio de uma expressão que traduz um modelo de barras idealizado, mediante a aplicação de uma força concentrada a meio vão em uma viga boiapoada. A segunda parcela de flexibilidade $\left(\theta_{2}\right)$ foi quantificada em função da folga do furo e das distâncias horizontais e verticais entre furos. Da mesma forma que Tan et al. (2002), Yang e 
Liu (2012) estimaram a parcela de rotação no apoio $\left(\theta_{3}\right)$ por meio da expressão $(2.12)$ proposta por Bryan (1993).

A respeito da resistência do sistema, o momento último foi avaliado por meio do clássico método da largura efetiva nas seções críticas, ou seja, no meio do vão e no fim da luva. Outra avaliação realizada pelos autores leva em consideração o efeito combinado do momento fletor e da força concentrada na borda dos furos. As duas avaliações conduziram a resultados a favor da segurança. Entretanto, a consideração da força concentrada conduziu a valores mais conservadores em relação à primeira avaliação.

Nas regiões críticas mencionadas anteriormente, os modos de falha correspondentes são a instabilidade local na alma do perfil da terça, devido à combinação do momento fletor e da força concentrada na extremidade da ligação (Figura 2.14a), a falha na mesa tracionada devido à flexão (Figura 2.14b) e a instabilidade distorcional na mesa comprimida devido à flexão (Figura 2.14c).
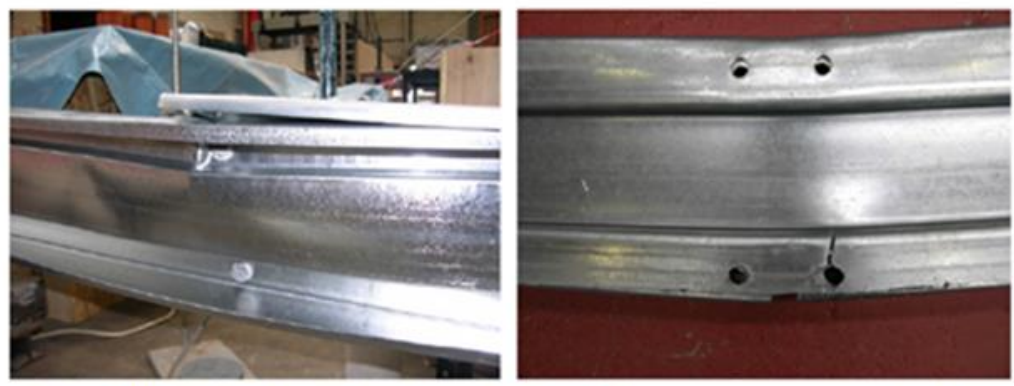

a) Instabilidade local na alma da seção b) Ruptura na mesa tracionada da luva da terça (extremidade da ligação)

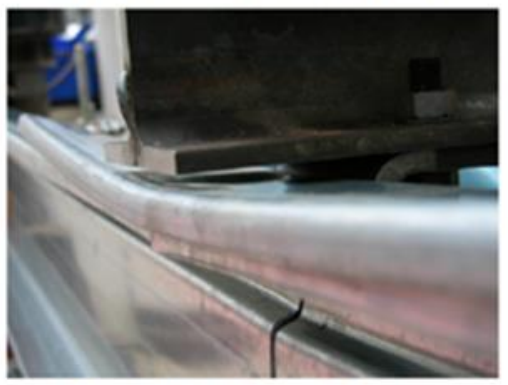

c) Instabilidade distorcional na mesa comprimidada da luva

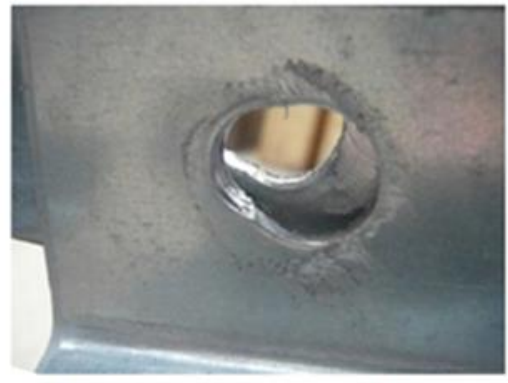

d) Deformação da parede do furo

Figura 2.14 -Modos de falha da ligação (adaptada de YANG E LIU, 2012).

Com base na companha experimental desenvolvida por Yang e Liu (2012), Liu et al. (2015b) calibraram modelos numéricos desenvolvidos via elementos finitos no software ANSYS ${ }^{\text {TM }}$. Validados experimentalmente, tais modelos numéricos permitiram um estudo paramétrico, cujas variáveis investigadas foram o comprimento e a espessura da luva. 
Para os sistemas estudados, tais autores concluíram que o aumento na espessura da luva $\left(t_{s}\right)$ até 1,5 vezes a espessura da terça $\left(t_{p}\right)$ resulta em um significativo ganho de resistência da ligação. Entretanto, relações $t_{s} / t_{p}>1,5$ e $L_{\mathbb{S}} / D \geq 4$ não afetam muito o momento fletor resistente da conexão, ou seja, a resistência total pode ser atingida.

O aumento do comprimento da luva implicou no aumento considerável da rigidez e do momento fletor resistente da ligação. Comparado aos sistemas contínuos, as conexões por meio de luvas desenvolveram uma rigidez parcial.

Apesar das diferenças entre os trabalhos de Moore (1990), Tan et al. (2002), Gutierrez et al. (2011 e 2015), Yang e Liu (2012) e Liu et al. (2015), as curvas momento-rotação obtidas experimentalmente deixaram evidente a resposta não linear dos sistemas estudados. Assim sendo, Wang et al. (2012) propõem um método para análise da rigidez rotacional levando em conta a não linearidade momento-rotação devida à deformação da parede do furo, tendo como base os ensaios de cisalhamento direto.

No mesmo sentido, Ye et al. (2013) aprofundaram os estudos para caracterizar as variáveis que influenciam nesse comportamento não linear. Os autores utilizaram perfis de seção transversal do tipo "Z modificado" com enrijecedores intermediários nas mesas e na alma. Com o propósito de validar os modelos numéricos em elementos finitos, realizaram um programa experimental que consistiu no ensaio de três conjuntos contínuos por meio de luvas e um conjunto contínuo fisicamente. Os protótipos ensaiados apresentaram relações $L_{p} / D$ e $L_{s} / L_{t}$ iguais a 3,94 e 0,32, respectivamente. Os resultados experimentais e numéricos possibilitaram a construção de curvas força-deslocamento experimentais (Protótipos 1, 2 e 3), terças contínuas fisicamente (CON) e os modelos em elementos finitos (EF MZ e EF CON, respectivamente) exibidas na Figura 2.15.

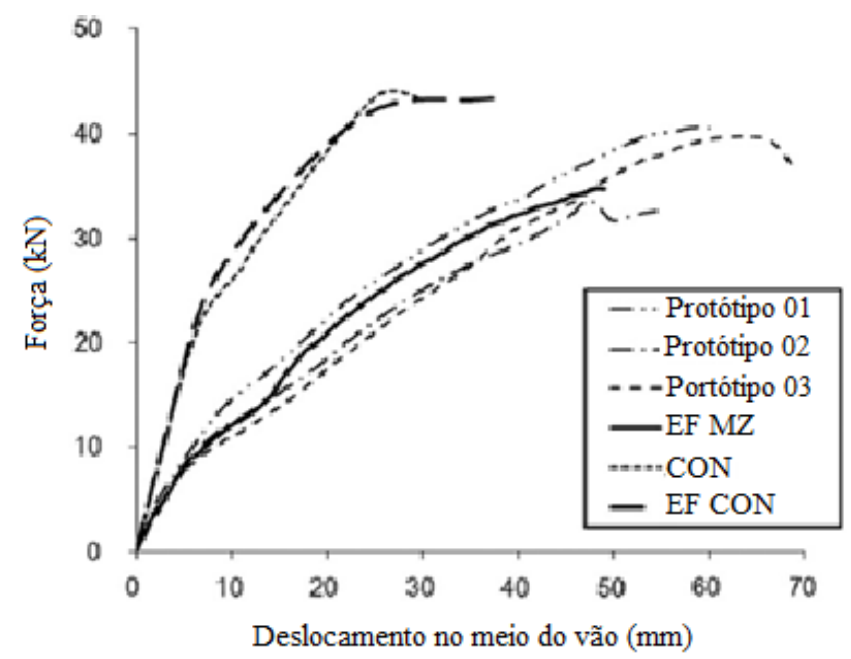

Figura 2.15 - Curvas força-deslocamento para o modelo de Bryan e para os protótipos ensaiados (YE et al., 2013). 
Ye et al. (2013) dividiram as curvas em quatro partes aproximadamente lineares: $(i)$ no primeiro segmento (entre 0 e $8 \mathrm{~mm}$ ), a ligação mostra uma rigidez inicial influenciada pelas forças de atrito entre a terça e a luva; (ii) no segundo segmento (entre 8 e $15 \mathrm{~mm}$ ), a força externa vence a força de atrito e o sistema sofre o efeito do escorregamento, experimentando uma redução na rigidez rotacional da ligação; (iii) no terceiro segmento (entre 15 e $50 \mathrm{~mm}$ ), o contato entre o fuste do parafuso com a parede do furo restringe esse escorregamento entre a terça e a luva, quando observa-se o aumento da rigidez rotacional e (iv) por fim, no quarto segmento (a partir de $50 \mathrm{~mm}$ ), a curva é aproximadamente horizontal, caracterizando a máxima força que o conjunto pode suportar.

O efeito do segundo trecho é ignorado, pois não influência de modo significativo a capacidade da estrutura. Dessa forma, o segundo segmento pode ser tratado como parte do terceiro.

Os modelos numéricos simulados por Ye et al. (2013) envolveram as seguintes variáveis: comprimento da luva, altura e espessura dos perfis e o vão de ensaio. As relações $L_{s} / D$ estudadas variaram entre 1,33 e 5,18 , e as relações $L_{s} / L_{t}$ entre 0,1 e 0,39 . Os autores observaram que o comprimento da luva e a intensidade do momento fletor aplicado têm efeito expressivo na rigidez da ligação.

Com base nos resultados experimentais e numéricos, Ye et al. (2013) propuseram uma expressão para o cálculo do momento fletor resistente e do fator de modificação da rigidez a flexão na região da ligação $(\alpha)$, razão entre a rigidez à flexão da região na luva e a rigidez à flexão da terça. Dentre os parâmetros estudados, o mais significativo foi o comprimento da luva para dado nível de solicitação.

Logo, a expressão proposta pelos autores está relacionada com o momento fletor aplicado e o comprimento da luva de forma potencial $\left(\alpha=m M^{n}\right)$, sendo $m$ dado por $\left(0,0012 L_{S^{-}}\right.$ $0,20)$ e $n$ dado por $(0,0009 L s-0,67)$ linearmente dependentes do comprimento da luva e $M$ o momento fletor solicitante. Em relação aos momentos máximos, o autor atribuiu um coeficiente $\left(\gamma=M_{\max } / M_{c o n}\right)$ que representa a relação entre os valores obtidos experimentalmente dos momentos resistentes máximos dos protótipos com luvas e dos momentos dos protótipos contínuos fisicamente. Ao relacionar esses coeficientes com a variação da relação entre o comprimento da luva e a altura do perfil $\left(L_{s} / D\right)$, os autores constataram um crescimento linear da curva até relações $L_{S} / D=4\left(\gamma=0,2 L_{\S} / D+0,05\right)$, permanecendo com valor constante $\gamma=0,85$ para relações $L_{\S} / D$ superiores a 4 . 
Dentre as variáveis estudadas, as expressões desenvolvidas pelos autores mostraramse adequadas com os resultados experimentais não lineares, em detrimento ao modelo linear, que tem por base a metodologia proposta por Bryan (1993), conforme mostrado na Figura 2.16.

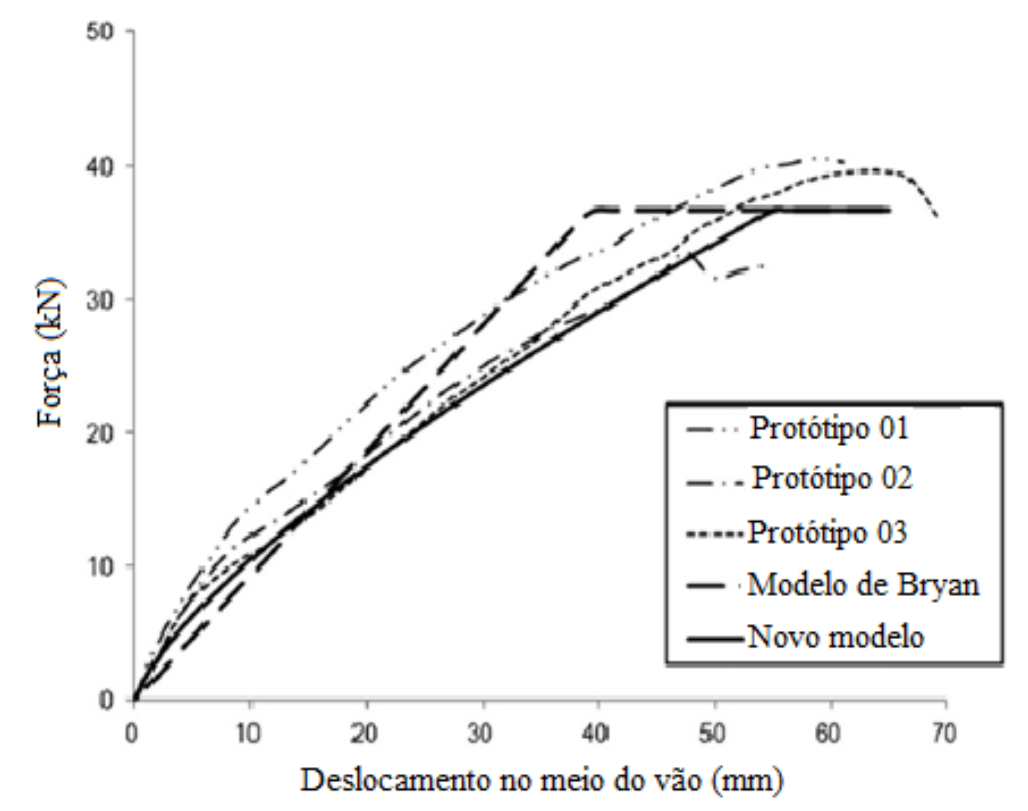

Figura 2.16 - Comparação entre os protótipos ensaiados: modelo de Bryan e modelo proposto (YE et al., 2013).

O modelo de Bryan (1993), apoiado no método vetorial de forças, admite que a terça e a luva girem em torno do centroide do grupo de parafusos, resultando em forças iguais nos furos. No entanto, resultados numéricos indicam que a distribuição de tensão em torno dos furos próximos a meio vão é muito maior que nos furos no final da luva (Figura 2.17). Isto mostra que as forças não são as mesmas e o centro de rotação da conexão não coincide com o centroide do grupo de parafusos. Isso pode ser constado também no trabalho de Gutierrez et al. (2011).

a

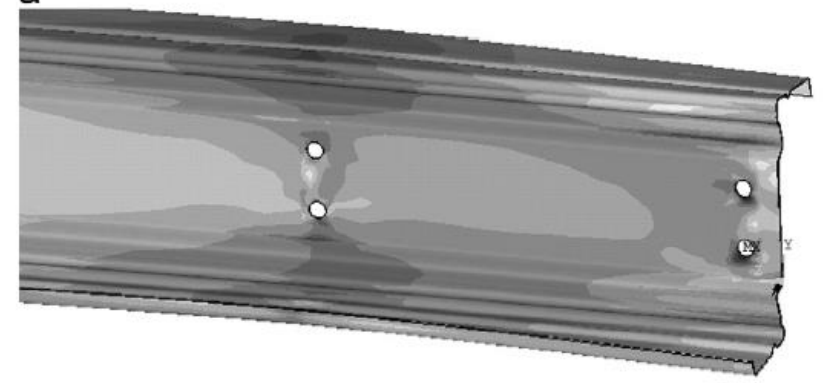

b

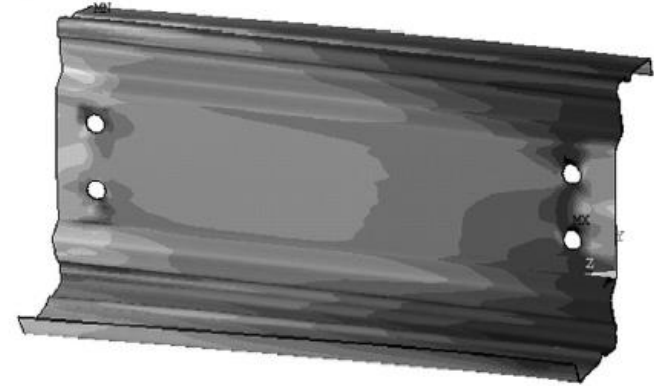

$\begin{array}{llll}360 & 420 \quad 480 & 540\end{array}$

Figura 2.17 - Distribuição de tensões de von Mises em MPa: a) terça e b) luva (YE et al., 2013). 
Diferentemente dos modos de falha observados nos trabalhos anteriores, os protótipos de Ye et al. (2013) apresentaram falha por instabilidade local da alma da luva, região compreendida entre os furos (Figura 2.18a). Tal diferença foi atribuída à presença dos enrijecedores nos perfis. Assim como em Gutierrez et al. (2011), observaram-se deformações significativas nas paredes dos furos próximos ao suporte (Figuras $2.18 \mathrm{~b}$ e $4.18 \mathrm{c}$ ).
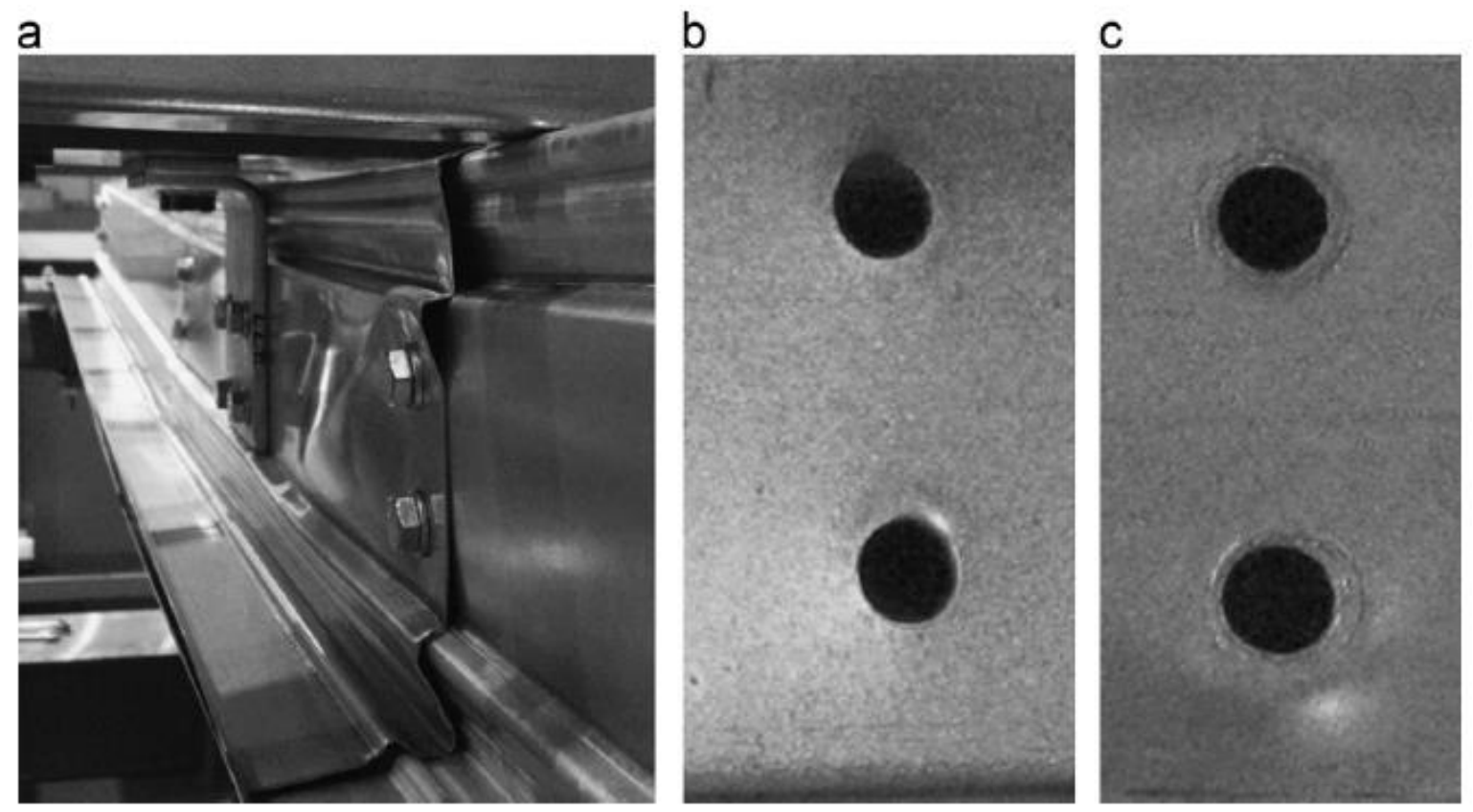

Figura 2.18 - Configuração final da terça com luva:

a) instabilidade local da alma da luva, b) deformação dos furos próximos ao meio do vão e c) deformação dos furos no final da luva (YE et al., 2013).

Fávero Neto (2013) realizou um estudo experimental de terças contínuas nos apoios por meio de luvas ou transpasse. Quanto às ligações com luvas, o autor ensaiou dois protótipos de perfis do tipo "Z" enrijecido a $55^{\circ}$, com relações $L_{\S} / D$ e $L_{s} / L_{t}$ iguais a 3,84 e 0,173 , respectivamente, variando apenas as espessuras nominais (ora 1,75 $\mathrm{mm}$ ora 2,70 $\mathrm{mm}$ ).

Os resultados experimentais indicaram que a capacidade do protótipo com espessura de $1,75 \mathrm{~mm}$ foi associada à ocorrência de um mecanismo plástico (nomeado por localdistorcional), que se desenvolveu no final da luva devido ao efeito combinado das instabilidades distorcional e local (Figura 2.19a). Para o caso do perfil com espessura de 2,70 mm, a falha ocorreu apenas pela instabilidade distorcional da luva (Figura 2.19b). As terças com luvas apresentaram momentos fletores experimentais $29 \%$ e $21 \%$ menores que as terças fisicamente contínuas, para as espessuras de $1,75 \mathrm{~mm}$ e $2,70 \mathrm{~mm}$, respectivamente. 


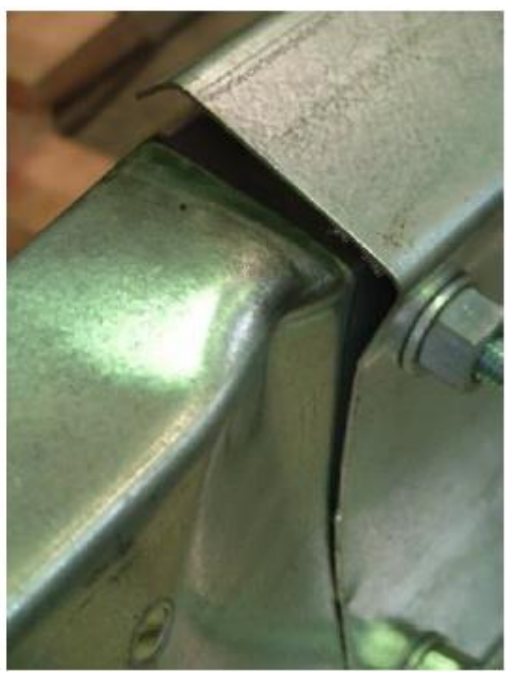

a) Falha local-distorcional

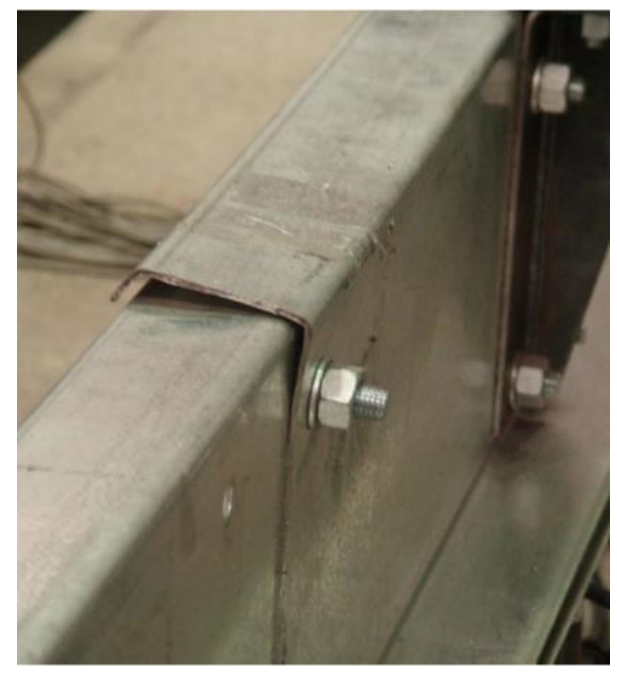

b) Falha distorcional

Figura 2.19 - Mecanismo de falha para as terças com luvas (FÁVERO NETO, 2013).

De modo geral, Fávero Neto (2013) propôs dois modelos para analisar terças contínuas nos apoios por meio de ligações parafusadas. Admitiu que o deslocamento vertical máximo é composto por parcelas advindas da força cortante, do momento fletor e da deformação dos furos. As duas primeiras parcelas de deformação podem ser obtidas automaticamente mediante a implementação em um programa via elementos finitos de barra. A última parcela pode ser considerada por meio de dois métodos de cálculo sugeridos pelo autor: Método da Rigidez Rotacional (MRR) e Método da Rigidez Equivalente (MRE).

O Método da Rigidez Equivalente leva em consideração a parcela de flexibilidade da deformação do furo por meio de um fator de modificação do momento de inércia $(\alpha)$. O fator $\alpha$ tem a finalidade de alterar a rigidez à flexão na região da ligação. Tal método idealiza a região da ligação como contínua e perfeitamente rígida. Com base no programa experimental, o parâmetro $\alpha$ é determinado, ou seja, o momento de inércia da região da ligação é alterado de forma que o deslocamento no meio do vão seja igual ao determinado experimentalmente. Em relação à abrangência do método, o autor restringiu sua aplicação para determinação de deslocamentos e esforços em serviço (50\% da capacidade).

O Método da Rigidez Rotacional idealiza a região da ligação mediante a colocação de molas de rotação, na posição do centro de rotação teórico da ligação (Figura 2.20). 


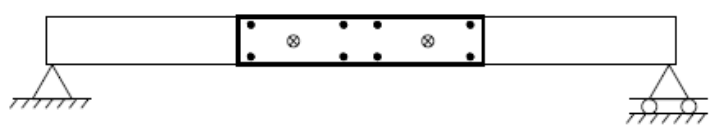

(Luva)

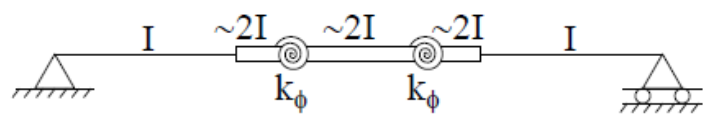

Figura 2.20- Modelo de barras acoplado ao Método da Rigidez Rotacional (FÁVERO NETO, 2013).

Para o caso específico desse trabalho, Fávero Neto (2013) considerou a flexibilidade da ligação devido à deformação do furo por meio do acoplamento do clássico modelo vetorial ao modelo mecânico apresentado na Figura 2.21. No Apêndice A é apresentada uma análise completa dos esforços solicitantes desenvolvida para os sistemas de terças com luvas, considerando o modelo supracitado.

a)
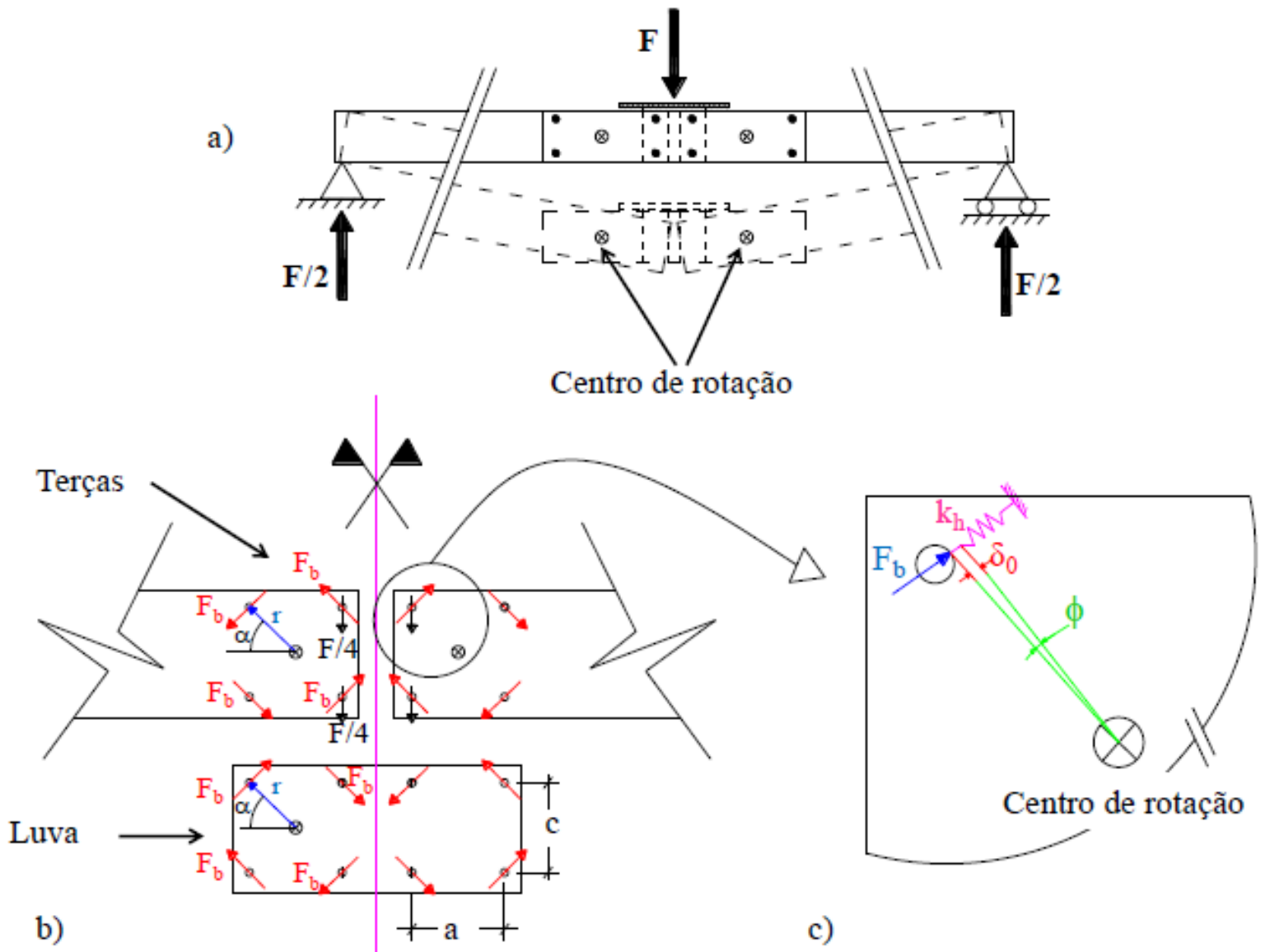

Figura 2.21 - Forças desenvolvidas no modelo mecânico do MRR (adaptado de FÁVERO NETO, 2013). 
Logo, faz-se necessário o conhecimento prévio da rigidez de contato da parede do furo $\left(K_{h}\right)$ para a determinação da rigidez secante da mola rotacional $K_{\phi}$ (Expressão 2.18). Em Fávero Neto (2013), os valores de $K_{h}$ são estimados por meio da expressão 2.13, sendo $r$ a distância do parafuso ao centroide da ligação (Figura 4.14). Assim como Fávero Neto, Dubina e Ungureanu (2010) também aplicaram a expressão 2.13 nos sistemas de terças contínuas por meio de transpasse.

$$
K_{\phi}=\frac{M}{\phi}=4 K_{h} r^{2}
$$

Esse método possibilita análises de deslocamentos e esforços em estados limites de serviço e último. Entretanto, o autor justifica que as previsões médias de deslocamentos por esse modelo teórico (MRR) são inferiores aos experimentais, pois o mesmo não leva em conta a perda de rigidez devida à instabilidade local e distorcional dos perfis. 


\section{PROGRAMA EXPERIMENTAL}

\subsection{INTRODUÇÃO}

Sistemas de coberturas estão usualmente submetidos a carregamentos gravitacionais (peso próprio, sobrecargas na cobertura, cargas acidentais, entre outros) e à ação do vento (sobrepressão e sucção), os quais incidem na superfície da cobertura (telhas) e são transferidos para as terças.

Simulações experimentais de coberturas em tamanho real, com aplicações de carregamentos uniformemente distribuídos por unidade de área, exigem grandes caixas de pressão. A norma americana AISI S908 (2013) (Base Test Method for Purlins Supporting Standing Seam Roof System) apresenta recomendações para a realização desse tipo de ensaio.

Conforme verificado nos estudos de Javaroni (1999) e Wibbernmeyer (2010), os procedimentos para a execução de ensaios em caixas de pressão são trabalhosos, pois exigem muitos detalhes e cuidados especiais a serem seguidos para evitar falhas, principalmente no controle da pressão no interior da caixa. Outros problemas recaem nas grandes dimensões dos protótipos em laboratório, a perda de material em regiões que não são de interesse ao estudo, o volume de informações que dificultam uma análise paramétrica e a instrumentação onerosa, uma vez que não se sabe o ponto de falha.

Portanto, modelos experimentais simplificados foram utilizados no corrente trabalho, atingindo de forma eficiente e econômica ao interesse específico deste estudo.

\subsection{IDEALIZAÇÃO DO ENSAIO DE TERÇAS COM LUVAS}

O grau de continuidade estabelecido nos sistemas de terças contínuas por meio de luvas ou transpasse depende do desempenho das ligações parafusadas e da rigidez entre os tramos adjacentes, tendo reflexo direto na distribuição de esforços solicitantes do sistema. Portanto, o momento fletor nos apoios intermediários de uma viga contínua ou semicontínua pode variar entre os valores extremos de zero (no caso de apoios idealmente rotulados) e $q L^{2} / 12$ (no caso de continuidade total), sendo $L$ a distância entre apoios e $q$ uma força uniformemente distribuída. Para vigas contínuas ou semicontínuas, a ABNT NBR 8800:2008 apresenta uma simplificação (Figura 3.1) para as distâncias entre pontos de momento nulo. 


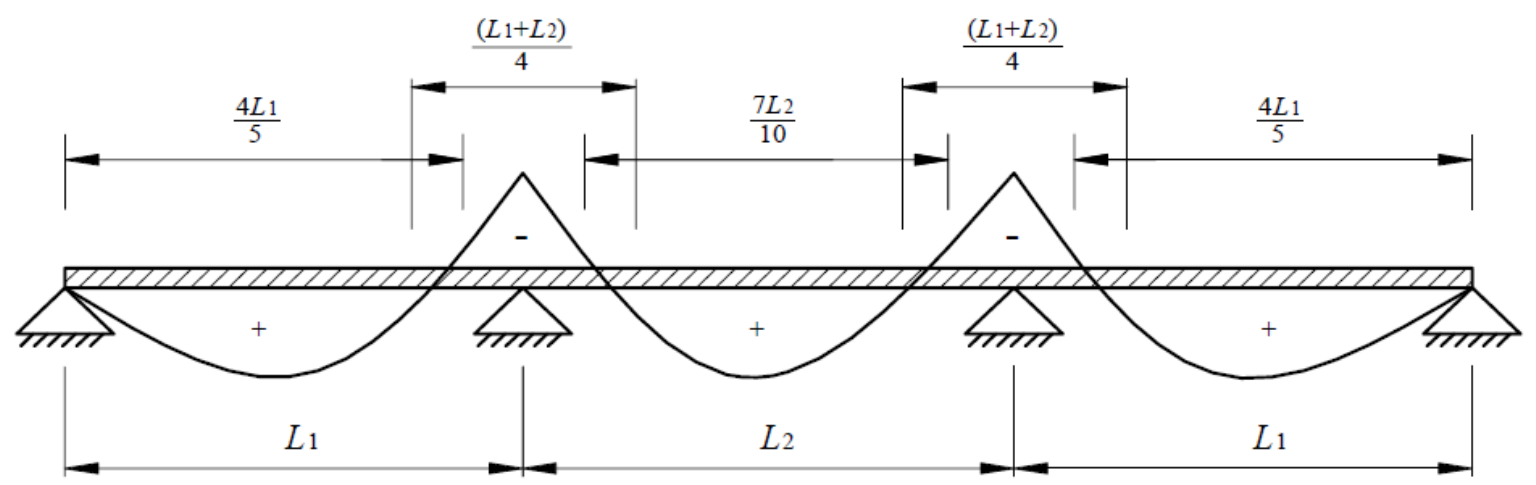

Figura 3.1 - Representação esquemática das distâncias entre pontos de momento nulo em uma viga contínua ou semicontínua (ABNT NBR 8800:2008).

A metodologia experimental empregada neste trabalho é uma idealização proposta por Ghosn e Sinno (1995), que simplifica o estudo de terças contínuas nos apoios por meio de ligações parafusadas. Com base no sistema contínuo de múltiplos vãos, com carregamento distribuído uniformemente (Figura 3.2a), os pontos de momento fletor nulo definem os apoios de uma viga equivalente na condição estática simplesmente apoiada. Tais pontos de momento fletor nulo (Figura 3.2b) encontram-se à esquerda e à direita do apoio interno, a uma distância compreendida entre 0,21 a 0,25 vezes o vão $(L)$. Assim sendo, adotou-se o comprimento de $0,5 L$ para o vão de ensaio $\left(L_{t}\right)$. Para a introdução do carregamento na estrutura, o apoio interno é substituído por uma força concentrada a meio vão, que representa a reação vertical do apoio (Figura 3.2c).

a)

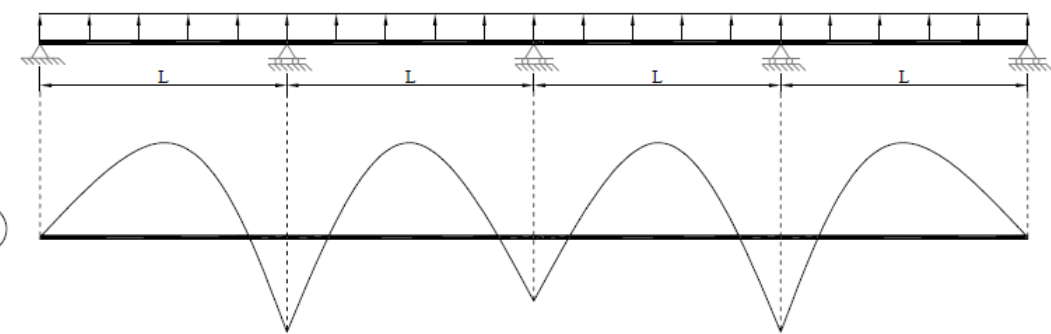

Ponto de

Momento

Nulo

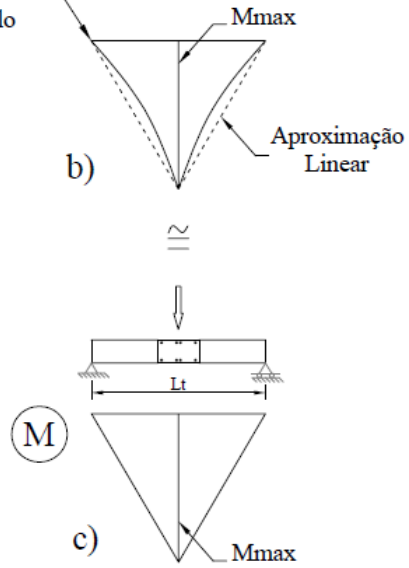

Figura 3.2 - Esquema geral do modelo de ensaio adotado: a) viga contínua com carregamento uniformemente distribuído, b) diagrama de momento fletor e pontos de inflexão e c) viga simplesmente apoiada equivalente. 
Logo, a estratégia de ensaio adotada tem por base uma viga na condição estática biapoiada com aplicação de uma força concentrada a meio vão. Desse modo, os esforços solicitantes podem ser calculados de forma direta, sem a necessidade prévia da rigidez da ligação.

\subsection{DESCRIÇÃO DOS PRÓTOTIPOS}

Conforme apresentado anteriormente, o problema das terças com luvas recai na determinação da rigidez da ligação, por ora, de difícil mensuração analítica ou numérica. Assim sendo, desenvolveu-se um programa experimental composto por 15 protótipos de terças para a investigação do comportamento estrutural do sistema.

Todos os protótipos empregados neste trabalho apresentam seção transversal do tipo “Z” enrijecido a $90^{\circ}$ e mesas com pequena diferença na largura, para permitir a sobreposição entre a terça e a luva na região da ligação. Tais perfis de mesma seção transversal são posicionados de modo a combinar mesa maior com mesa menor. Os materiais e as configurações geométricas dos protótipos estudados são compatíveis com a prática atual da indústria brasileira.

Neste trabalho, a prioridade foi investigar a influência de quatro variáveis no comportamento estrutural de terças com luvas: o comprimento efetivo da luva $\left(L_{p}\right)$, a altura do perfil $(D)$, o vão $\left(L_{t}\right)$ e a espessura da luva $\left(t_{s}\right)$; ilustradas na Figura 2.5.

Os protótipos foram divididos em três séries identificadas por A, B e C. Basicamente, cada série apresenta, como referência, um protótipo contínuo fisicamente (Figura 3.3a) e três protótipos contínuos por meio de luvas (Figura 3.3b), com relações entre o comprimento efetivo da luva e a altura do perfil $\left(L_{p} / D\right)$ de 2,4 e 6 , respectivamente.

Na série B foi incluído um protótipo conectado apenas pelo suporte (Figura 3.3c), ou seja, sem a luva, representando na prática a condição estática admitida em projeto como biapoiada, sendo uma referência para o estudo da capacidade de continuidade do suporte. 

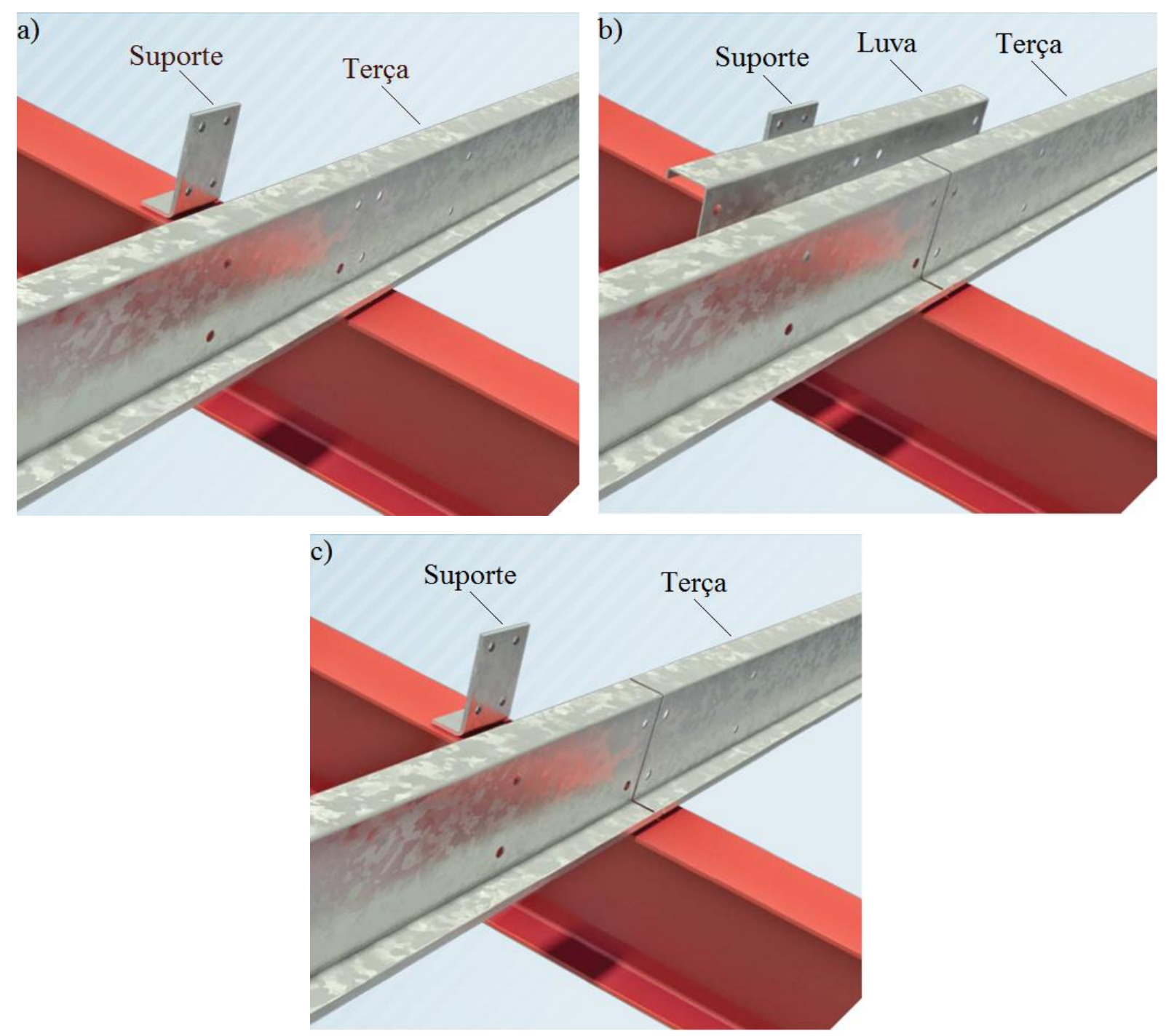

Figura 3.3 - Sistemas de terças ensaiadas: a) terça contínua fisicamente, b) terça contínua por meio de luva e c) terça contínua apenas pelo suporte (adaptada de BW INDUSTRIES, 2016).

Todos os protótipos foram fabricados pela empresa Modular Sistema Construtivo, em chapa zincada com espessura nominal de $1,95 \mathrm{~mm}$. Apenas nas séries B e C foi adicionado um protótipo com luva de espessura nominal de 3,00 mm e relação $L_{p} / D$ igual a 4 para um estudo preliminar do comportamento frente a essa variável.

As dimensões nominais especificadas para fabricação dos protótipos estão apresentadas no Apêndice B (Tabela B.1). A Tabela 3.1 expõe a descrição e as dimensões dos protótipos.

Com o intuito de complementar, os protótipos da campanha experimental de Fávero Neto (2013) relacionados ao presente tema foram incluídos em duas séries extras (D e E), apresentadas na Tabela 3.1. Tratam-se dos protótipos contínuos por meio de luvas (Z1-L5 e Z2L5); cuja variável principal foi a espessura, com valores nominais de 1,75 mm e 2,70 mm, 
respectivamente. Como referência para comparação direta, os protótipos contínuos fisicamente (Z1-C e Z2-C) também foram incluídos. Esses quatro exemplares foram nomeados de acordo com a legenda deste trabalho, seguida da titulação original entre parentes.

Tabela 3.1 - Descrição e dimensões dos protótipos ensaiados.

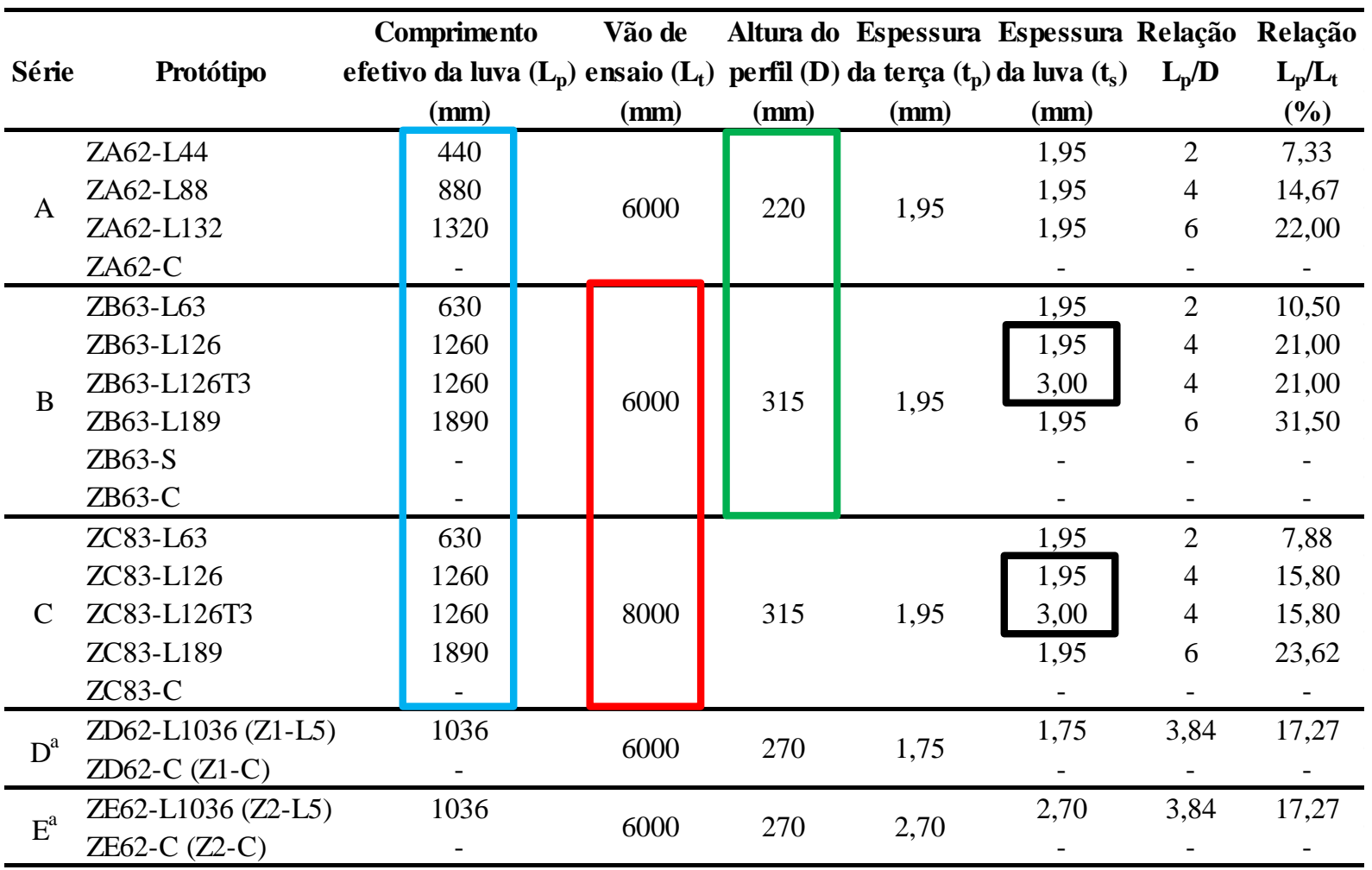

${ }^{\mathrm{a}}$ As séries D e E referem-se a Fávero Neto (2013).

Variavéis estudadas

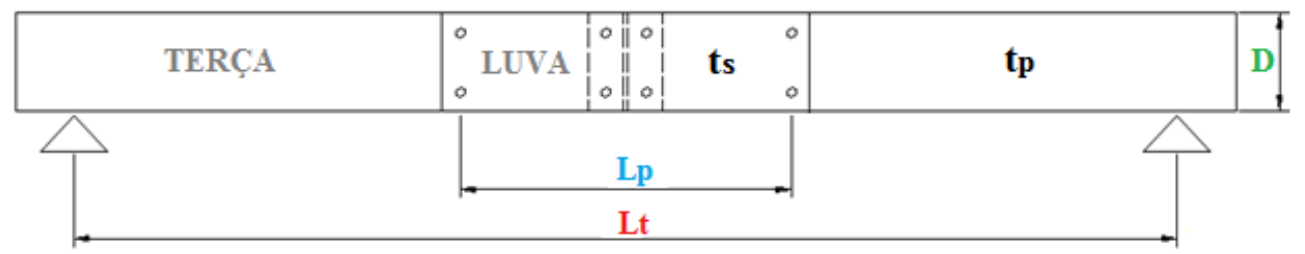

Legenda para identificação dos protótipos

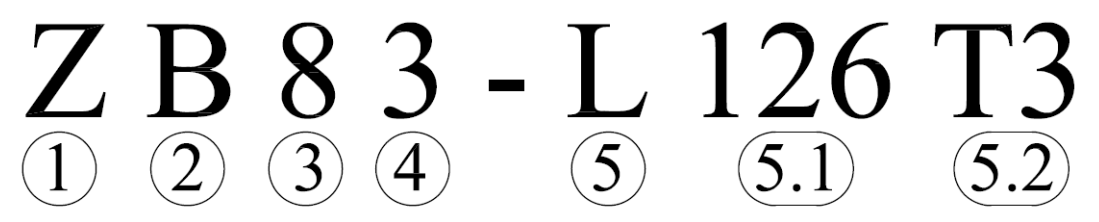

1 - Perfil com seção transversal do tipo "Z"

2 - Letra que simboliza a série (A, B ou C)

3 - Comprimento do vão de ensaio $(6=6000 \mathrm{~mm}$ e $8=8000 \mathrm{~mm})$

4 - Altura do perfil $(2=220$ ou $270 \mathrm{~mm} \mathrm{e} 3=315 \mathrm{~mm})$

5 - Tipo de emenda $(\mathrm{C}=$ contínua, $\mathrm{S}=$ apenas suporte e $\mathrm{L}=$ luva $)$

5.1 - Comprimento da ligação em centímetros $\left(\mathrm{L}_{\mathrm{p}}\right)$

5.2 - Espessura da luva $(\mathrm{T} 3=3 \mathrm{~mm})$ 


\subsection{MATERIAIS UTILIZADOS}

O material utilizado para fabricação das terças e luvas foi o aço zincado estrutural, conforme ABNT NBR 7008-3 (ABNT,2012) grau ZAR-345. O padrão de revestimento adotado foi o Z275, com massa mínima de zinco depositada em ambas as faces de $275 \mathrm{~g} / \mathrm{m}^{2}$, correspondente a uma espessura de cobrimento mínima de $0,02 \mathrm{~mm}$ por face. Como o revestimento não desempenha função estrutural, deve ser desconsiderado nos cálculos. Portanto, as dimensões reais medidas no laboratório (valores médios apresentados no Apêndice B - Tabela B.1) foram corrigidas mediante a desconsideração dessa camada de zinco.

A resistência mínima ao escoamento $\left(f_{y}\right)$ para esse tipo de aço é $345 \mathrm{MPa}$, e para a resistência à ruptura $\left(f_{u}\right), 430 \mathrm{MPa}$. O alongamento na ruptura deve ser superior a $12 \%$ para base de medida de $50 \mathrm{~mm}$. As propriedades mecânicas do aço apresentadas no Apêndice $\mathrm{C}$ Tabela C.1 foram caracterizadas com base em ensaios de tração em concordância com a norma ASTM A370:2014.

Os parafusos (M16) utilizados na região da ligação foram de alta resistência, especificação A325 (ASTM, 2013). Os parafusos utilizados para prender os travamentos laterais (M12) foram de aço comum, especificação A307 (ASTM, 2012). Em relação ao diâmetro dos furos, a empresa Modular Sistema Construtivo adota furos alargados (diâmetro + $4 \mathrm{~mm}$ ) para parafusos com diâmetro igual ou superior a $12,7 \mathrm{~mm}$. Tal folga é um padrão adotado pela empresa, tendo em vista permitir a montagem em campo frente a imperfeições de fabricação.

\subsection{MONTAGEM DOS ENSAIOS}

$\mathrm{Na}$ montagem dos protótipos, as terças foram dispostas aos pares e devidamente travadas entre si de modo a evitar a instabilidade global (FLT) e propiciar a condição de flexão restringida, isto é, flexão em torno do eixo perpendicular à alma.

Os travamentos (Figura 3.4) foram dispostos com o cuidado de não inibir possíveis instabilidades distorcional e/ou local na região da ligação. Os dispositivos de travamento são os empregados na prática e compostos por duas cantoneiras parafusadas na alma das terças e interligadas por um perfil do tipo "U" soldado nas abas das respectivas cantoneiras. 


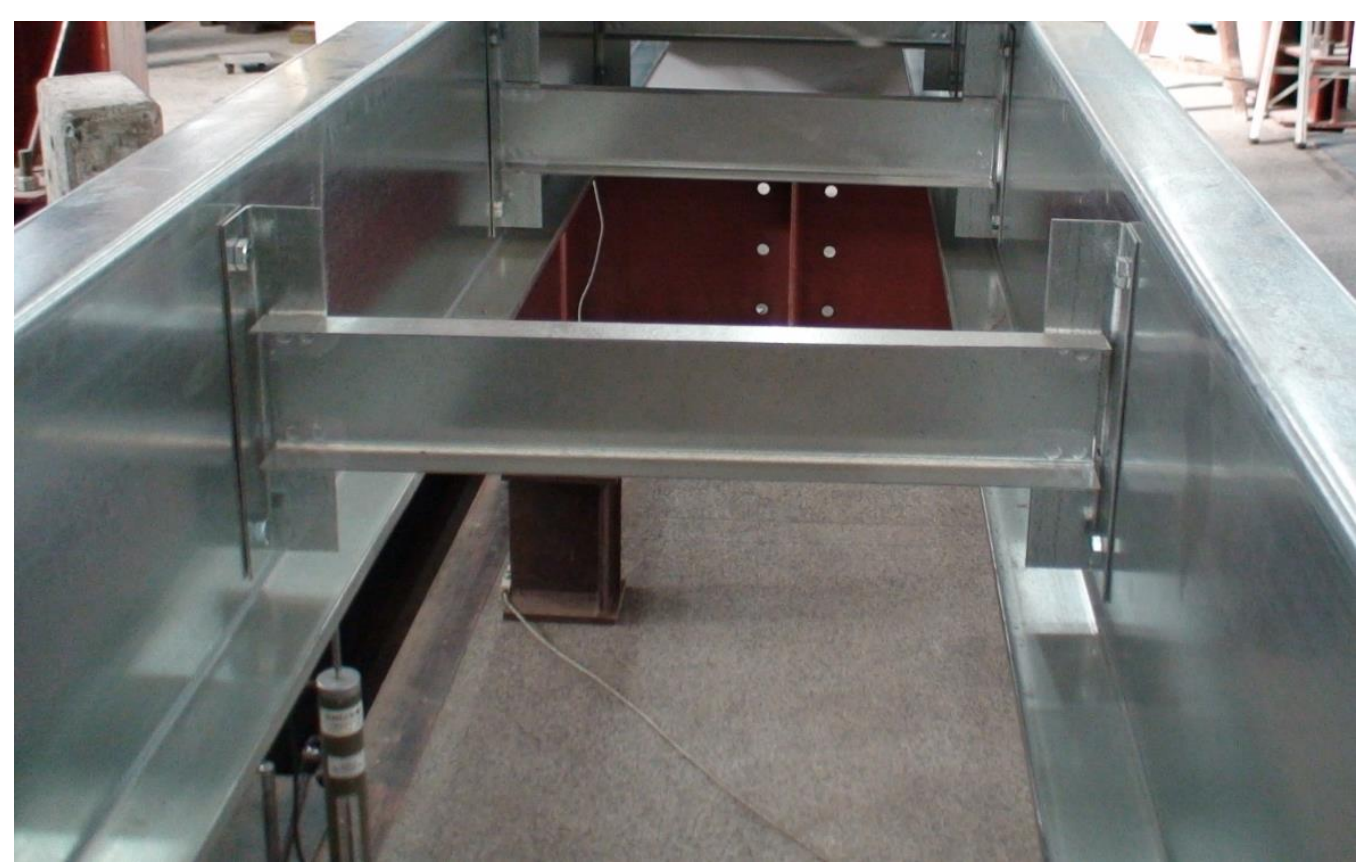

Figura 3.4 - Dispositivos de travamento lateral.

Além disso, painéis metálicos (steel decks) foram parafusados nas mesas superiores dos perfis, nas proximidades dos apoios, com o intuito de conferir travamento lateral adicional ao sistema (Figura 3.5).

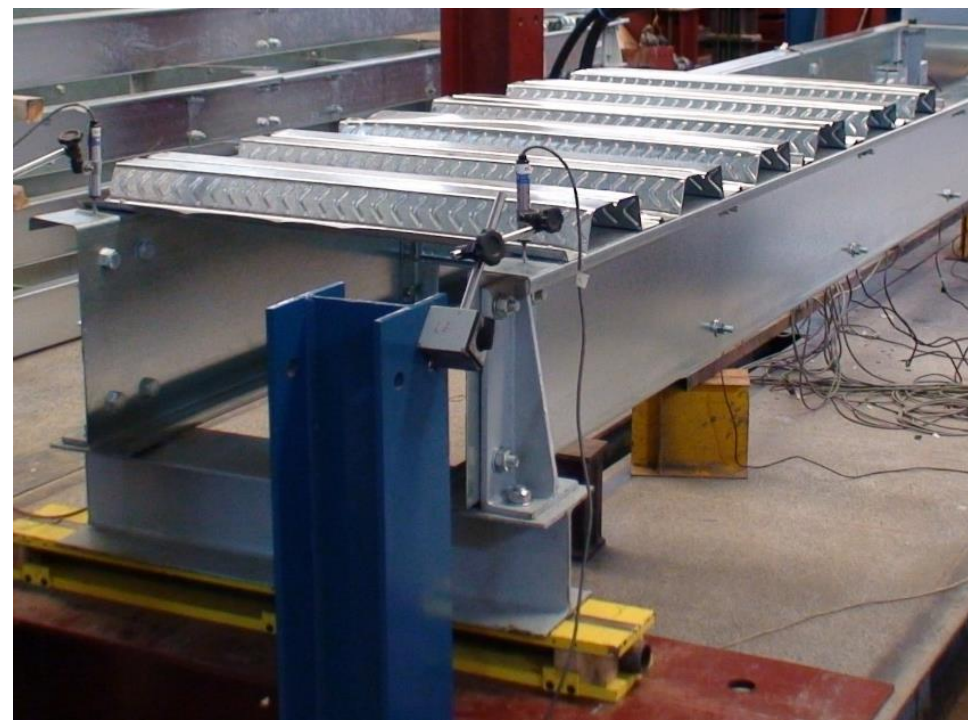

Figura 3.5 - Travamento lateral de extremidade por meio de painéis steel deck parafusados.

Para a aplicação da força foi utilizado um atuador servo-hidráulico, com capacidade nominal de $500 \mathrm{kN}$ e curso do pistão de $150 \mathrm{~mm}$. Um dispositivo, composto por um perfil $\mathrm{W}$ e dois suportes, foi posicionado a meio vão do conjunto de terças (Figura 3.6) para a introdução 
da força diretamente na alma dos perfis, simulando o apoio das terças nos sistemas usualmente empregados no Brasil.

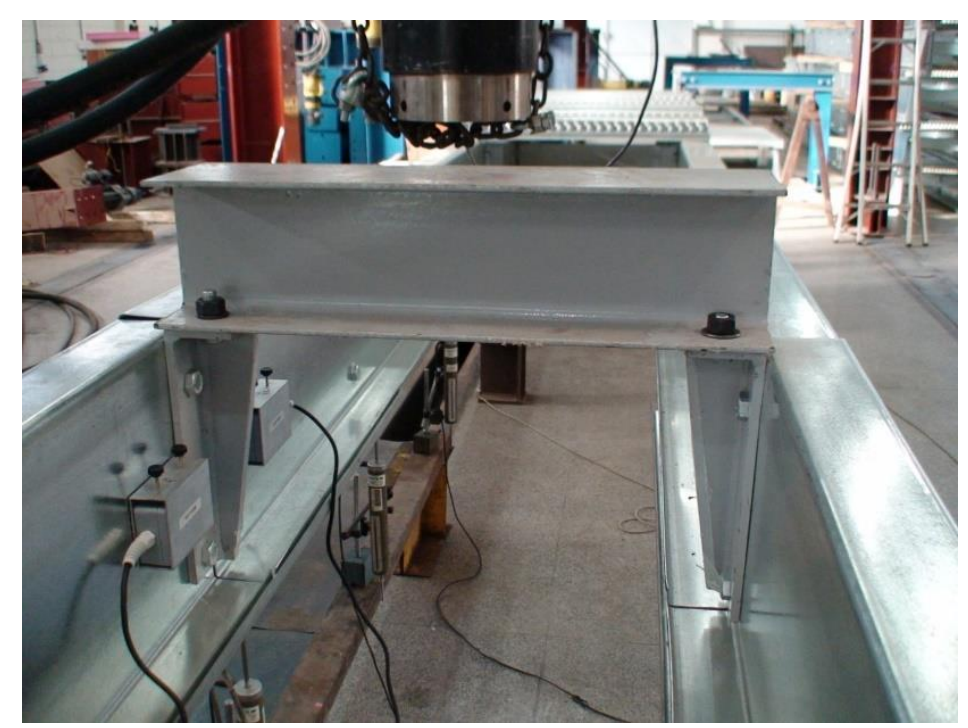

Figura 3.6 - Dispositivo para aplicação da força no conjunto de terças.

De maneira semelhante, os apoios das terças também continham esse dispositivo fixado na alma dos perfis (Figura 3.5). Para atender à condição idealizada no item 3.1 (viga biapoiada), esses dispositivos de apoio foram posicionados sobre rótulas, conferindo apoio fixo de um lado e apoio móvel do outro lado (Figura 3.7).
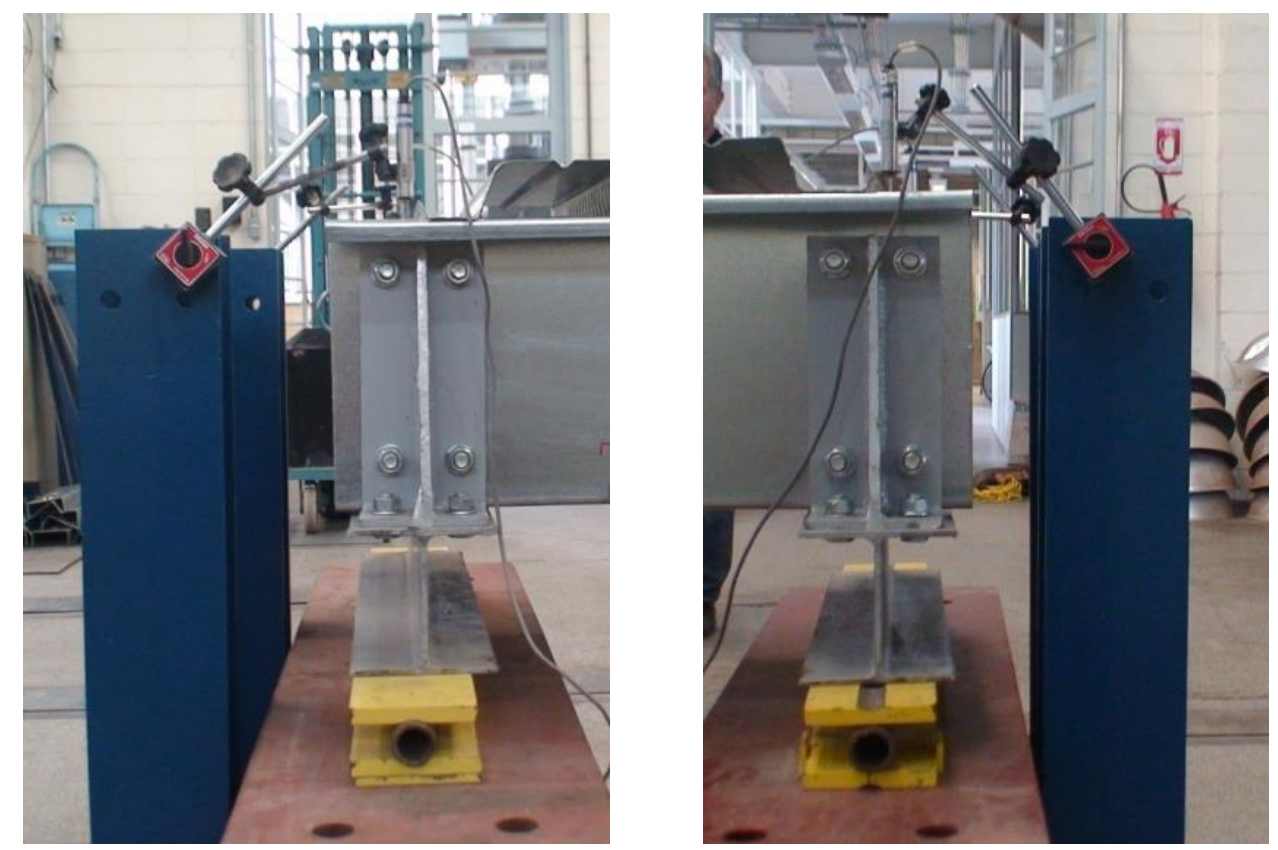

Figura 3.7 - Dispositivos rotulados posicionados nas extremidade dos conjuntos: apoio fixo (à esquerda) e apoio móvel (à direita). 
Além dos travamentos citados anteriormente, os dispositivos de apoio e de aplicação da força funcionam também como travamentos laterais das terças.

A figura 3.8 apresenta uma vista geral de um protótipo e do aparato de ensaio, e a figura 3.9 os detalhes típicos adotados em todos os protótipos.

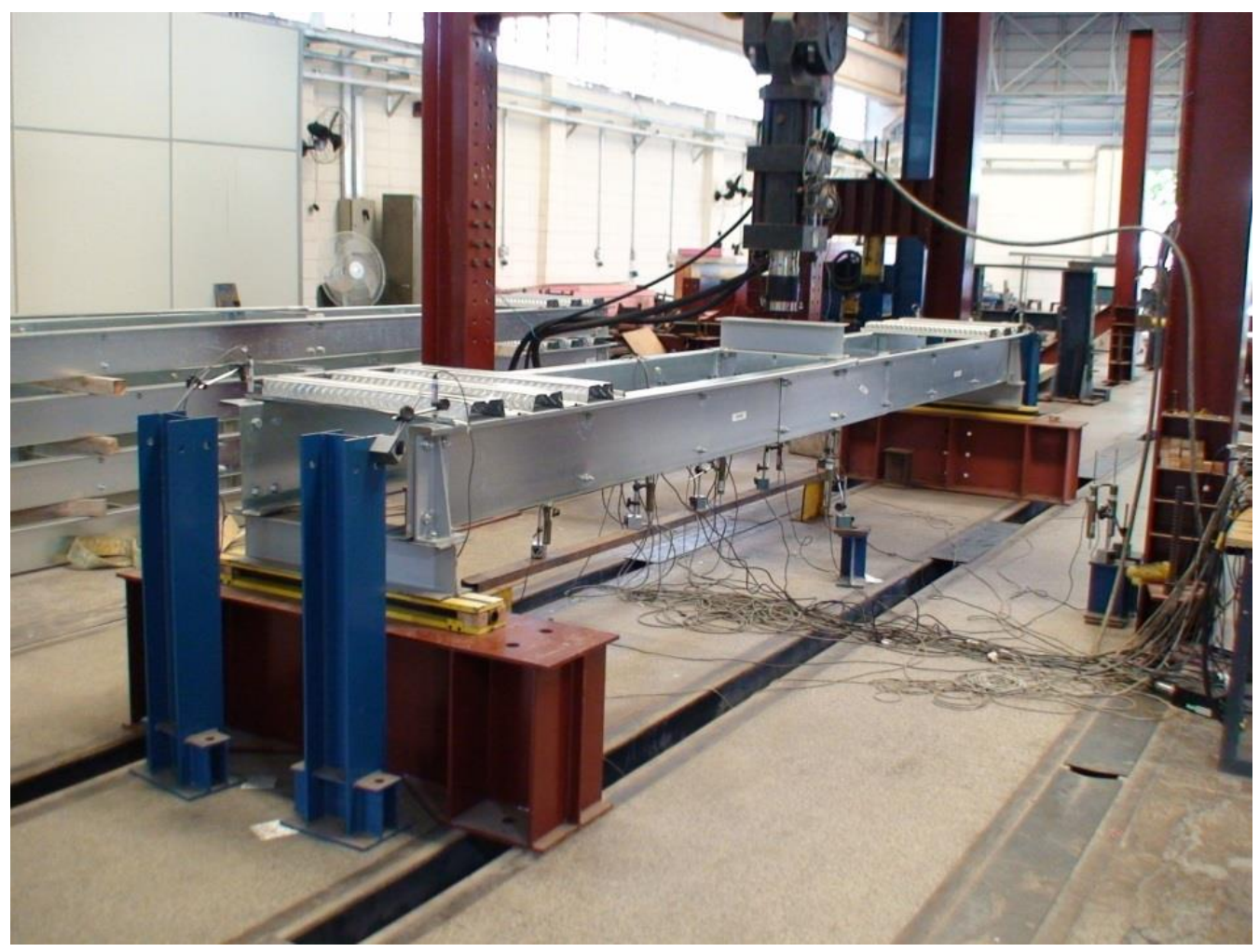

Figura 3.8 - Vista geral de um protótipo e aparato de ensaio.

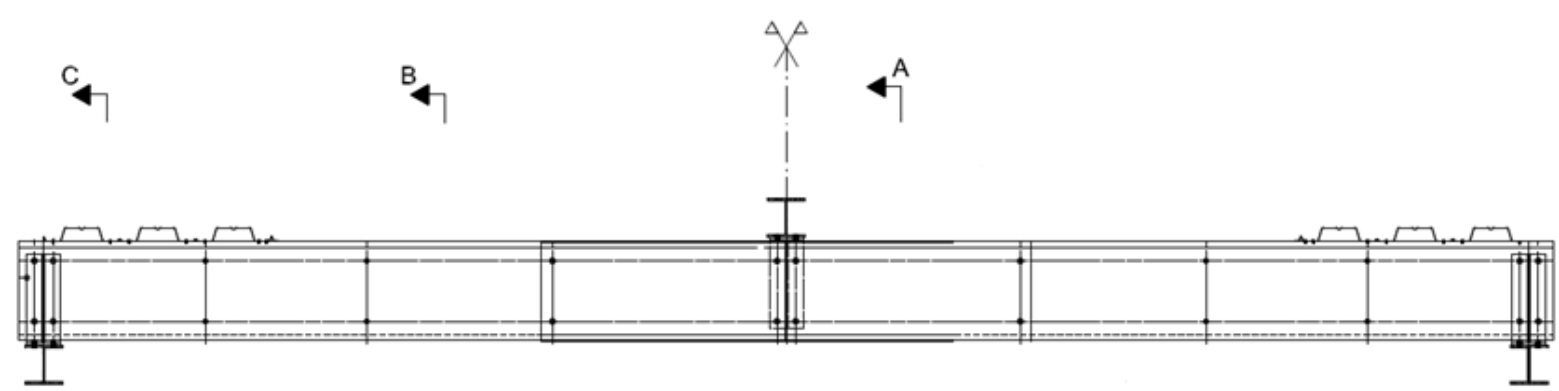

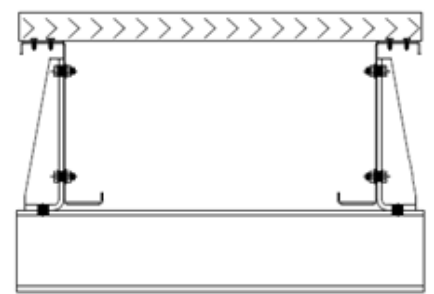

Corte C

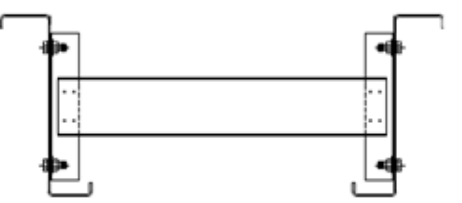

Corte B

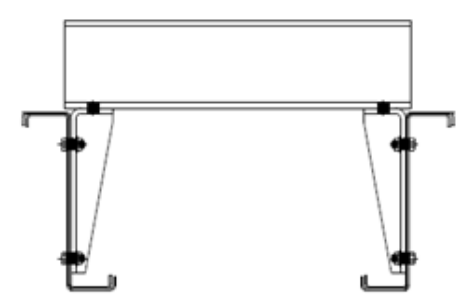

Corte A

Figura 3.9 - Detalhes do dispositivo central para a introdução de força (Corte A), do travamento lateral típico (Corte B) e dos dispositivos de extremidade dos protótipos (Corte C). 


\subsection{INSTRUMENTAÇÃO DOS PROTÓTIPOS}

Basicamente, a instrumentação consistiu na colocação de extensômetros uniaxiais, inclinômetros e transdutores de deslocamentos. Uma apresentação geral da instrumentação é mostrada para as terças contínuas fisicamente (Apêndice D - Figura D.1), contínuas por meio de luvas (Apêndice D - Figura D.2) e contínuas apenas pelo suporte (Apêndice D - Figura D.3).

Objetivando a otimização da instrumentação devido à extensa campanha experimental realizada, apenas uma das terças do conjunto foi instrumentada. Esta simplificação é fundamentada na simetria do comportamento esperado. Entretanto, transdutores centrais (números 1 e 10) foram colocados em ambas as terças do conjunto, com a finalidade de avaliar a simetria dos deslocamentos verticais e a parcela da força aplicada nas duas terças do conjunto.

A terça instrumentada do conjunto (denominada Terça-1) continha transdutores de deslocamento (1, 2, 3, 4 e 5) ao longo de seu comprimento. Dessa forma, a evolução dos deslocamentos verticais pôde ser monitorada em diferentes seções. Posteriormente aos ensaios, os valores absolutos oriundos de todos os transdutores foram corrigidos em relação aos transdutores de deslocamento (6, 7, 8 e 9) posicionados nos apoios (Figura 3.7).

Em todos os protótipos com luvas (Apêndice D - Figura D.2) foram colados extensômetros uniaxiais, posicionados na mesa superior e inferior de duas seções típicas: na seção da luva a meio vão (Figura D.2 - Corte AA) e na seção da terça próxima à luva (Figura D. 2 - Corte BB).

A série B foi escolhida como referência para o estudo da evolução das deformações longitudinais nas mesas. Basicamente, os pontos escolhidos para tal medição foram os pontos próximos à alma (extensômetros com numeração ímpar) e próximos ao enrijecedor (extensômetros com numeração par). Nas demais séries foram colados extensômetros apenas próximos à alma. Nenhum extensômetro foi colado no protótipo com continuidade conferida apenas pelo suporte, uma vez que o objetivo principal foi obter a curva de referência forçadeslocamento.

Os inclinômetros (1, 2, 3 e 4) foram posicionados estrategicamente aos pares nas seções de interesse, permitindo, dessa forma, acompanhar a evolução das rotações relativas nos pontos escolhidos. 


\subsection{PROCEDIMENTO DE ENSAIO}

Visando à acomodação (eliminação de folgas) do aparato de ensaio bem como a verificação da instrumentação, todos os protótipos foram inicialmente carregados com aproximadamente $15 \%$ da força máxima estimada e em seguida descarregados. Em seguida foi realizado o ensaio propriamente dito até se atingir o estado-limite último.

Todos os ensaios foram conduzidos com controle de deslocamento do pistão do atuador, a taxas que variaram de $0,03 \mathrm{~mm} / \mathrm{s}$ a $0,1 \mathrm{~mm} / \mathrm{s}$. Tal variação ocorreu à medida que havia acréscimos de deslocamento sem o correspondente aumento da força aplicada. Conforme o sistema estabilizava, o procedimento de controle era repetido até que falha do sistema fosse atingida, sendo as medidas de deslocamento, rotação e deformação específica registradas a cada segundo. 


\section{RESULTADOS DA ANÁLISE EXPERIMENTAL E NÚMERICA}

Este capítulo discorrerá dos resultados coletados da análise experimental e das simulações numéricas desenvolvidas via ANSYS ${ }^{\mathrm{TM}}$. Foram avaliadas a rigidez e a resistência, direcionando, assim, ao entendimento do comportamento estrutural dos sistemas de terças contínuas nos apoios por meio de luvas.

Como forma de avaliação dos resultados obtidos, modelos numéricos de terças de múltiplos vãos foram desenvolvidos para comparação com as propostas existentes na literatura.

\subsection{RIGIDEZ DA LIGAÇÃO}

\subsubsection{Avaliação das curvas força versus deslocamento}

As curvas experimentais força-deslocamento no meio do vão são apresentadas nas Figuras 4.1, 4.2 e 4.3 para as séries A, B e C, respectivamente. Em cada série, adicionaram-se duas curvas teóricas, representando o comportamento elástico linear dos protótipos contínuos fisicamente (deslocamento no meio do vão igual a $F L_{t} / 48 E I$ ) e o comportamento elástico linear dos exemplares com luvas longas $(L p / D=6)$; sendo $F$ a força aplicada no meio do vão, $L_{t} \mathrm{o}$ vão, $E$ o módulo de elasticidade longitudinal (200.000 MPa), I o momento de inércia da seção transversal.

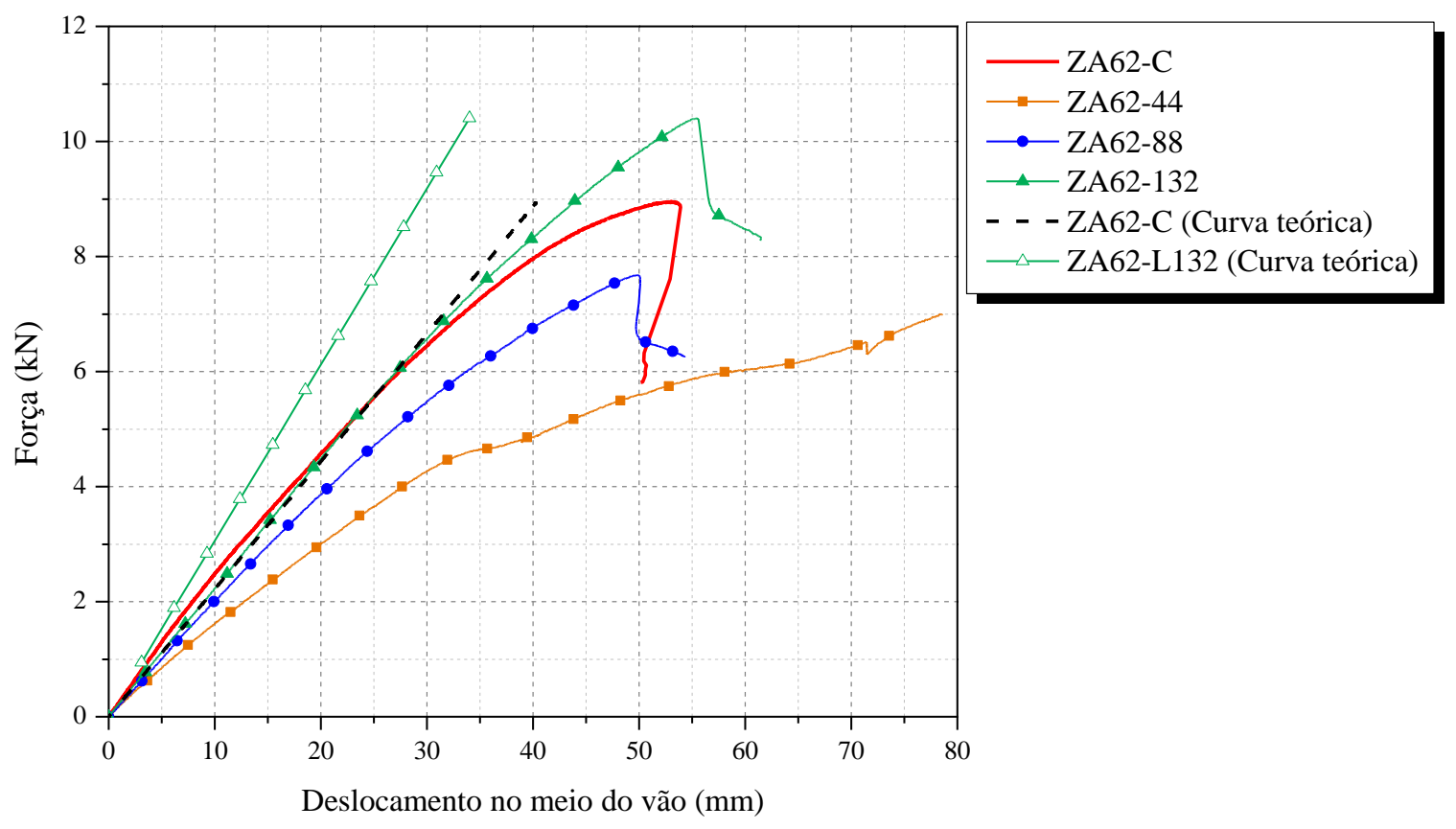

Figura 4.1 - Curvas força-deslocamento a meio vão para os protótipos da série A. 
De modo geral, a variação do comprimento da luva influenciou significativamente na rigidez dos protótipos ensaiados. À medida que a relação $L_{p} / D$ aumentou, o comportamento das terças contínuas por meio de luvas aproximou-se da referência (terças contínuas fisicamente). As curvas associadas aos protótipos com maior relação $L_{p} / D$ resultaram muito próximas ou até mesmo ultrapassaram a curva correspondente ao protótipo contínuo fisicamente, indicando sua capacidade de promover a continuidade.

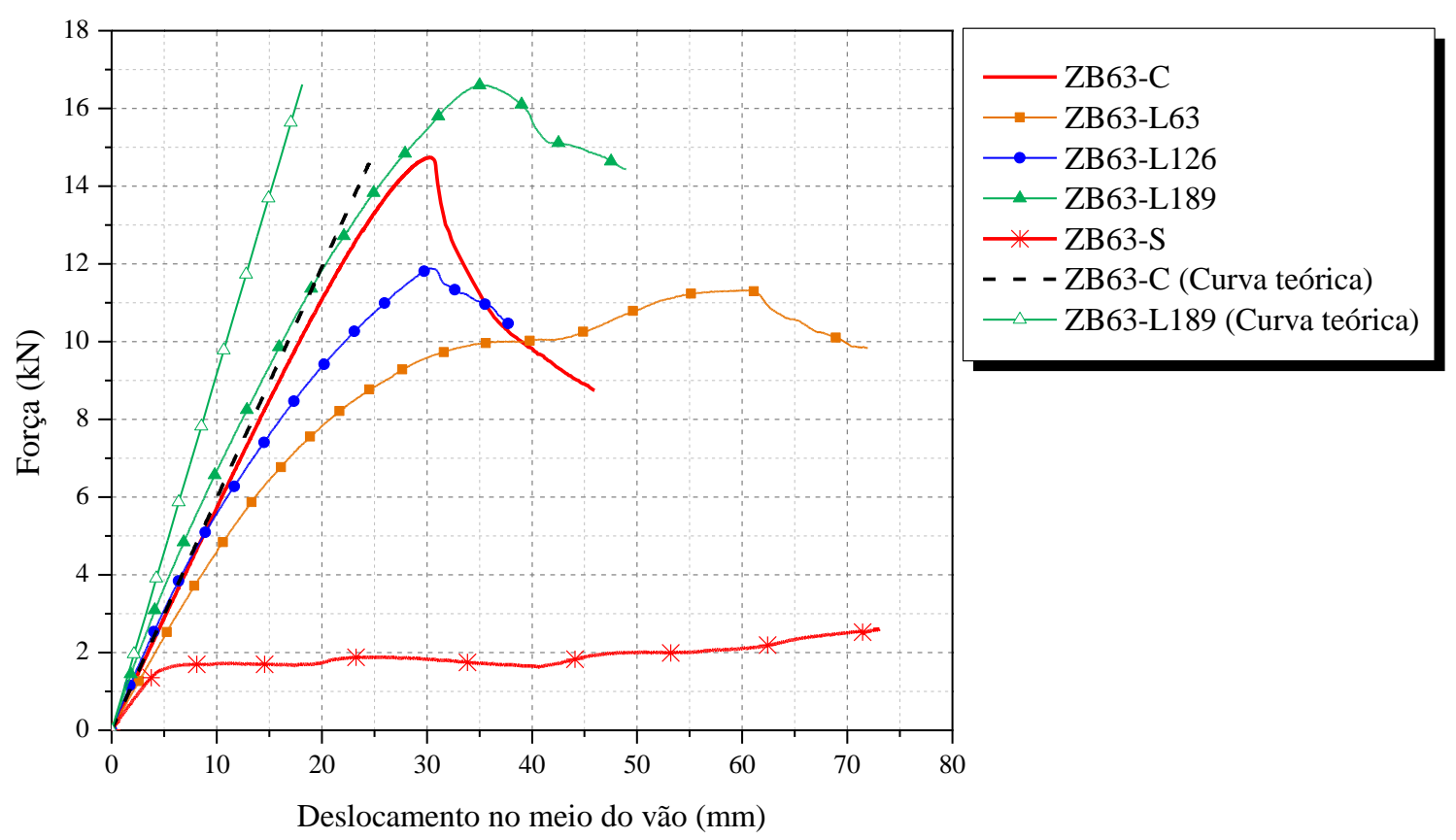

Figura 4.2 - Curvas força-deslocamento a meio vão para os protótipos da série B.

$\mathrm{Na}$ Figura 4.2, a curva do protótipo ZB63-S (terças interligadas apenas pelo suporte) é outra curva referência. Para pequenos incrementos da força, os resultados mostraram os grandes deslocamentos desenvolvidos pelo sistema, aproximando-se de uma ligação rotulada (sistema biapoiado), isto é, possui reduzida capacidade de promover a continuidade, embora seja responsável pela transmissão de uma pequena parcela do momento fletor na ligação quando associado ao conjunto terça-luva. 


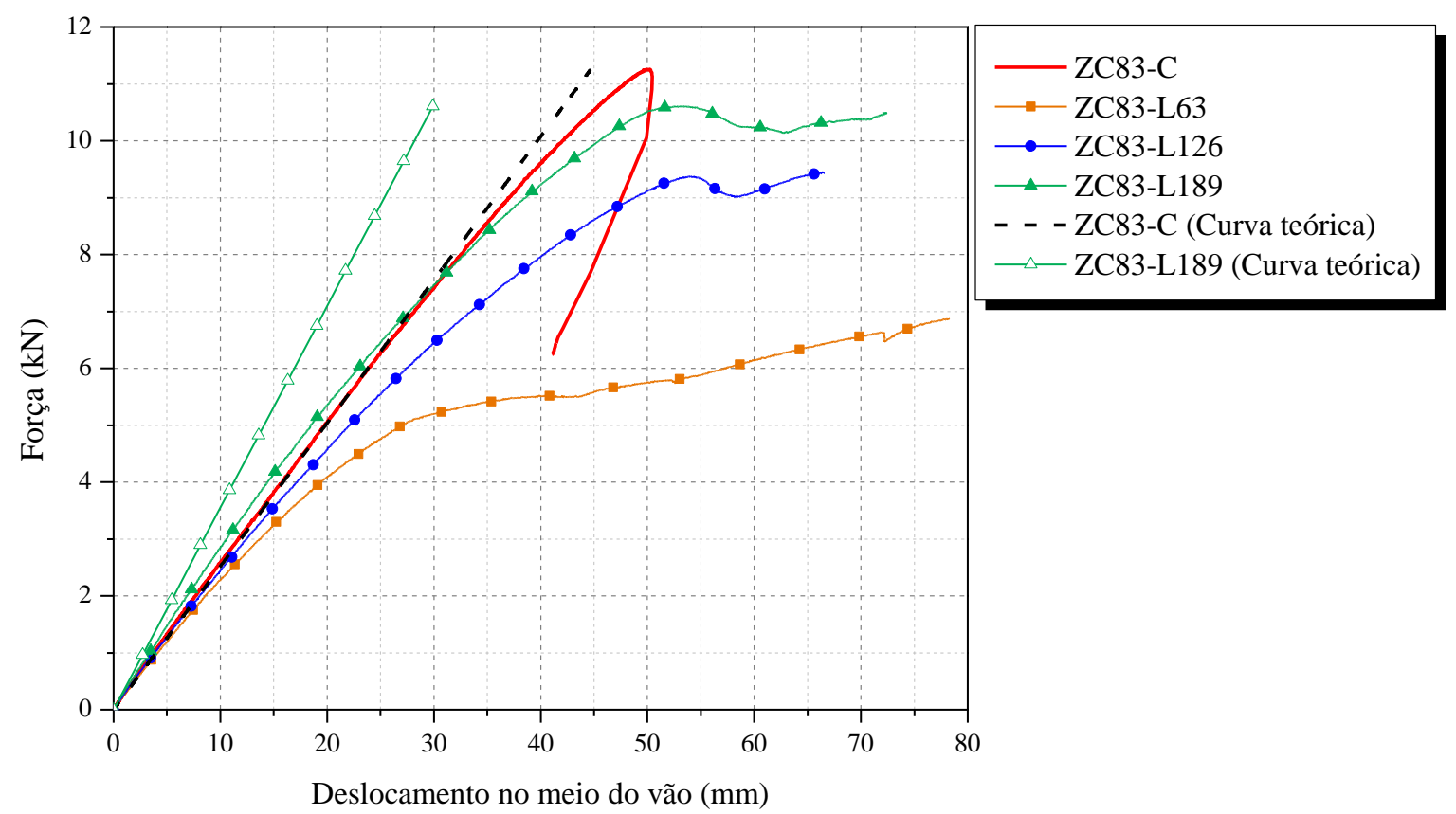

Figura 4.3 - Curvas força-deslocamento a meio vão para os protótipos da série C.

As curvas força-deslocamento evidenciaram a influência da rigidez da ligação nas várias configurações ensaiadas. Logo, torna-se relevante a caracterização do comportamento da ligação (relação momento-rotação) na avaliação da resposta estrutural do sistema de terças com luvas.

\subsubsection{Curvas momento-rotação}

Como apontado na literatura, a complexidade na determinação da rigidez da ligação está atribuída a diversos fatores, entre outros: a interação entre os componentes da ligação parafusada (terça, luva e suporte), as mudanças bruscas nas propriedades geométricas da seção, a descontinuidade na transmissão de tensões longitudinais, a magnitude dos esforços solicitantes, as forças concentradas introduzidas na alma dos perfis, as dimensões geométricas e os fenômenos de instabilidade.

Gutierrez et al. 2011, Yang e Liu (2012) e Ye et al. (2013) atribuíram as deformações excessivas da borda dos furos a uma parcela significativa da flexibilidade da ligação. Após o encerramento do programa experimental deste trabalho, todos os conjuntos de terças foram desmontados para uma inspeção visual. A Figura 4.4 exemplifica a região da ligação do protótipo ZA62-L44 desmontado, sendo as terças justapostas na parte superior da figura e a luva na parte inferior. 


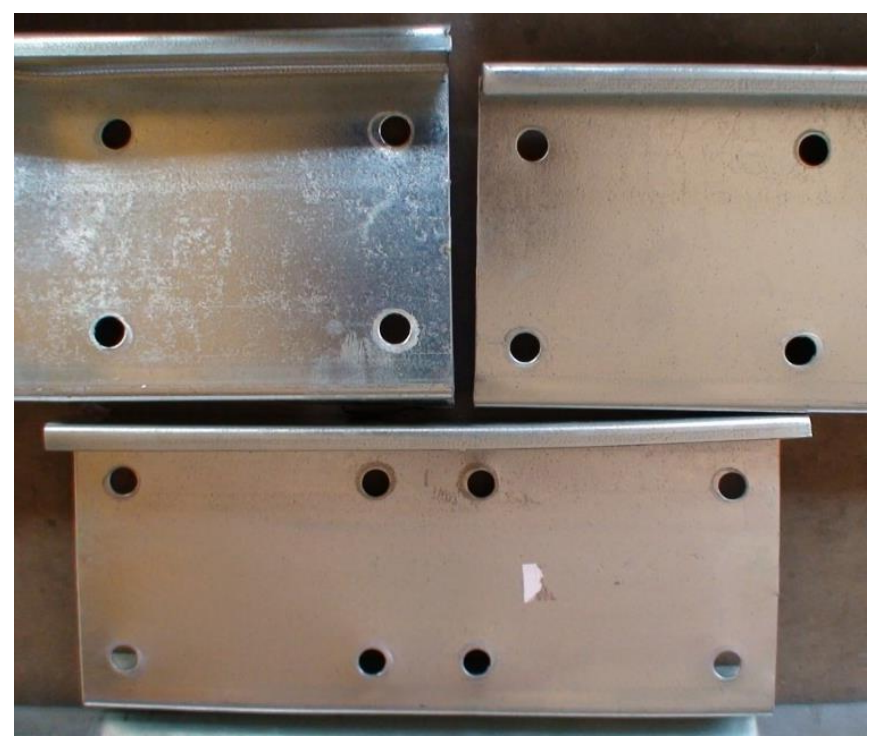

Figura 4.4 - Aspecto dos furos do protótipo ZA62-L44 após ensaio.

Pode-se observar que as bordas dos furos não sofreram esmagamento ou "ovalização" significativa durante o contato com o corpo do parafuso. Logo, as deformações localizadas não foram expressivas para o decréscimo da rigidez como constatado nas pesquisas supracitadas.

Neste estudo, as parcelas de flexibilidade foram avaliadas de forma global e, posteriormente, concentradas em molas rotacionais. Tais molas, quando associadas a um modelo simples de barras, permitem a representação do comportamento da ligação.

Trabalhos como os de Moore (1990), Gutierrez et al. (2011 e 2015), Yang e Liu (2012) e Fávero Neto (2013) também apresentam modelos barra-mola aplicados a sistemas com luvas. O comportamento dessas molas são descritos por curvas momento-rotação (M- $\Theta$ ) obtidas por meio de ensaios ou simulações numéricas.

Neste trabalho, as curvas M- $\Theta$ foram calibradas experimentalmente para as variáveis investigadas. Como exemplo dos passos seguidos em todos os protótipos com luvas, uma descrição completa dos procedimentos que resultaram nas curvas momento-rotação é apresentada para o protótipo ZB63-L126.

Inicialmente, modelos planos foram implementados no ANSYSTM, objetivando a representação numérica dos protótipos ensaiados. Para tanto, uma viga disposta na condição estática biapoada foi discretizada em elementos do tipo BEAM3, com momento de inércia duas vezes maior na região da conexão (superposição da terça com a luva). A Figura 4.5 ilustra a configuração adotada, sendo I o momento de inércia da seção da terça. Esse elemento elástico de viga BEAM3 possui dois nós com três graus de liberdade por nó, duas translações e uma 
rotação. A deformação por esforço cortante foi desprezada, sendo considerado o modelo cinemático de Euler-Bernoulli.

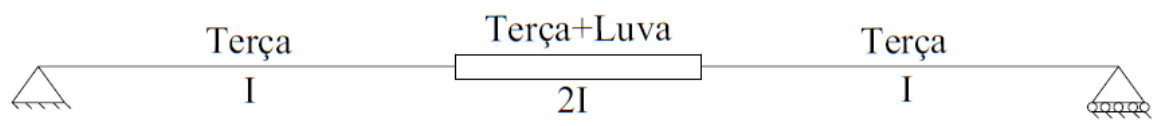

Figura 4.5 - Configuração adotada nas simulações numéricas.

A influência da ligação foi incorporada aos modelos de barra mediante a introdução de molas rotacionais não lineares (COMBIN39). Esse elemento de mola possui dois nós e possibilita a entrada de curvas momento-rotação não linear. Para cada valor de momento fletor solicitante, essas molas são responsáveis por representar a rotação relativa dos trechos conectados. Dessa forma, as curvas momento-rotação da ligação são fundamentais para representatividade dos resultados experimentais por meio desses modelos numéricos.

Para esse fim, os inclinômetros mediram as rotações a cada incremento de força. Colocados aos pares na seção de interesse, as rotações relativas foram quantificadas a cada incremento de força e associadas ao momento fletor correspondente, resultando nas curvas momento fletor versus rotação relativa da ligação. Essas curvas $\mathrm{M}-\Theta$ experimentais são conhecidas para todos os protótipos na seção do meio do vão (S1) e no final da luva (S2) e correspondem às rigidezes rotacionais $\mathrm{K}_{\mathrm{S} 1}$ e $\mathrm{K}_{\mathrm{S} 2}$, respectivamente. Tais curvas são apresentadas na Figura 4.6 para o protótipo ZB63-L126, juntamente com as curvas referentes as molas $\mathrm{K}_{\mathrm{S1}-2}, \mathrm{~K}_{\mathrm{MS1}}, \mathrm{K}_{\mathrm{MS} 2}, \mathrm{~K}_{\mathrm{MS1-2}}$, que serão descritas no decorrer deste item.

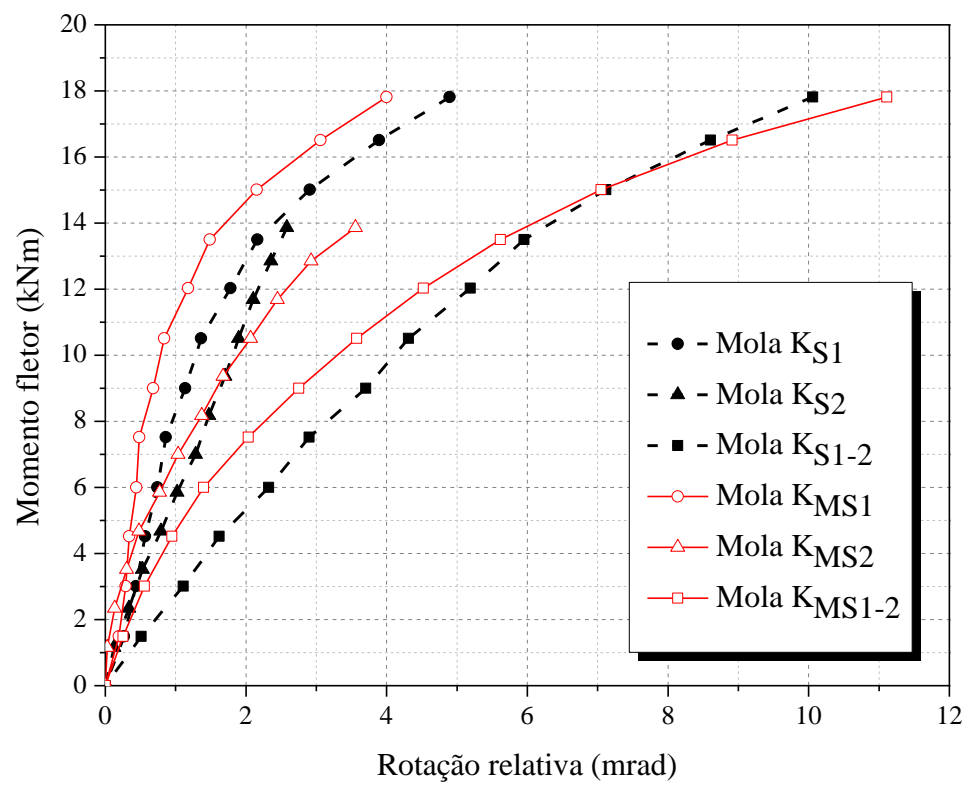

Figura 4.6 - Comportamento momento-rotação das molas implementadas nas simulações numéricas do protótipo ZB63-L126. 
As molas $\mathrm{K}_{\mathrm{S} 1}$ e $\mathrm{K}_{\mathrm{S} 2}$ foram então introduzidas ao modelo de barras via três molas posicionadas nas seções S1 e S2. Nomeado B3S, a Figura 4.7a exemplifica esse modelo.

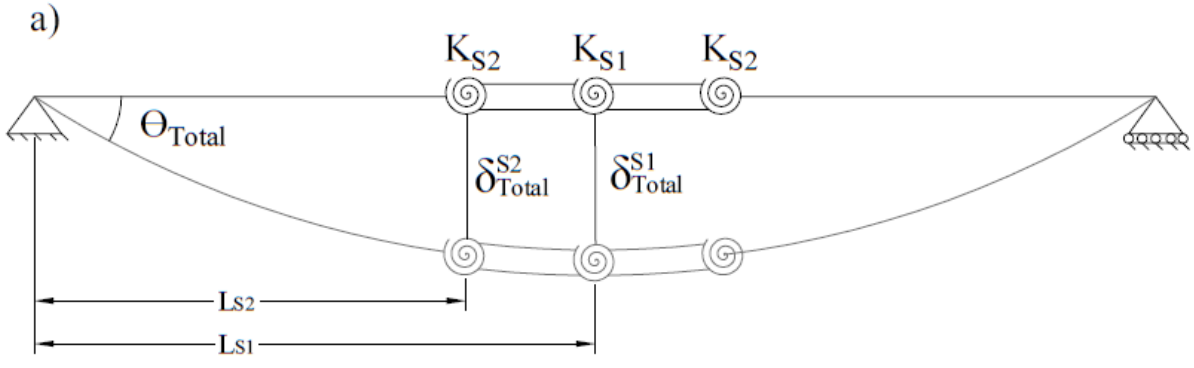

b)
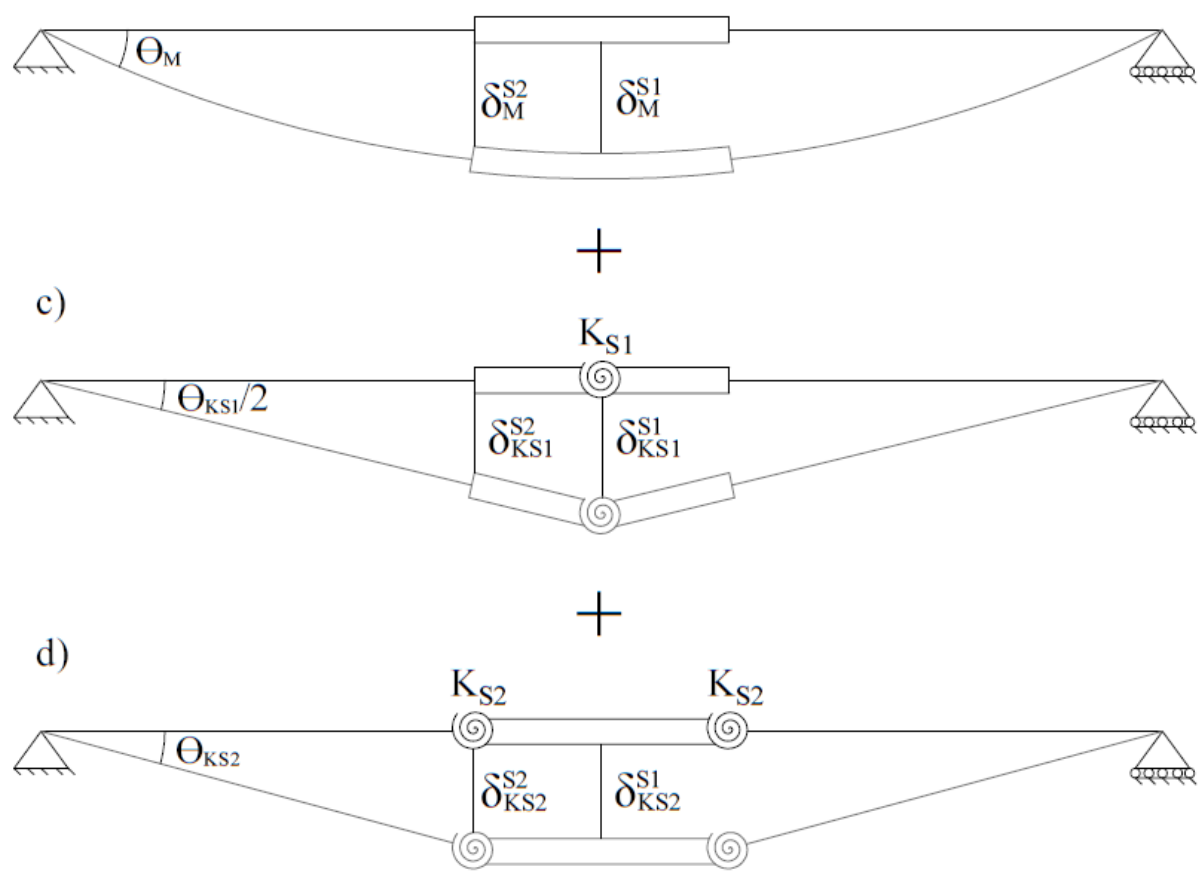

Figura 4.7 - Modelo de barras com três molas e componentes do deslocamento.

Os deslocamentos totais ( $\delta_{\text {Total }}$ - Figura 4.7 a) foram quantificados experimentalmente para as seções S1 e S2 por meio de transdutores de deslocamento. Simplificadamente, esse deslocamento total foi dividido em três parcelas provenientes: do momento fletor $\left(\delta_{\mathrm{M}}\right.$ - Figura 4.7b), da mola $K_{S 1}\left(\delta_{K S 1}-\right.$ Figura $\left.4.7 c\right)$ e das molas $K_{S 2}\left(\delta_{K S 2}-\right.$ Figura $4.7 d$ ). Logo, os deslocamentos atribuídos aos fenômenos pertinentes à ligação $\left(\delta_{\text {Lig. }}\right)$ são representados pelas Expressões 4.1 e 4.2 . 


$$
\begin{aligned}
& \delta_{\text {Lig. }}=\delta_{\text {Total }}-\delta_{M} \\
& \delta_{\text {Lig. }}=\delta_{K S 1}+\delta_{K S 2}
\end{aligned}
$$

Admitindo pequenas rotações, os deslocamentos nas seções S1 e S2 são determinados pelas respectivas Expressões 4.3 e 4.4:

$$
\begin{aligned}
& \delta_{\text {Lig. }}^{S 1}=\frac{\theta_{K S 1}}{2} L_{S 1}+\theta_{K S 2} L_{S 2} \\
& \delta_{\text {Lig. }}^{S 2}=\frac{\theta_{K S 1}}{2} L_{S 2}+\theta_{K S 2} L_{S 2}
\end{aligned}
$$

Antes de mensurar os deslocamentos a partir das rotações experimentais, procedeu-se uma correção nas rotações da mola $\mathrm{K}_{\mathrm{S} 1}$. Devido à presença dos suportes no meio do vão, os inclinômetros responsáveis pela medição da rotação relativa da mola $\mathrm{K}_{\mathrm{S} 1}$ foram afastados a uma distância de 138 mm. Assim, corrigiram-se as leituras desses inclinômetros, com a subtração das rotações oriundas do momento fletor a cada incremento de força, avaliadas por meio do modelo elástico linear exposto na Figura 4.7b. Assim, as rotações modificadas $\Theta_{M K S 1}$ foram obtidas.

Uma vez realizadas tais alterações nas molas $\mathrm{K}_{\mathrm{S} 1}$, foram calculados os deslocamentos teóricos nas seções S1 (Expressão 4.3) e S2 (Expressão 4.4) provenientes da ligação. Somados aos deslocamentos do modelo idealizado da Figura 4.7b, foram obtidos os deslocamentos totais teóricos $\left(\delta_{\mathrm{Lig}}+\delta_{\mathrm{M}+\mathrm{V}}\right)$. A diferença entre o deslocamento total experimental $\left(\delta_{\text {Total }}\right)$ e $\mathrm{o}$ deslocamento total teórico $\left(\delta_{\mathrm{Lig}}+\delta_{\mathrm{M}+\mathrm{V}}\right)$ foi determinada na seção S2 (Expressão 4.5).

$$
R_{S 2}=\delta_{\text {Total }}^{S 2}-\delta_{M}^{S 2}-\delta_{\text {Lig. }}^{S 2}
$$

Para cada incremento de força, os resíduos $\left(R_{S 2}\right)$ foram somados nas rotações experimentais na seção $\mathrm{S} 2$, transformando-os em rotação pela simples divisão pelo comprimento $L_{S 2}$. Dessa forma, foram obtidas as rotações modificadas $\theta_{M K S 2}$ (Expressão 4.6).

$$
\theta_{M K S 2}=\theta_{K S 2}+\frac{R_{S 2}}{L_{S 2}}
$$


Posteriormente, essas rotações modificadas foram associadas ao momento fletor solicitante na seção correspondente, resultando nas rigidezes modificadas $\mathrm{K}_{M S 1}$ e $\mathrm{K}_{\mathrm{MS} 2}$ (Figura 4.6). Assim, um novo modelo B3S-M, semelhante ao modelo B3S, foi simulado com as rigidezes atualizadas.

Almejando uma simplificação, as três molas consideradas nos modelos B3S e B3S-M foram substituídas por uma única mola equivalente, resultando nos modelos B1S e B1S-M com apenas uma mola no meio do vão. As curvas momento-rotação dessas molas, $\mathrm{K}_{\mathrm{S1-2}}$ e $\mathrm{K}_{\mathrm{MS1-2}}$, são apresentadas na Figura 4.6.

As curvas força versus deslocamento no meio do vão, provenientes dos quatro modelos numéricos (B3S, B3S-M, B1S e B1S-M) estão plotadas na Figura 4.8, juntamente com o resultado experimental do protótipo ZB63-L126.

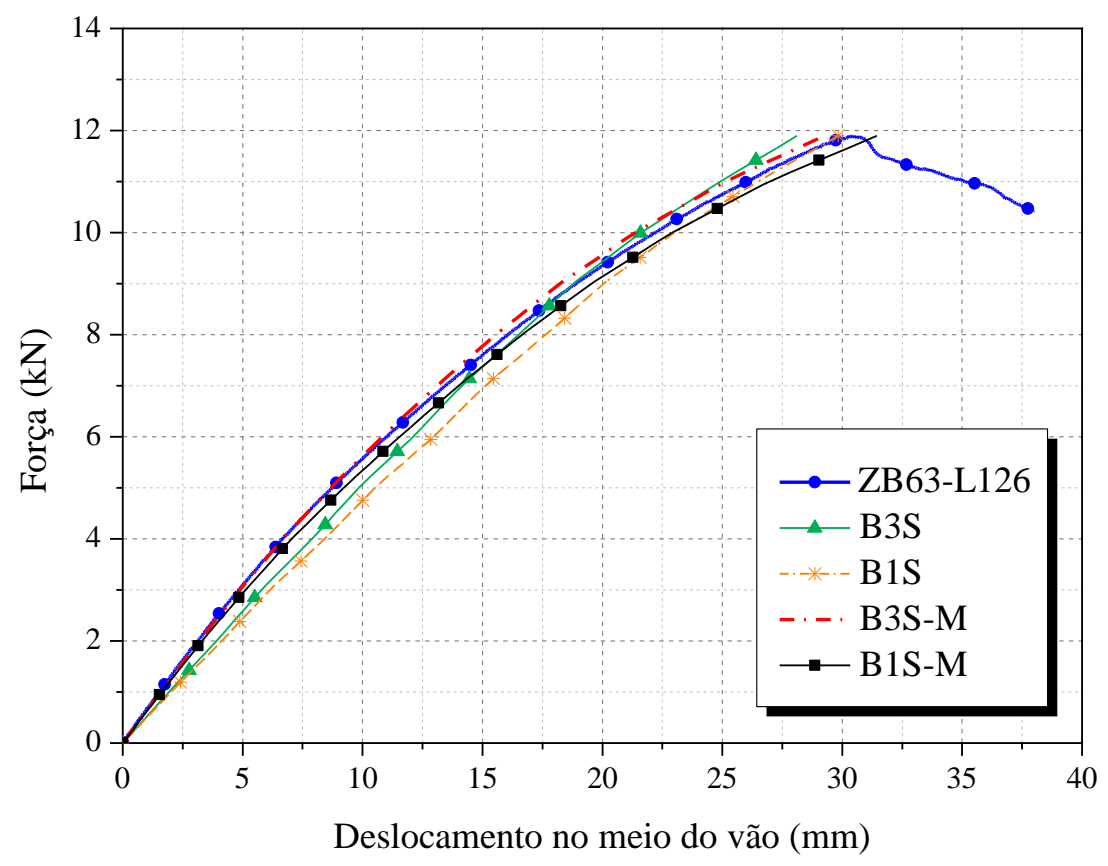

Figura 4.8 - Curvas força versus deslocamento no meio do vão do protótipo ZB63-L126.

Todos os modelos numéricos apresentaram resultados próximos aos obtidos em laboratório, principalmente o B1S-M, capaz de simular o comportamento da ligação por meio de uma mola apenas. Explorando esse modelo de uma única mola, uma nova proposta para obtenção das curvas M-Ө é apresentada na Figura 4.9.

Essa proposta conduziu a uma estratégia mais simples de estimar a rigidez da mola $\mathrm{K}_{\ominus}$, cuja formulação está indicada nas Expressões 4.7, 4.8 e 4.9. Uma comparação entre as duas rigidezes $\left(\mathrm{K}_{\ominus}\right.$ e $\mathrm{K}_{\mathrm{MS1-2}}$ ) é apresentada na Figura 4.10 para o protótipo ZB63-L126. 


$$
\begin{aligned}
& \delta_{K \theta}^{S 2}=\delta_{\text {Total }}^{S 2}-\delta_{M}^{S 2} \\
& \theta_{K \theta}=\frac{2 \delta_{K \theta}^{S 2}}{L_{S 2}} \\
& K_{\theta}=\frac{M}{\theta_{K \theta}}
\end{aligned}
$$

a)

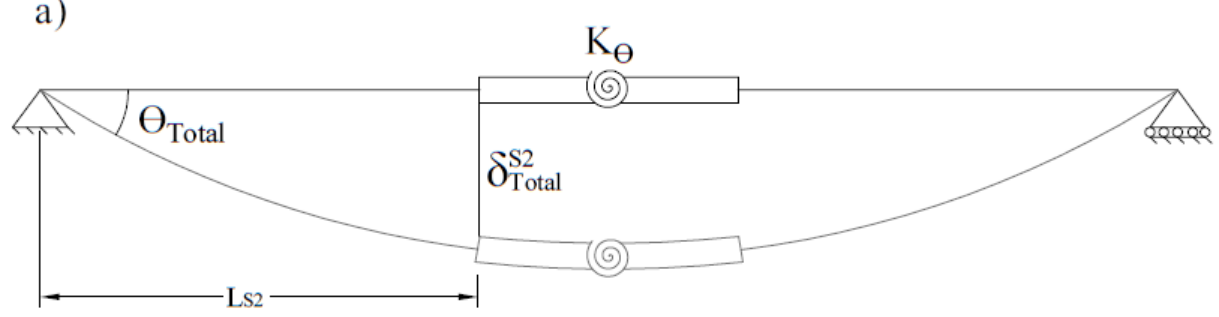

b)

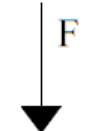

\section{.}




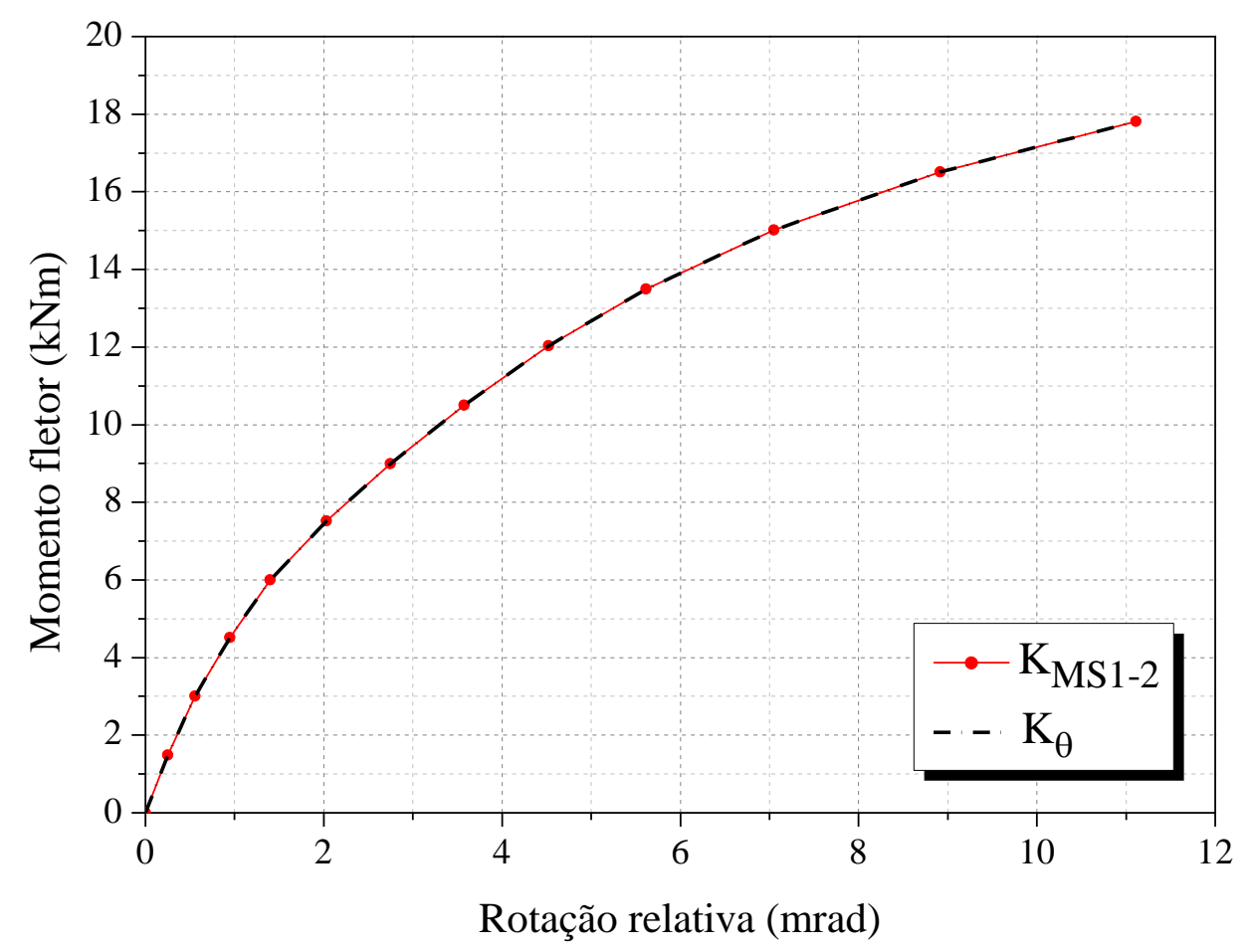

Figura 4.10 - Comparação entre os modelos com três molas $\left(\mathrm{K}_{\mathrm{MS1} 1-2}\right)$ e uma única mola $\left(\mathrm{K}_{\ominus}\right)$ para o protótipo ZB63-L126.

$\mathrm{Na}$ Figura 4.11, as curvas experimentais força versus deslocamento do protótipo ZB63-L126 foram comparadas com os resultados oriundos do modelo de barras com uma mola $\left(\mathrm{K}_{\ominus}\right)$ e correspondem aos pontos do meio do vão (Transdutor 1), das extremidades da ligação (Transdutores 2 e 3) e a 1.500 mm do meio do vão (Transdutores 4 e 5).

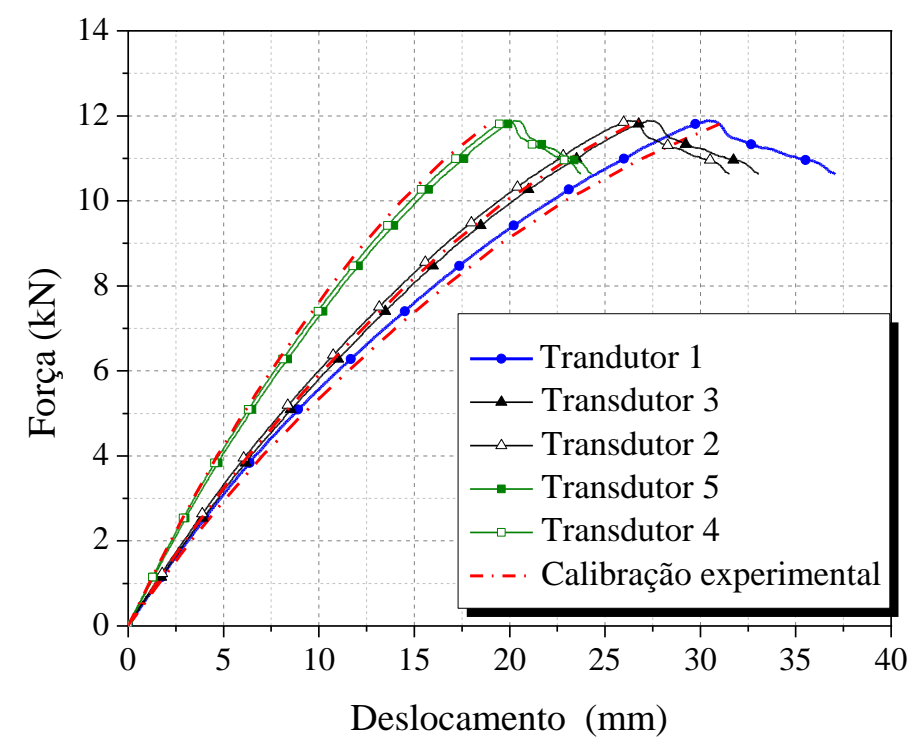

Figura 4.11 - Curvas força versus deslocamento experimental e numérica para o protótipo ZB63-L126. 
Ao comparar essas curvas, observa-se que o modelo barra-mola com apenas uma mola rotacional reproduziu muito bem o comportamento experimental. Na Figura 4.12, as curvas momento-rotação calibradas experimentalmente (obtidas de forma indireta por meio do modelo indicado na Figura 4.9) são apresentadas para todos os protótipos com luvas das séries A, B e C. Tais curvas foram interrompidas no momento máximo (força máxima) atingido pelas terças instrumentadas (Terça-1).

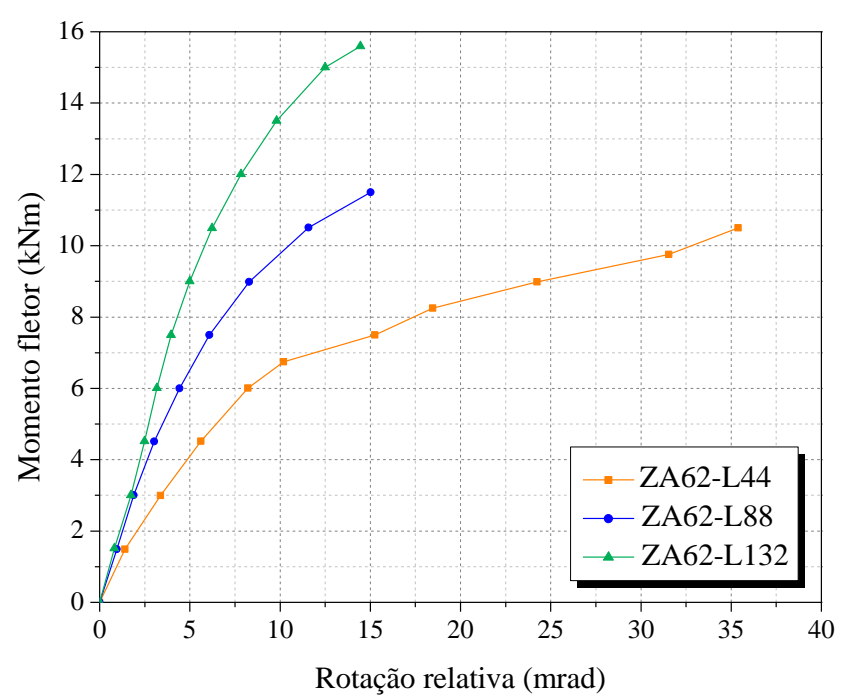

a) Série $\mathrm{A}$

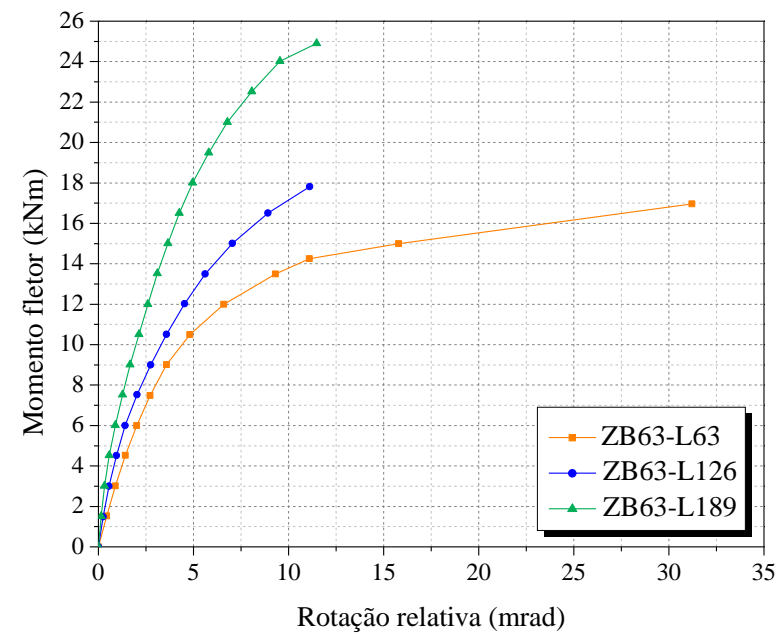

b) Série B

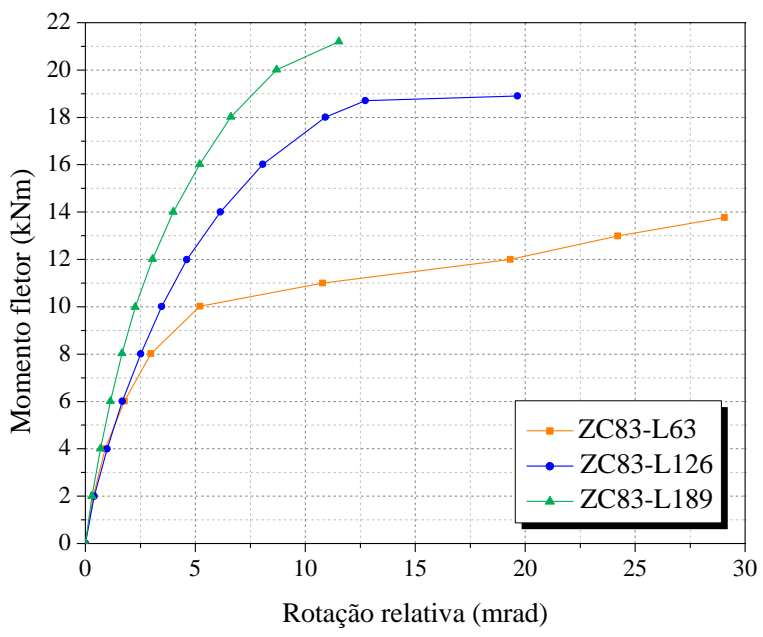

c) Série C

Figura 4.12 - Curvas momento-rotação, calibradas experimentalmente, de todos os protótipos com luvas.

As curvas representativas da mola $\mathrm{K}_{\ominus}$ (Figura 4.12) mostram a evolução da rigidez rotacional dos sistemas com luvas ensaiados. Conforme constatado anteriormente nas curvas 
força versus deslocamento no meio do vão (Figuras 4.1, 4.2 e 4.3), o aumento da relação $L_{p} / D$ para cada série eleva a rigidez do sistema.

\subsubsection{PARAMETRIZAÇÃO DAS CURVAS MOMENTO-ROTAÇÃO}

Inicialmente, as curvas representativas das molas foram reorganizadas de acordo com a relação $L_{p} / D$, conforme apresentadas na Figura 4.13. Esse arranjo permite uma comparação direta dos parâmetros investigados, isto é, das variações na altura do perfil (série A versus série B) e no vão (série B versus série C).

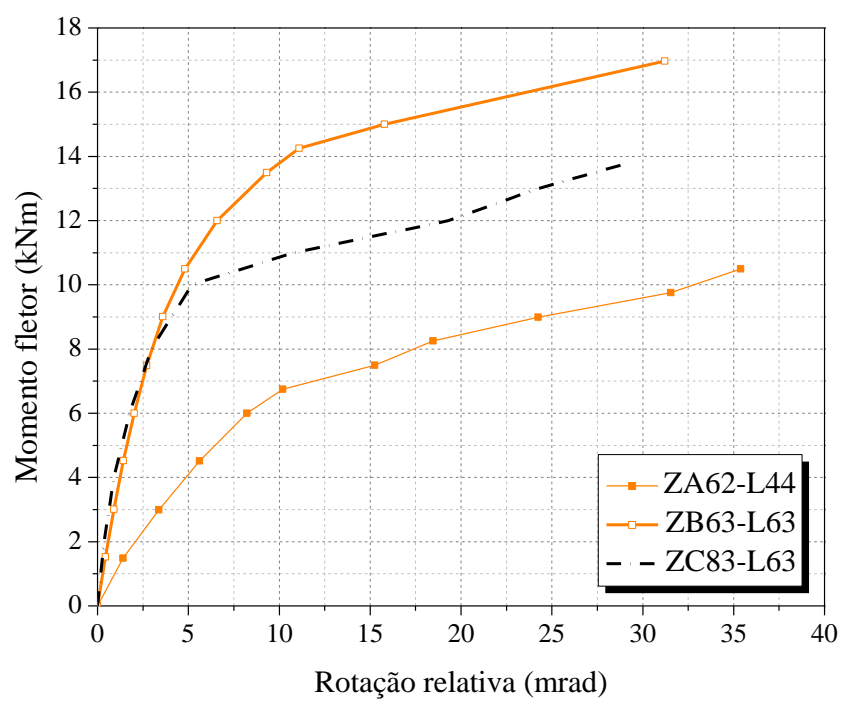

a) Relação $L_{p} / D=2$

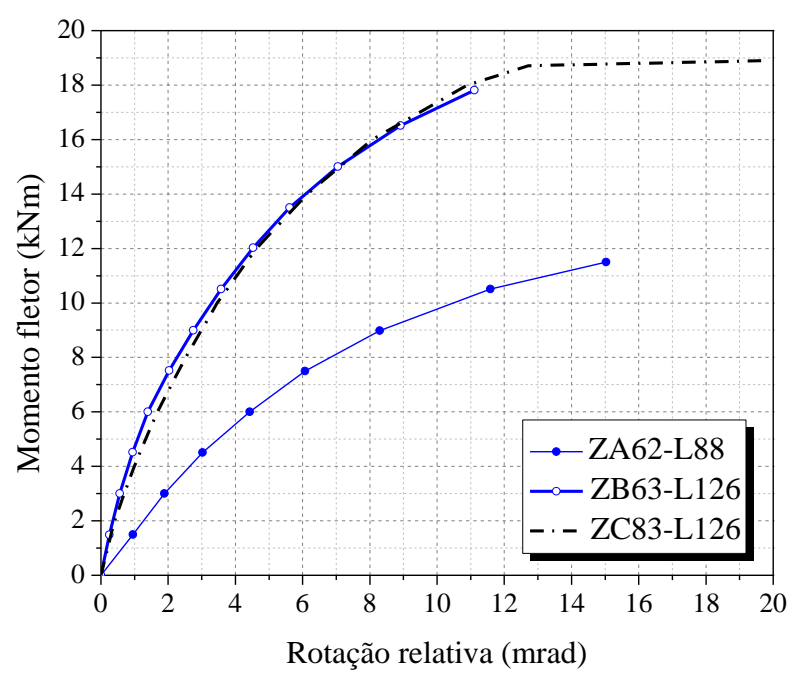

b) Relação $L_{p} / D=4$

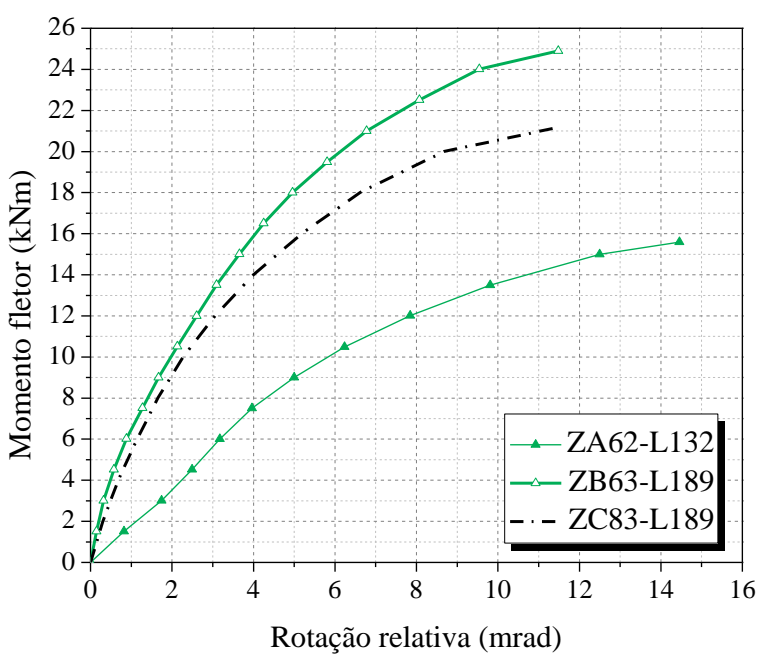

c) Relação $L_{p} / D=6$

Figura 4.13 - Curvas momento-rotação de todos os protótipos com luvas. 
A partir de comparações entre os protótipos das séries A e B, constata-se uma expressiva influência na rigidez rotacional quando a altura do perfil passou de $220 \mathrm{~mm}$ para $315 \mathrm{~mm}$. Em relação ao vão, as curvas mostram comportamentos semelhantes para os protótipos com $L_{p} / D=2$ e $L_{p} / D=4$, divergindo para $L_{p} / D=6$. A tendência de uniformização da distribuição de momento fletor na região da ligação à medida que o vão aumenta, influencia na evolução dessas curvas. Portanto, o protótipo ZB63-L189 é mais rígido que o protótipo ZC83-L189.

Outra particularidade da série C está relacionada à falha do protótipo ZC83-L63, que consistiu num mecanismo plástico localizado na extremidade da luva (Figura 4.39), de forma diferente das falhas observadas nos demais conjuntos com luvas. A interferência desse modo de falha na rigidez fica evidente na Figura 4.13a pela divergência entre as curvas dos protótipos ZB63-L63 e ZC83-L63 para momentos fletores superiores a 10 kN.m.

A resposta não linear das curvas da ligação apresentadas na Figura 4.13 foram aproximadas por diversas expressões, sendo que uma expressão exponencial M- $\Theta$ (Expressão 4.12) se adequou de forma mais expressiva as curvas momento-rotação deste estudo, com coeficientes de determinação superiores a 0,99. Os parâmetros analisados foram a altura da seção transversal $(D)$, comprimento efetivo da luva $\left(L_{p}\right)$ e o vão de ensaio $\left(L_{t}\right)$. Essas variáveis foram incorporadas em uma expressão exponencial M- $\Theta$ por meio dos coeficientes $\alpha$ e $\beta$, com aproximação linear para as variações da relação $L_{p} / D$. Considerando terças e luvas com a mesma espessura em faixas de valores usuais, tem-se a expressão 4.12:

$$
M=\alpha r\left(1-e^{-\beta D r \theta}\right)
$$

Onde:

$\theta$ é a rotação relativa da ligação;

$\alpha=-15,42 L_{p} / D+123,03 \quad$ quando $2 \leq L_{p} / D \leq 4 ;$

$\alpha=\left[16,45\left(1-L_{t} / 6\right)-1,43\right] L_{p} / D+\left[67,10-65,77\left(1-L_{t} / 6\right)\right] \quad$ quando $4<L_{p} / D \leq 6 ;$

$\beta=-0,59 L_{p} / D+5,20 \quad$ quando $2 \leq L_{p} / D \leq 6 ;$

$r=0,5\left(a^{2}+c^{2}\right)^{1 / 2}$, com $a$ e $c$ definidos na Figura 4.14;

Unidades de medida: $L_{p}, D, L_{t}$ e $r$ em metros, $M$ em kN.m e $\theta$ em mrad. 


\section{LEGENDA}

- Centro geométrico da ligação

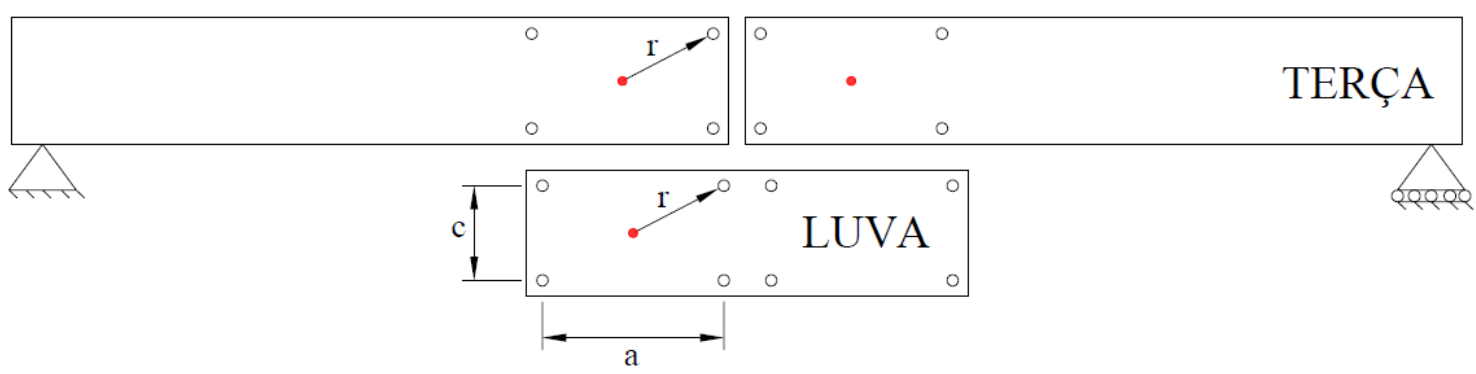

Figura 4.14 - Dimensões a, c e r da ligação com luva.

As Figuras 4.15, 4.16 e 4.17 apresentam uma comparação entre as curvas experimentais força-deslocamento no meio do vão e as curvas momento-rotação do modelo de barras, com as molas rotacionais obtidas de forma indireta (Figura 4.13) e as molas estimadas pela Expressão 4.12 proposta.

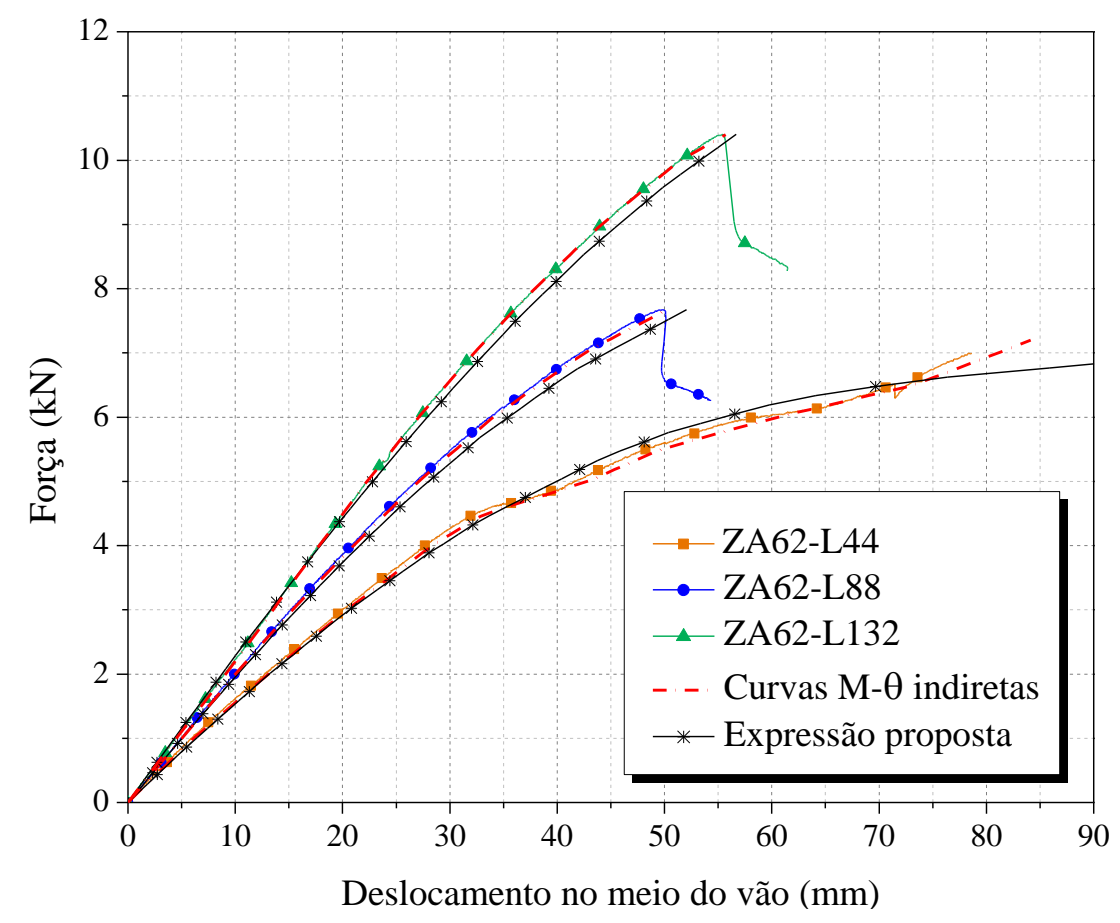

Figura 4.15 - Curvas força versus deslocamento no meio do vão experimentais e numéricas para os protótipos da série A. 


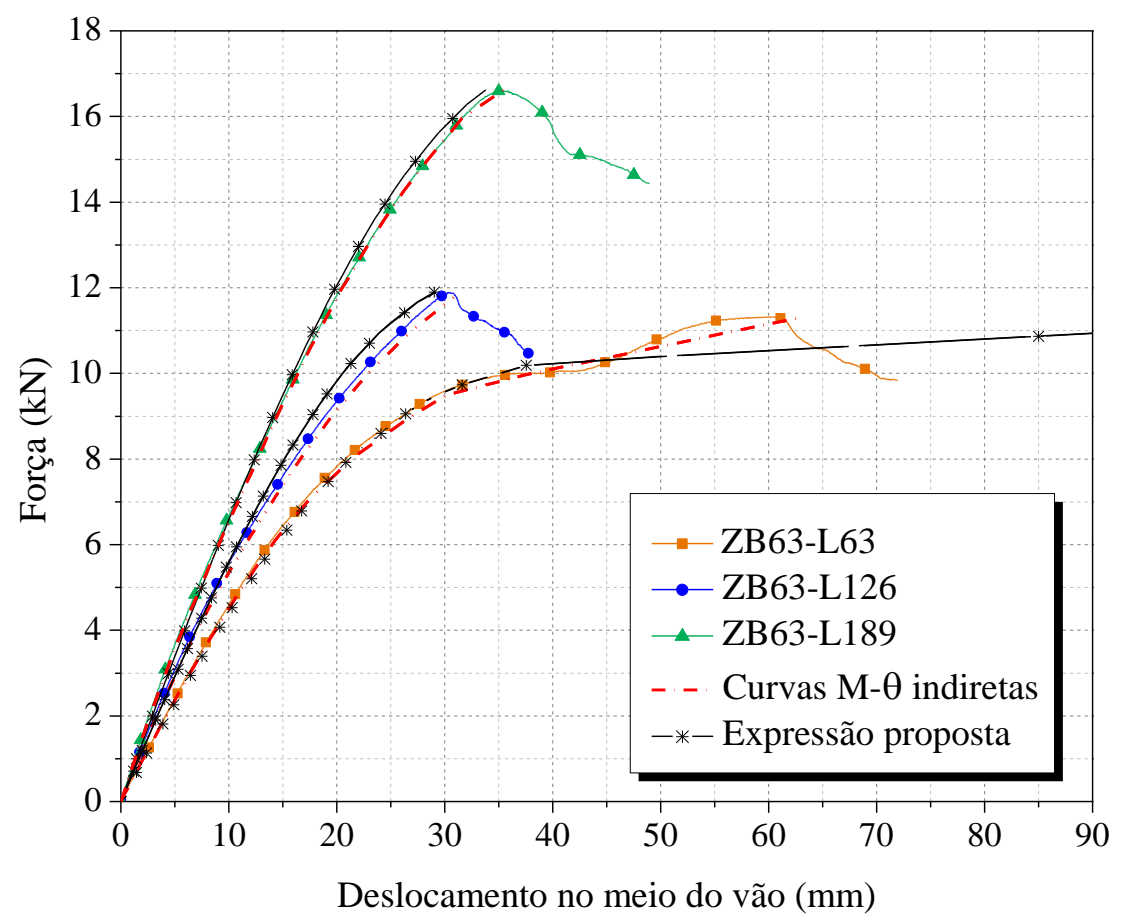

Figura 4.16 - Curvas força versus deslocamento no meio do vão experimentais e numéricas para os protótipos da série $\mathrm{B}$.

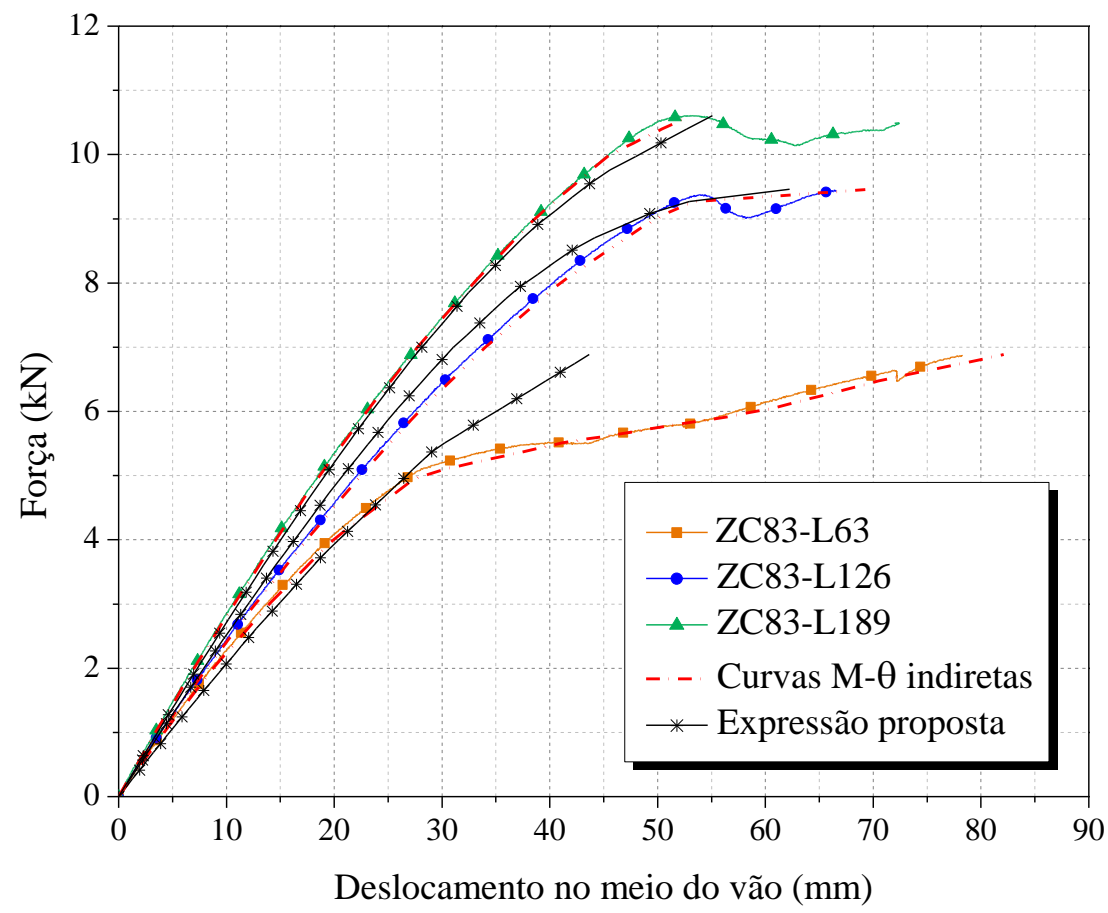

Figura 4.17 - Curvas força versus deslocamento no meio do vão experimentais e numéricas para os protótipos da série $\mathrm{C}$. 
Conclui-se que, tanto os modelos com molas obtidas indiretamente como as estimativas da rigidez rotacional por meio da expressão 4.12 se aproximaram dos valores experimentais. No entanto, a expressão proposta não incorporou o decréscimo de rigidez proveniente do mecanismo de falha ocorrido no protótipo ZC83-L63 (Figura 4.39).

\subsubsection{VARIAÇÃO DA ESPESSURA}

A espessura da luva também se mostrou relevante para o comportamento mecânico da ligação. Conforme mostrado nas Figuras 4.18 e 4.19, os protótipos com luva de espessura nominal 3,00mm e relação $L_{p} / D=4$ (ZB63-L126T3 e ZC83-L126T3) apresentaram deslocamentos muito próximos aos dos protótipos com luva de espessura $1,95 \mathrm{~mm}$ e relação $\mathrm{L}_{\mathrm{p}} / \mathrm{D}=6$ (ZB63-L189 e ZC83-L189), ou seja; capacidade superior de promover a continuidade em relação aos protótipos ZB63-L126 e ZC83-L126, com as mesmas configurações, diferenciando apenas a espessura nominal da luva de $1,95 \mathrm{~mm}$.

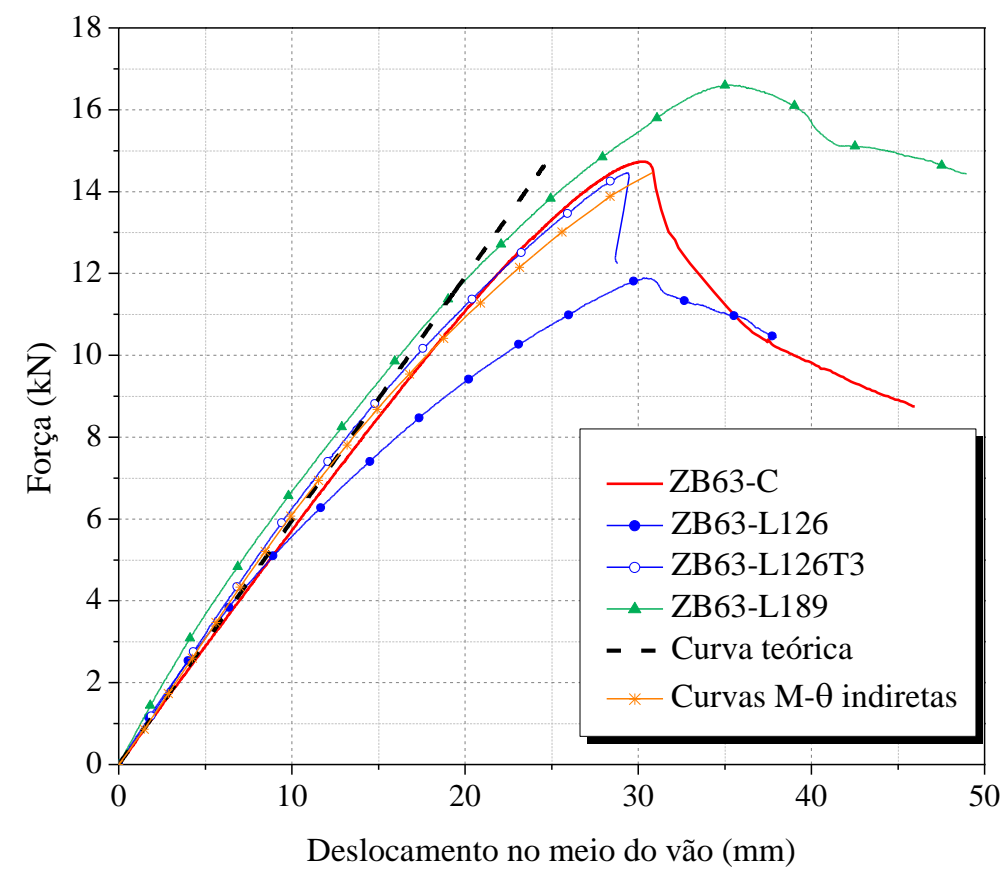

Figura 4.18 - Curvas força versus deslocamento no meio do vão utilizadas no estudo da variação da espessura da luva referentes aos protótipos da série B. 


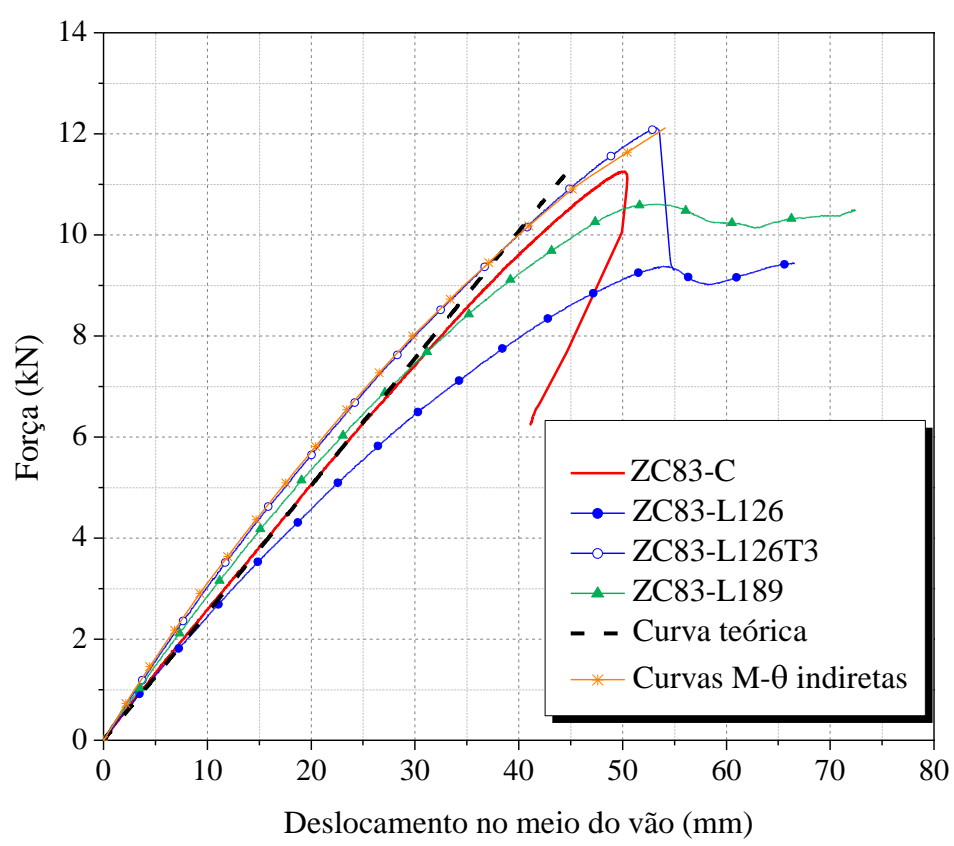

Figura 4.19 - Curvas força versus deslocamento no meio do vão utilizadas no estudo da variação da espessura da luva referentes aos protótipos da série C.

As curvas M- $\Theta$ correspondentes aos protótipos com ZB63-L126, ZC83-L126, ZB63L126T3 e ZC83-L126T3 são apresentadas na Figura 4.20. Observa-se uma elevação da rigidez quando a espessura nominal da luva passou de 1,95 $\mathrm{mm}$ para 3,00 $\mathrm{mm}$.

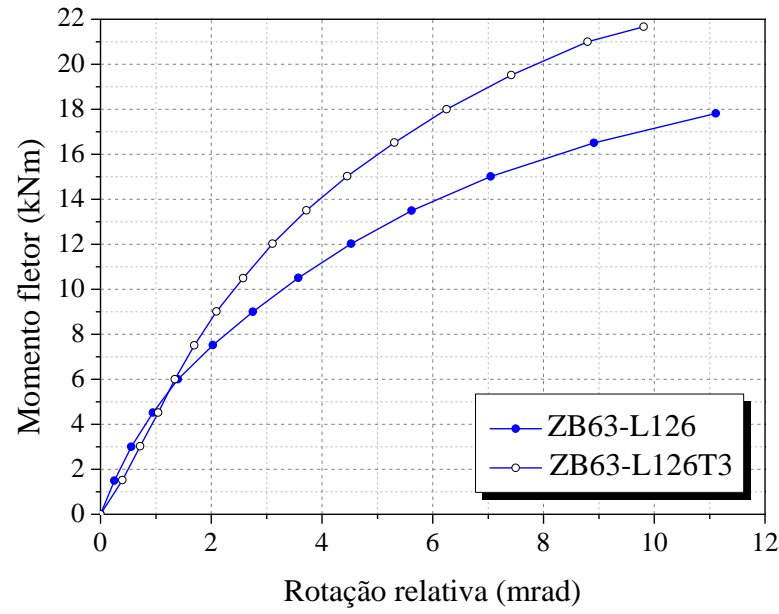

a) Protótipos ZB63-L126 e ZB63-L126T3

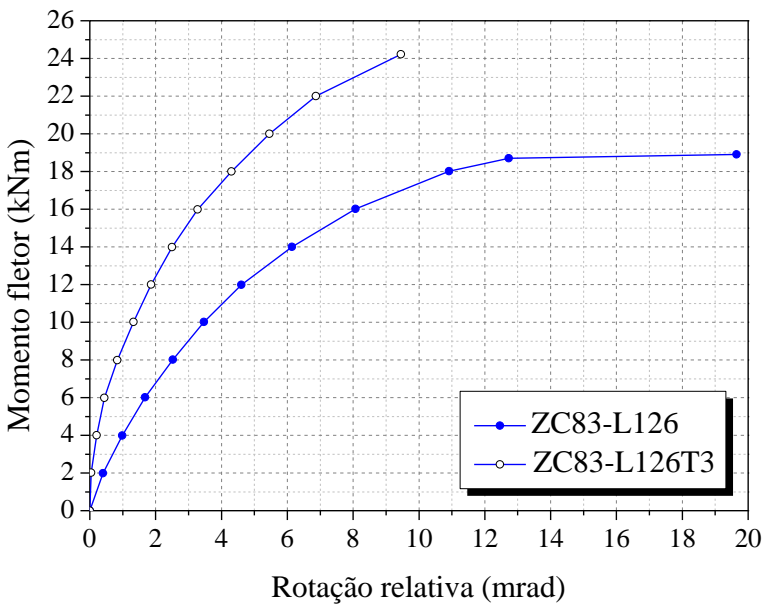

b) Protótipos ZC83-L126 e ZC83-L126T3

Figura 4.20 - Curvas momento-rotação relativa.

Complementando a presente análise, os protótipos com luvas ensaiados por Fávero Neto (2013) foram incluídos neste trabalho. Fávero Neto (2013) ensaiou dois protótipos com 
luvas com as mesmas dimensões, alterando apenas a espessura de 1,75 mm (ZD62-L1036) para 2,70 mm (ZE62-L1036).

Primeiramente, as curvas força versus deslocamento no meio do vão são plotadas nas Figuras 4.21 e 4.22, juntamente com as curvas referentes aos protótipos contínuos fisicamente e suas curvas teóricas (elástica-linear).

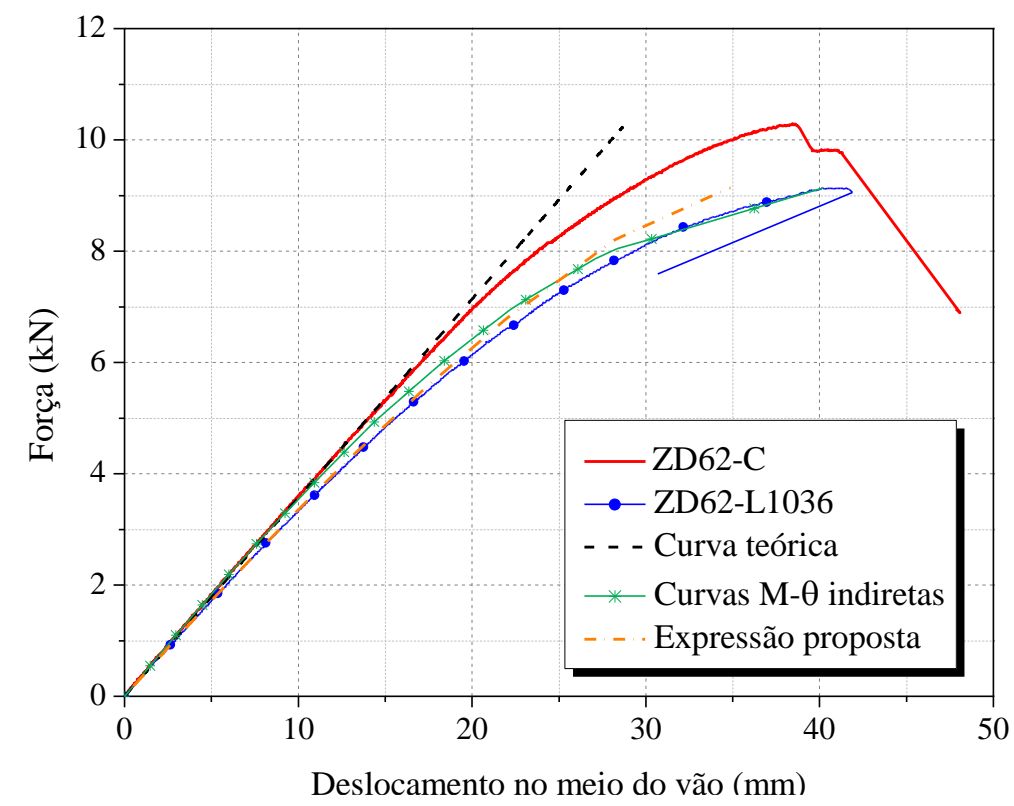

Figura 4.21 - Curvas força versus deslocamento no meio do vão do protótipo ZD62-L1036.

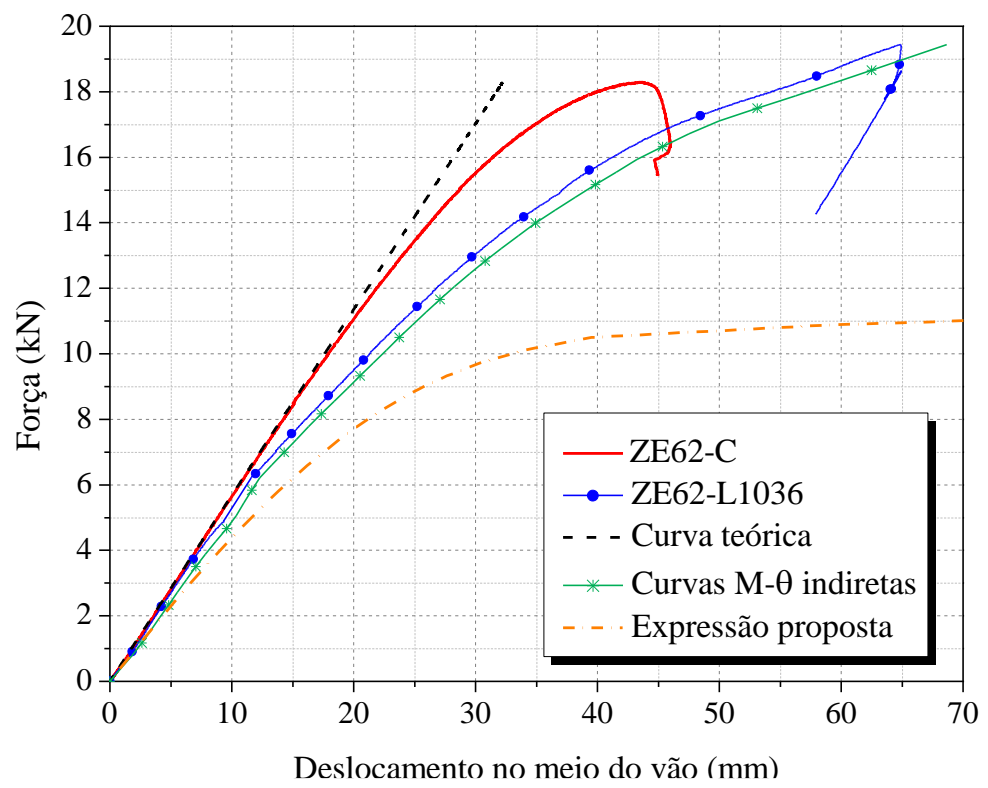

Figura 4.22 - Curvas força versus deslocamento no meio do vão do protótipo ZE62-L1036. 
Assim como observado para os protótipos com relação $L_{p} / D=4$ (Figuras 4.1, 4.2 e 4.3 ), as terças com luva e razão $L_{p} / D=3,84$ ensaiadas por Fávero Neto (2013) apresentaram curvas força-deslocamento abaixo da curva referente ao protótipo contínuo fisicamente.

O modelo barra-mola também foi aplicado nesses exemplares, cujo resultado está apresentado juntamente com os valores experimentais nas Figuras 4.21 e 4.22 (curvas M- $\Theta$ obtidas de forma indireta e por meio da expressão proposta). Para comparação entre a variação da rigidez rotacional da ligação, as curvas momento-rotação inseridas nas molas desses modelos numéricos foram plotadas na Figura 4.23.

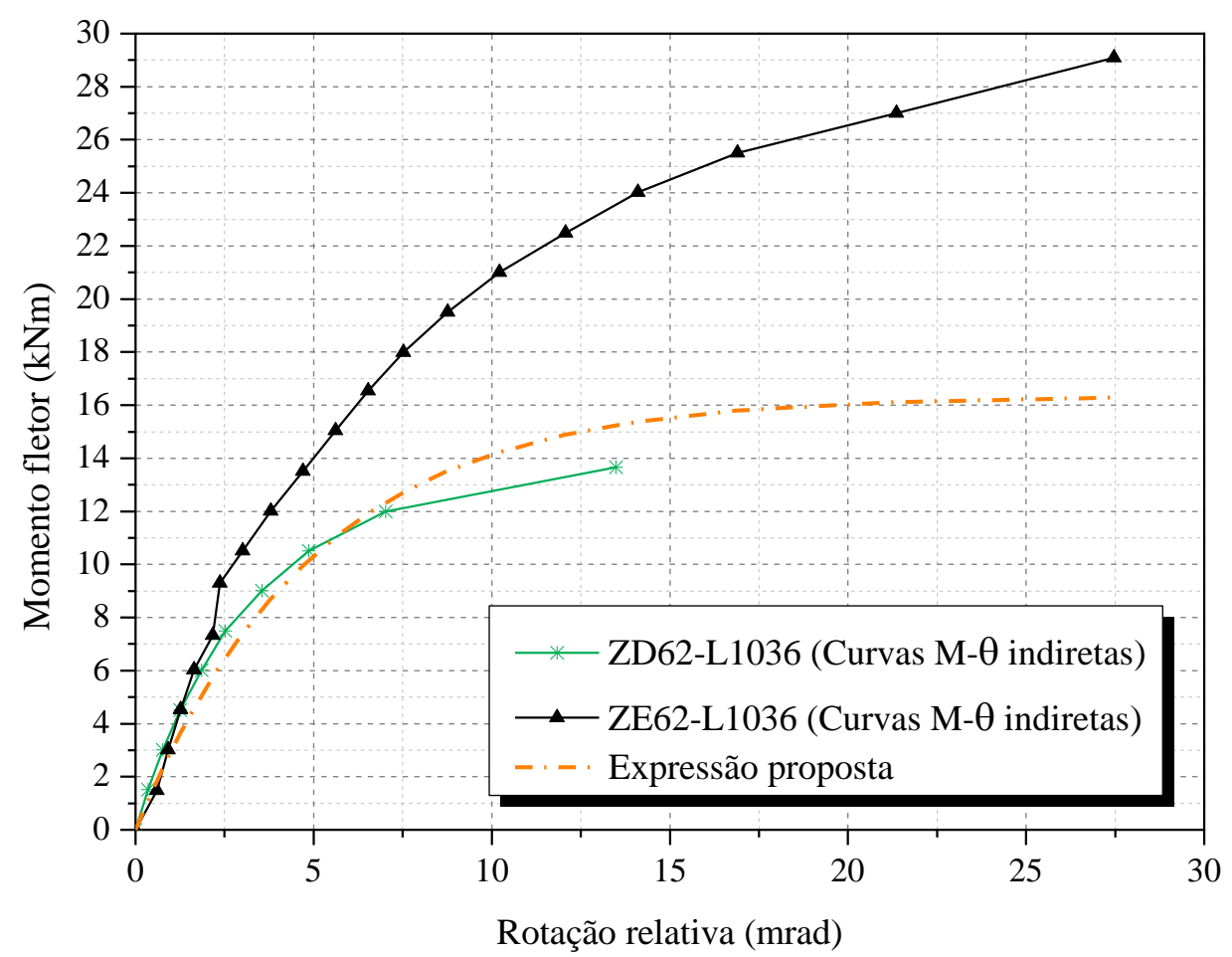

Figura 4.23 - Curvas momento-rotação relativa dos protótipos ZD62-L1036 e ZE62-L1036.

As curvas da Figura 4.23 exemplificam a diferença entre as rigidezes rotacionais quando se altera a espessura. Portanto, a variação da espessura somente da luva ou da terça e da luva, mostrou-se relevante nessas análises e carecem de uma investigação mais aprofunda. 


\subsection{SIMULAÇÕES NÚMERICAS}

Neste item serão apresentadas análises numéricas de terças contínuas por meio de luvas, via programa ANSYSTM, comparando a expressão 4.12 proposta nesta pesquisa com modelos teóricos existentes na literatura. Todos os exemplos consistiram de um sistema de múltiplos vãos (10 vãos) submetidos a um carregamento uniformemente distribuído de vento de sucção (Figura 4.24a).

a)

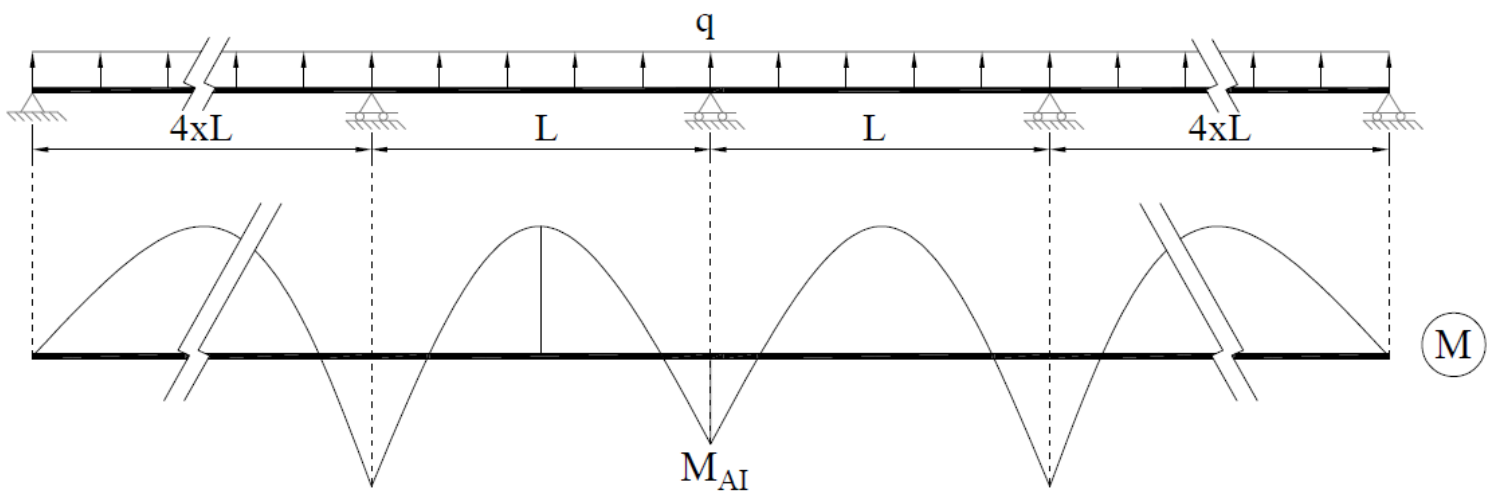

Figura 4.24 - Exemplo estudado: a) terças de múltiplos vãos e b) diagrama de momento fletor solicitante.

Foram adotados elementos de barra (BEAM3), com momento de inércia duas vezes maior na região da ligação (superposição da terça com a luva). Na região da ligação foram introduzidas molas rotacionais não lineares (COMBIN39) ou lineares (COMBIN40) responsáveis por simular o comportamento momento-rotação da ligação. Assim, cinco modelos numéricos foram testados:

- Modelo 1: composto por elementos de barras e uma mola rotacional de rigidez $\left(\mathrm{K}_{\Theta}\right)$ posicionada nos apoios (Figura 4.25). Esse modelo representa as curvas momentorotação obtidas de forma indireta e apresentadas na Figura 4.13, ou seja, a referência para uma comparação direta com os demais modelos;

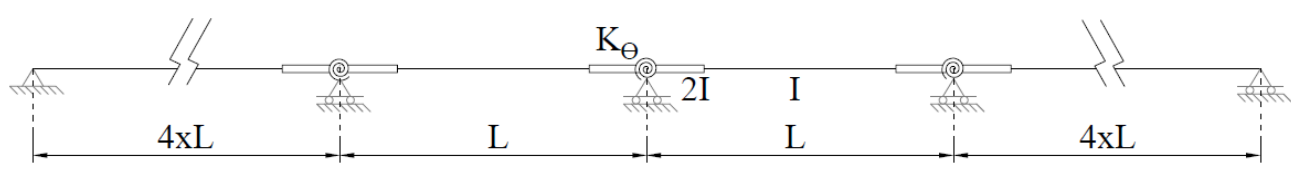

Figura 4.25 - Modelo de terças com luvas simulados com uma mola. 
- Modelo 2: similar ao modelo 1, porém a rigidez rotacional $\left(\mathrm{K}_{\ominus}\right)$ foi calculada por meio da Expressão 4.12 proposta neste trabalho;

- Modelo 3: composto por elementos de barras e duas molas rotacionais posicionadas nos respectivos centros geométricos da ligação (Figura 4.26). A rigidez rotacional $\left(K_{\theta}\right)$ foi calculada por meio da Expressão 2.18, sendo a rigidez de contato da parede do furo $\left(K_{h}\right)$ calculada segundo a Expressão 2.12 proposta por Bryan (1993);

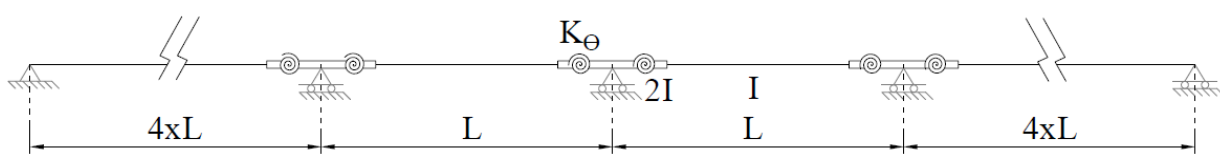

Figura 4.26 - Modelo de terças com luvas e molas simulado segundo a proposta de Bryan (1993) ou Dubina (2006).

- Modelo 4: semelhante ao modelo 3, entretanto a rigidez de contato da parede do furo $\left(K_{h}\right)$ foi calculada pela Expressão 2.13 proposta por Dubina (2006);

- Modelo 5: modelo teórico elástico-linear (Figura 4.27) que considera a continuidade total da terça nos apoios.

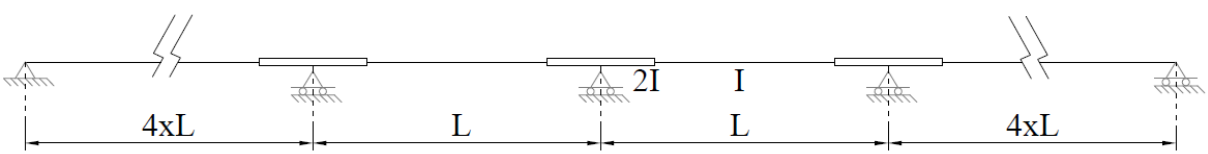

Figura 4.27 - Modelo teórico elástico-linear.

Como observado nas curvas M-Ө das Figuras 4.12 e 4.13, a variação no comprimento efetivo da luva $\left(L_{p}\right)$ e a altura do perfil $(D)$ influenciaram de forma mais expressiva a rigidez da ligação. Logo, as simulações foram conduzidas para todos os protótipos com luvas das séries A e B.

Os resultados obtidos permitem analisar a evolução dos deslocamentos no meio do vão em função do carregamento e as diferenças entre os momentos fletores solicitantes no apoio interno $\left(\mathrm{M}_{\mathrm{AI}}\right)$ e no meio do vão ( $\left.\mathrm{M}_{\mathrm{MV}}\right)$ (Figura 4.24b). Os valores considerados referem-se aos tramos internos da viga (quinto e sexto tramos). 


\subsubsection{Protótipos da série A}

Dados de entrada na construção dos modelos numéricos:

- $\mathrm{q}=1,0 \mathrm{kN} / \mathrm{m}$;

- $\mathrm{L}=12 \mathrm{~m}$;

- $n=3$ (constante do modelo de Bryan)

- $\quad$ Módulo de elasticidade longitudinal $=200.000 \mathrm{MPa}$;

- Valores médios das dimensões da seção transversal:

Altura $=220 \mathrm{~mm}$;

Espessura = 1,91 mm;

Momento de inércia $=4.948 .780 \mathrm{~mm}^{4}$.

Os valores de momento fletores solicitantes estão apresentados na Tabela $4.1 \mathrm{e}$ nas Figuras 4.28 e 4.29 e o comparativo da evolução dos deslocamentos na Figura 4.30.

Tabela 4.1 - Valores dos momentos fletores solicitantes nos protótipos com luva da série A.

\begin{tabular}{ccccccc}
\hline & \multicolumn{2}{c}{ Protótipo ZA62-L44 } & \multicolumn{2}{c}{ Protótipo ZA62-L88 } & \multicolumn{2}{c}{ Protótipo ZA62-L132 } \\
\hline Modelo & $\mathbf{M}_{\mathbf{A I}}(\mathbf{k N . c m})$ & $\mathbf{M}_{\mathbf{M V}}(\mathbf{k N . c m})$ & $\mathbf{M}_{\mathbf{A I}}(\mathbf{k N . c m})$ & $\mathbf{M}_{\mathbf{M V}}(\mathbf{k N . c m})$ & $\mathbf{M}_{\mathbf{A I}}(\mathbf{k N . c m})$ & $\mathbf{M}_{\mathbf{M V}}(\mathbf{k N . c m})$ \\
\hline 1 & 966,05 & 834,10 & 1121,80 & 679,16 & 1195,60 & 607,78 \\
2 & 974,66 & 825,36 & 1113,33 & 687,76 & 1188,80 & 614,37 \\
3 & 877,39 & 923,05 & 1123,90 & 678,91 & 1209,00 & 596,21 \\
4 & 826,19 & 974,11 & 1099,80 & 702,58 & 1196,80 & 607,90 \\
5 & 1228,50 & 577,48 & 1246,30 & 560,46 & 1266,90 & 540,87 \\
\hline
\end{tabular}




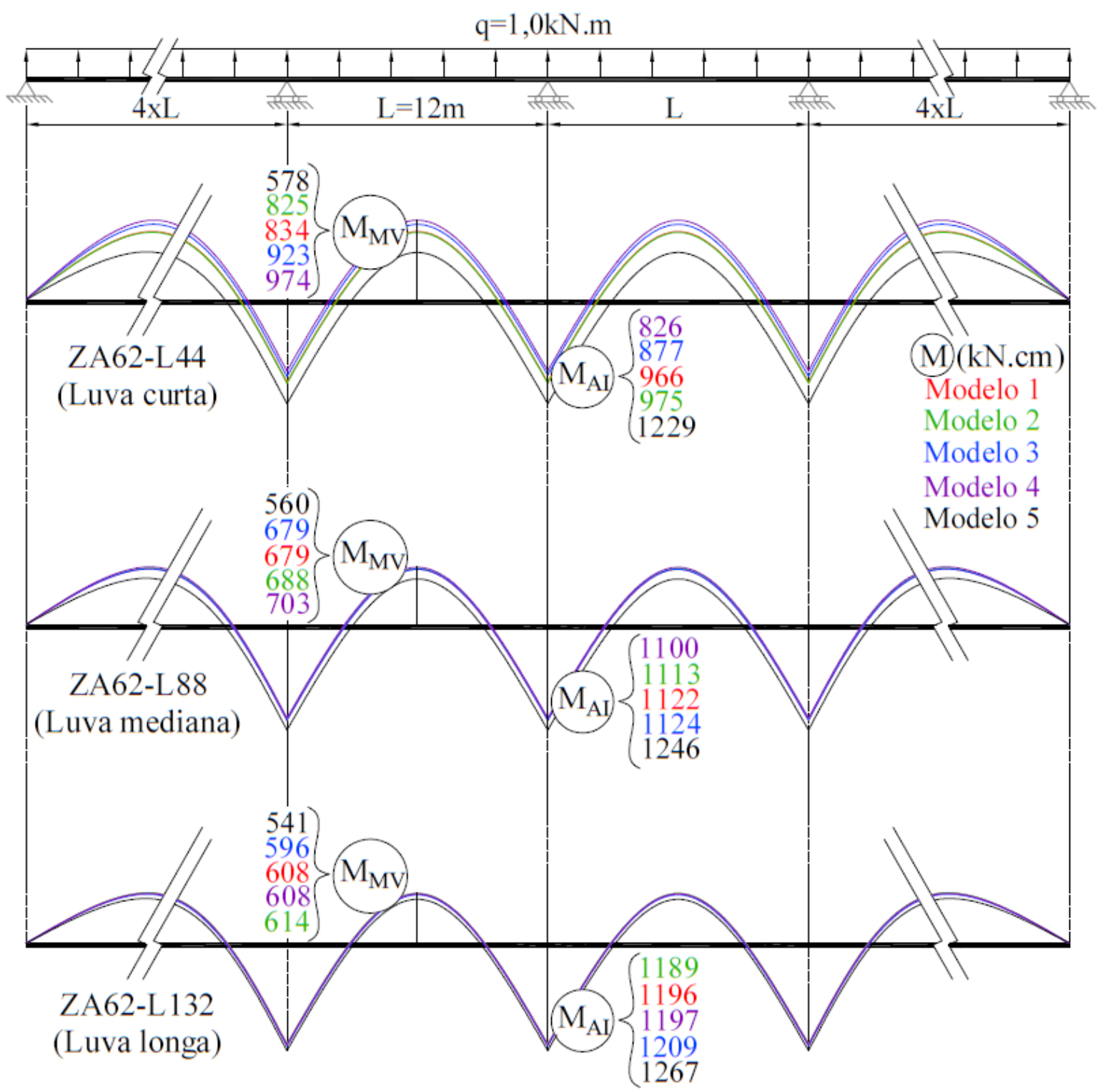

Figura 4.28 - Diagramas de momento fletor dos modelos de 1 a 5 para os protótipos da série A (luvas curta, mediana e longa). 


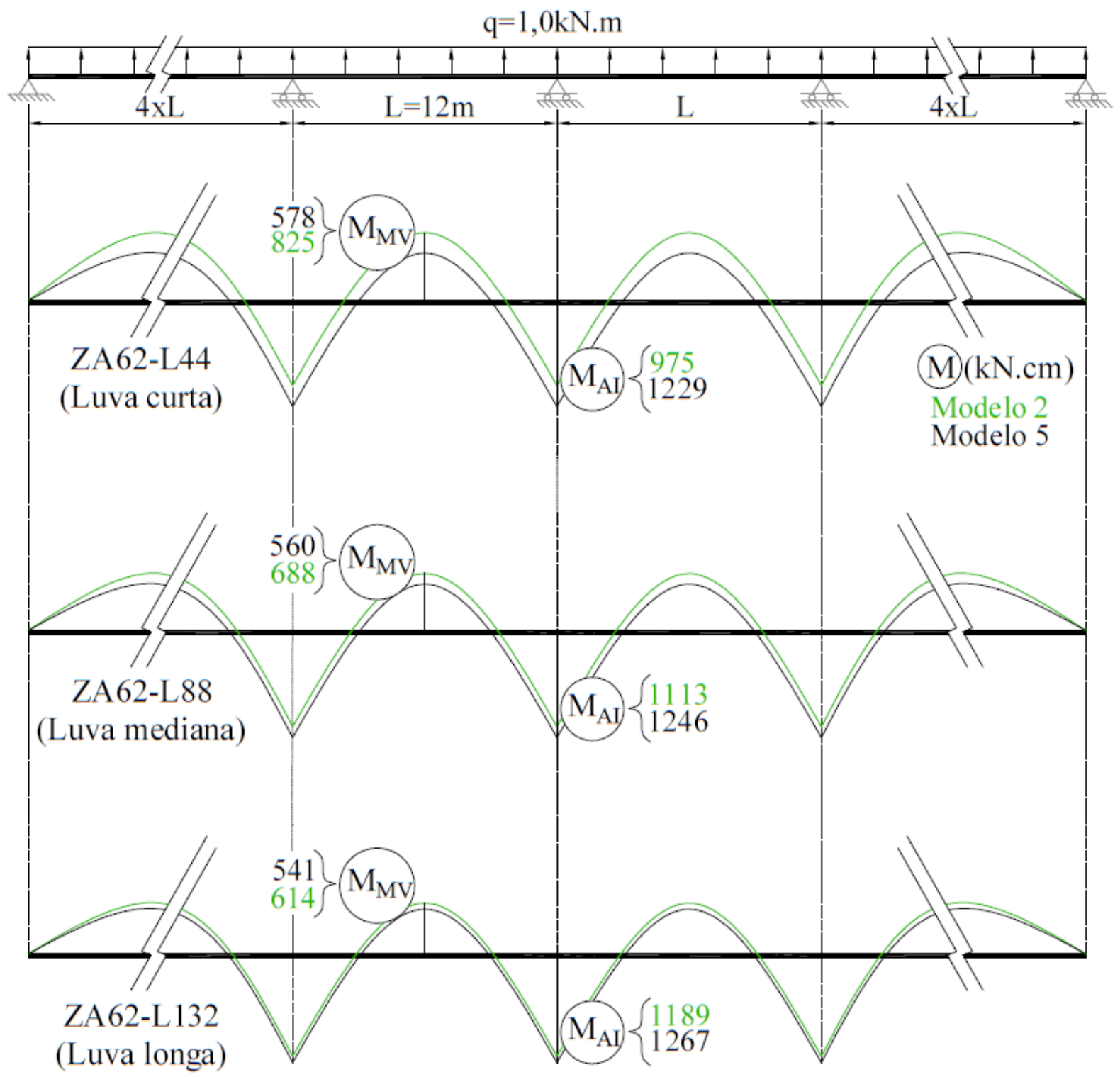

Figura 4.29 - Diagramas de momento fletor dos modelos 2 e 5 para os protótipos da série A (luvas curta, mediana e longa). 


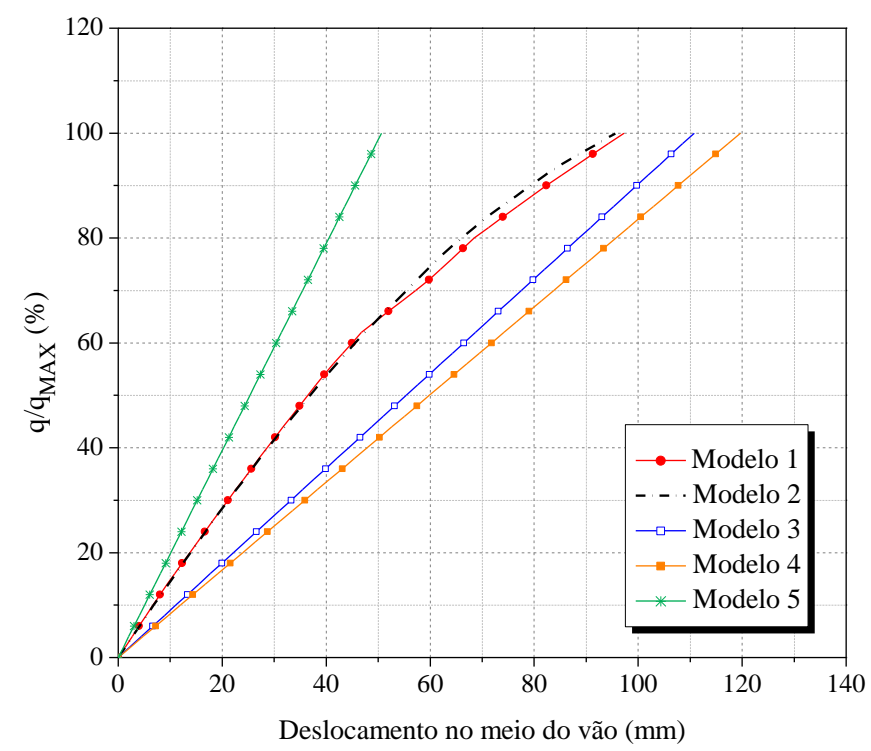

a) Protótipo ZA62-L44 $\left(L_{p} / D=2\right)$

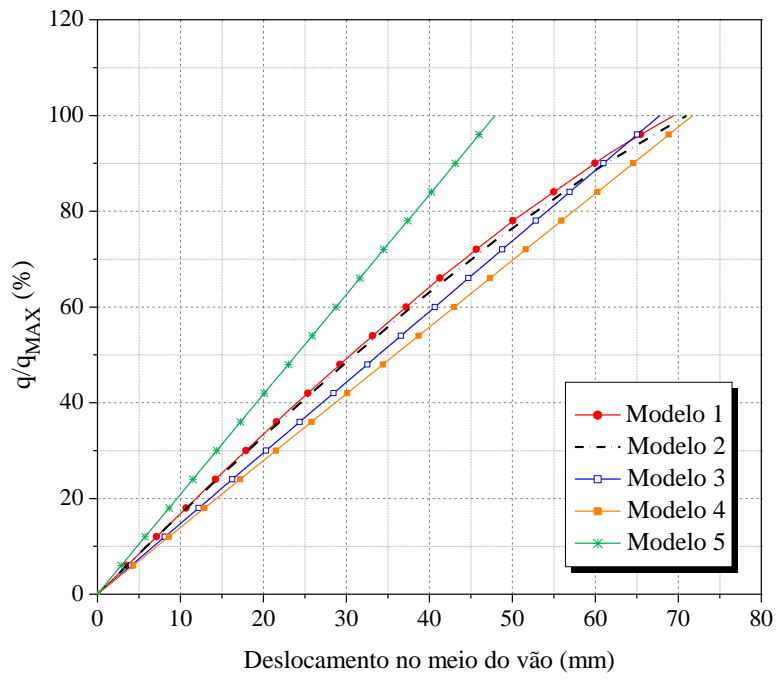

b) Protótipo ZA62-L88 $\left(L_{p} / D=4\right)$

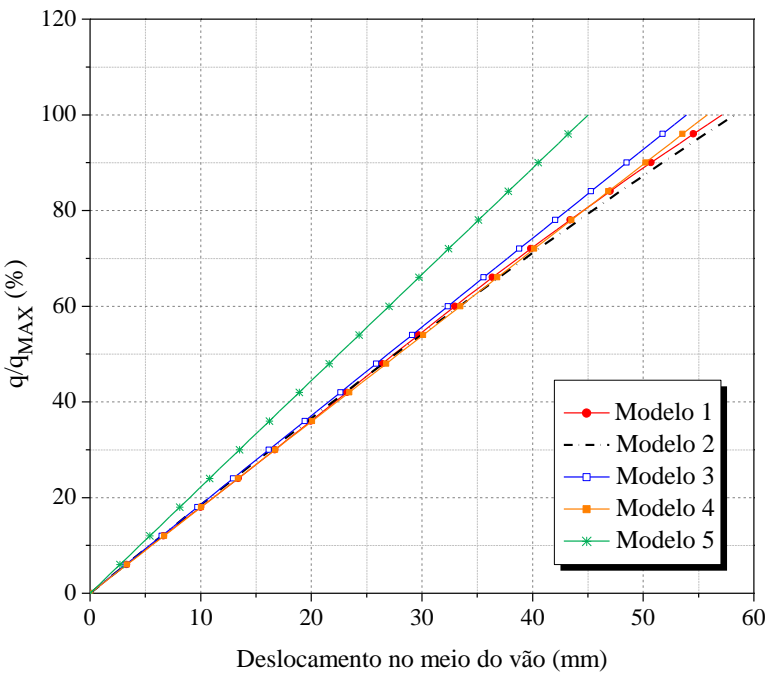

c) Protótipo ZA62-L132 $\left(\mathrm{L}_{\mathrm{p}} / \mathrm{D}=6\right)$

Figura 4.30 - Deslocamentos em função do carregamento para os protótipos da série A. 


\subsubsection{Protótipos da série $B$}

Dados de entrada na construção dos modelos numéricos:

- $\mathrm{q}=1,5 \mathrm{kN} / \mathrm{m}$;

- $\mathrm{L}=12 \mathrm{~m}$;

- $n=3$ (constante do modelo de Bryan);

- Módulo de elasticidade longitudinal = 200.000 MPa;

- Propriedades da seção transversal:

Altura $=315 \mathrm{~mm}$;

Espessura = 1,89 mm;

Momento de inércia $=13.433 .260 \mathrm{~mm}^{4}$.

Os valores de momento fletores solicitantes estão organizados na Tabela $4.2 \mathrm{e}$ nas Figuras 4.31 e 4.32 e o comparativo da evolução dos deslocamentos na Figura 4.33.

Tabela 4.2 - Valores dos momentos fletores solicitantes nos protótipos com luva da série B.

\begin{tabular}{ccccccc}
\hline & \multicolumn{2}{c}{ Protótipo ZB63-L63 } & \multicolumn{2}{c}{ Protótipo ZB63-L126 } & \multicolumn{2}{c}{ Protótipo ZB63-L189 } \\
\hline Modelo & $\mathbf{M}_{\mathbf{A I}}(\mathbf{k N . c m})$ & $\mathbf{M}_{\mathbf{M V}}(\mathbf{k N . c m})$ & $\mathbf{M}_{\mathbf{A I}}(\mathbf{k N . c m})$ & $\mathbf{M}_{\mathbf{M V}}(\mathbf{k N . c m})$ & $\mathbf{M}_{\mathbf{A I}}(\mathbf{k N . c m})$ & $\mathbf{M}_{\mathbf{M V}}(\mathbf{k N . c m})$ \\
\hline 1 & 1493,80 & 1206,20 & 1670,40 & 1030,60 & 1805,00 & 899,78 \\
2 & 1513,60 & 1186,40 & 1702,50 & 998,32 & 1814,60 & 890,63 \\
3 & 1284,10 & 1416,40 & 1676,20 & 1027,90 & 1827,10 & 881,18 \\
4 & 1205,00 & 1495,30 & 1635,00 & 1068,30 & 1805,50 & 901,99 \\
5 & 1855,90 & 853,54 & 1896,70 & 814,74 & 1932,60 & 780,90 \\
\hline
\end{tabular}




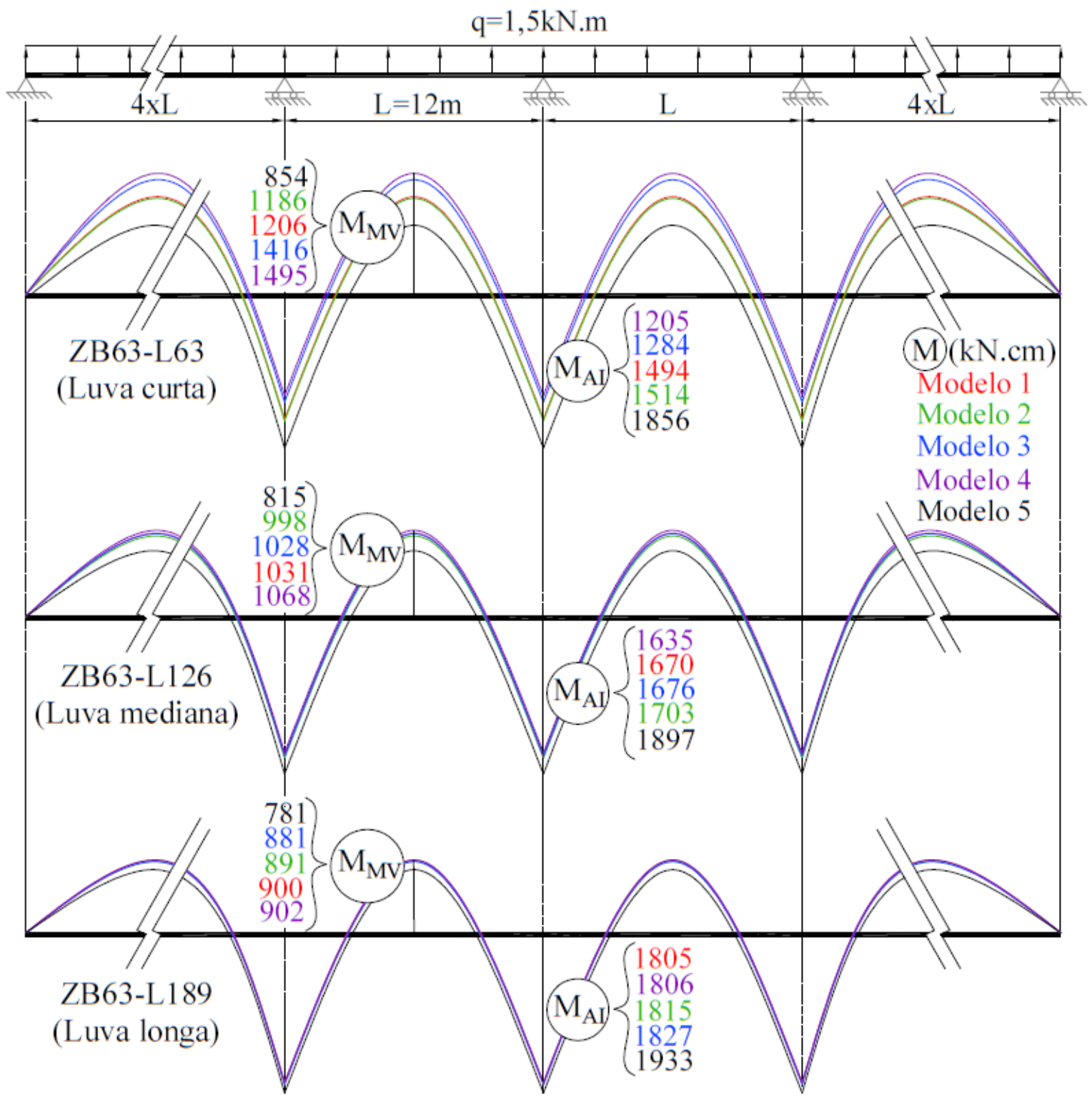

Figura 4.31 - Diagramas de momento fletor dos modelos de 1 a 5 para os protótipos da série B (luvas curta, mediana e longa). 


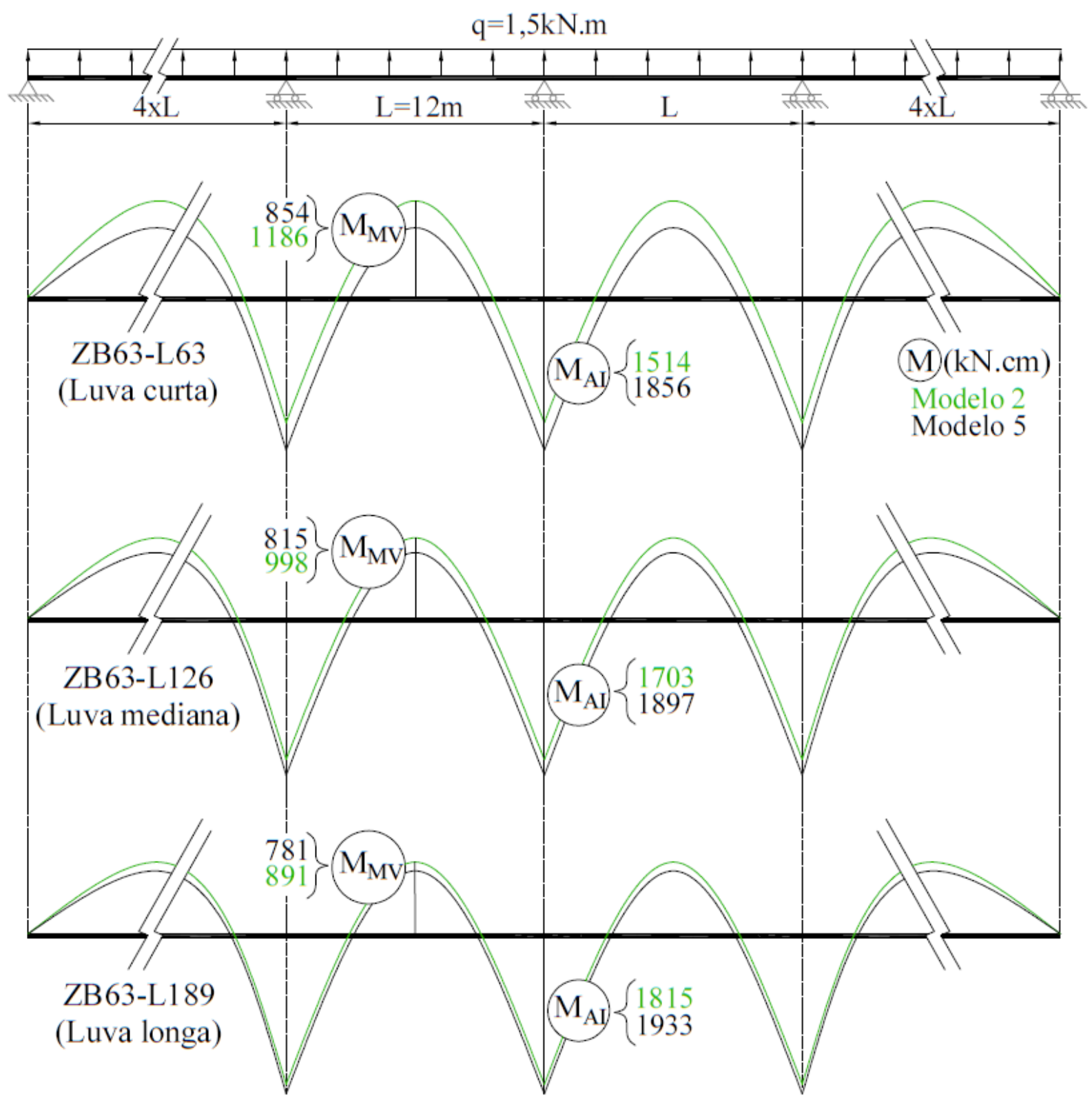

Figura 4.32 - Diagramas de momento fletor dos modelos 2 e 5 para os protótipos da série B (luvas curta, mediana e longa). 


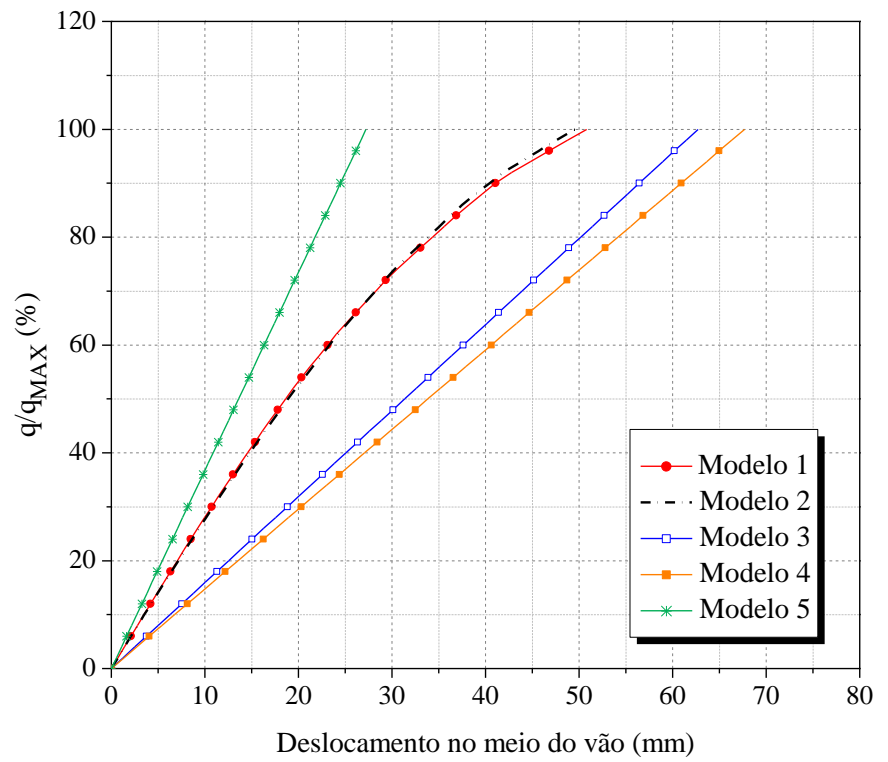

a) Protótipo ZB63-L63 $\left(L_{p} / D=2\right)$

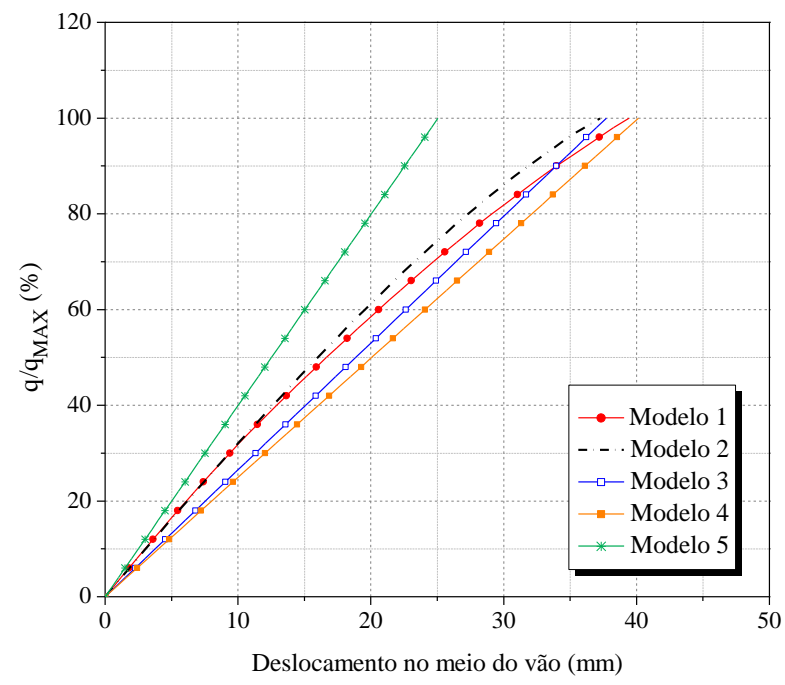

b) Protótipo ZB63-L126 $\left(L_{p} / D=4\right)$

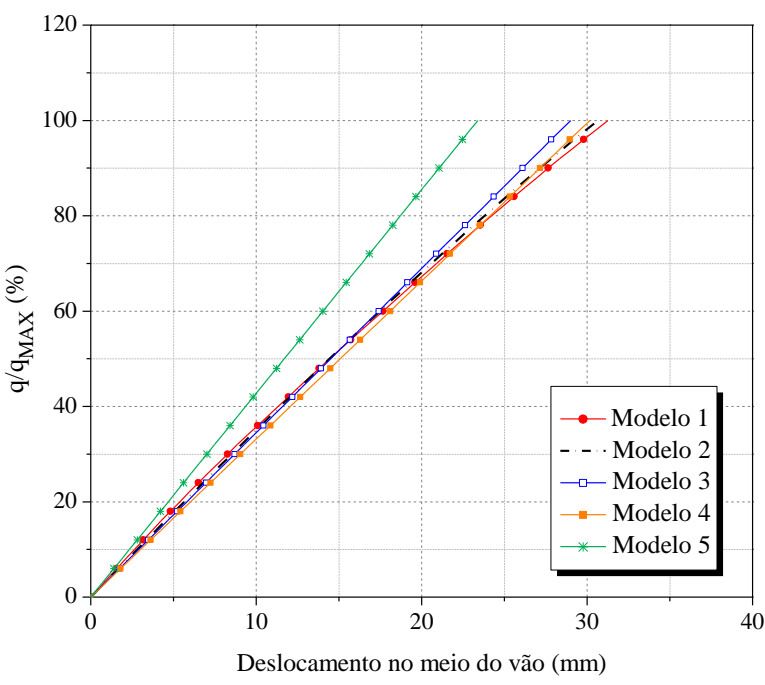

c) Protótipo ZB63-L189 $\left(L_{p} / D=6\right)$

Figura 4.33 - Deslocamentos em função do carregamento para os protótipos da série B.

A análise dos resultados numéricos exemplifica a divergência entre os modelos investigados. Quanto menor a relação $L_{p} / D$ (luvas mais curtas), maior a diferença em relação ao modelo 1 (modelo de referência).

A expressão M- $\Theta$ proposta neste trabalho, testada no modelo 2, resultou em previsões de deslocamentos e momentos fletores muito próximos ao modelo 1 em todos os protótipos avaliados. 
Os modelos 3 e 4 resultaram conservadores nas previsões dos deslocamentos e momento fletor no meio do vão $\left(M_{M V}\right)$ e contra a segurança nas previsões dos momentos fletores no apoio interno $\left(M_{A I}\right)$, para relações $L_{p} / \mathrm{D} \leq 4$.

O modelo 5 resultou conservador nas estimativas de momento fletor $M_{A I}$ e deslocamentos e contra a segurança para o momento fletor $M_{M V}$.

\subsection{ANÁLISE DE ESTADOS-LIMITES ÚLTIMOS}

\subsubsection{Cálculo dos esforços resistentes}

Os esforços resistentes foram calculados conforme ABNT NBR 14762:2010, sendo o momento fletor resistente calculado com base no método da resistência direta (MRD) por meio das expressões 2.1 a 2.10 e a força cortante resistente com base nas expressões 4.13 a 4.15. Como o objetivo da presente análise é comparar os valores máximos da força experimental com os valores teóricos, são considerados valores característicos dos esforços resistentes.

$$
\begin{gathered}
-\operatorname{para} \frac{h}{t} \leq 1,08\left(\frac{E k_{v}}{f_{y}}\right)^{0,5} \\
V_{R k}=0,6 f_{y} h t \\
\text { - para } 1,08\left(\frac{E k_{v}}{f_{y}}\right)^{0,5} \leq \frac{h}{t} \leq 1,4\left(\frac{E k_{v}}{f_{y}}\right)^{0,5} \\
V_{R k}=0,65 t^{2}\left(k_{v} f_{y} E\right)^{0,5} \\
\text { - para } \frac{h}{t} \geq 1,4\left(\frac{E k_{v}}{f_{y}}\right)^{0,5} \\
V_{R k}=\frac{0,905 E k_{v} t^{3}}{h}
\end{gathered}
$$

Onde:

$t$ é a espessura da alma;

$h$ é a largura da alma (altura da parte plana da alma); 
$E$ é o módulo de elasticidade longitudinal;

$\mathrm{f}_{\mathrm{y}}$ é a resistência ao escoamento do aço;

$k_{v}$ é o coeficiente de flambagem local por cisalhamento, igual a 5,0 para alma sem enrijecedores transversais.

A interação entre o momento fletor e a força cortante (interação $\mathrm{M}-\mathrm{V}$ ) deve ser considerada por meio da expressão de interação 4.16 (aqui apresentada em termos de valores característicos), aplicável às barras sem enrijecedores transversais de alma.

$$
\left(\frac{M_{S k}}{M_{R k}}\right)^{2}+\left(\frac{V_{S k}}{V_{R k}}\right)^{2} \leq 1
$$

Onde:

$M_{\mathrm{Sk}}$ é o momento fletor solicitante característico;

$M_{R k}$ é o momento fletor resistente característico, desconsiderando a instabilidade distorcional;

$V_{S k}$ é a força cortante solicitante característica;

$V_{R k}$ é a força cortante resistente característica.

O MRD pressupõe uma análise de estabilidade elástica para o cálculo das tensões críticas e identificação dos respectivos modos de flambagem. O software utilizado foi o CUFSM v.4.05 (SCHAFER; ADANY, 2006). Os dados de entrada para a análise via CUFSM foram as dimensões reais do perfil medidas em laboratório (apresentadas no Apêndice B Tabela B.1), descontando a espessura do revestimento de zinco de 0,02 $\mathrm{mm}$ em cada face e o módulo de elasticidade longitudinal $\mathrm{E}=200.000 \mathrm{MPa}$ (valor convencional estabelecido na ABNT NBR 14762:2010).

$\mathrm{Na}$ análise de estabilidade elástica, todos os protótipos foram admitidos como submetidos à flexão restringida (flexão em torno do eixo perpendicular à alma). Tal hipótese está apoiada no sistema de contenção lateral e confirmada pela análise experimental da distribuição de deformações nas mesas do protótipo ZB63-C (Apêndice E).

Os resultados das análises de estabilidade elástica estão apresentados nas Figuras 4.34 e 4.35 para os protótipos ZA62-L88 e ZB63-L126, respectivamente. A seção S1 corresponde à luva (mesa menor comprimida) e a seção S2 corresponde à terça (mesa maior comprimida). 


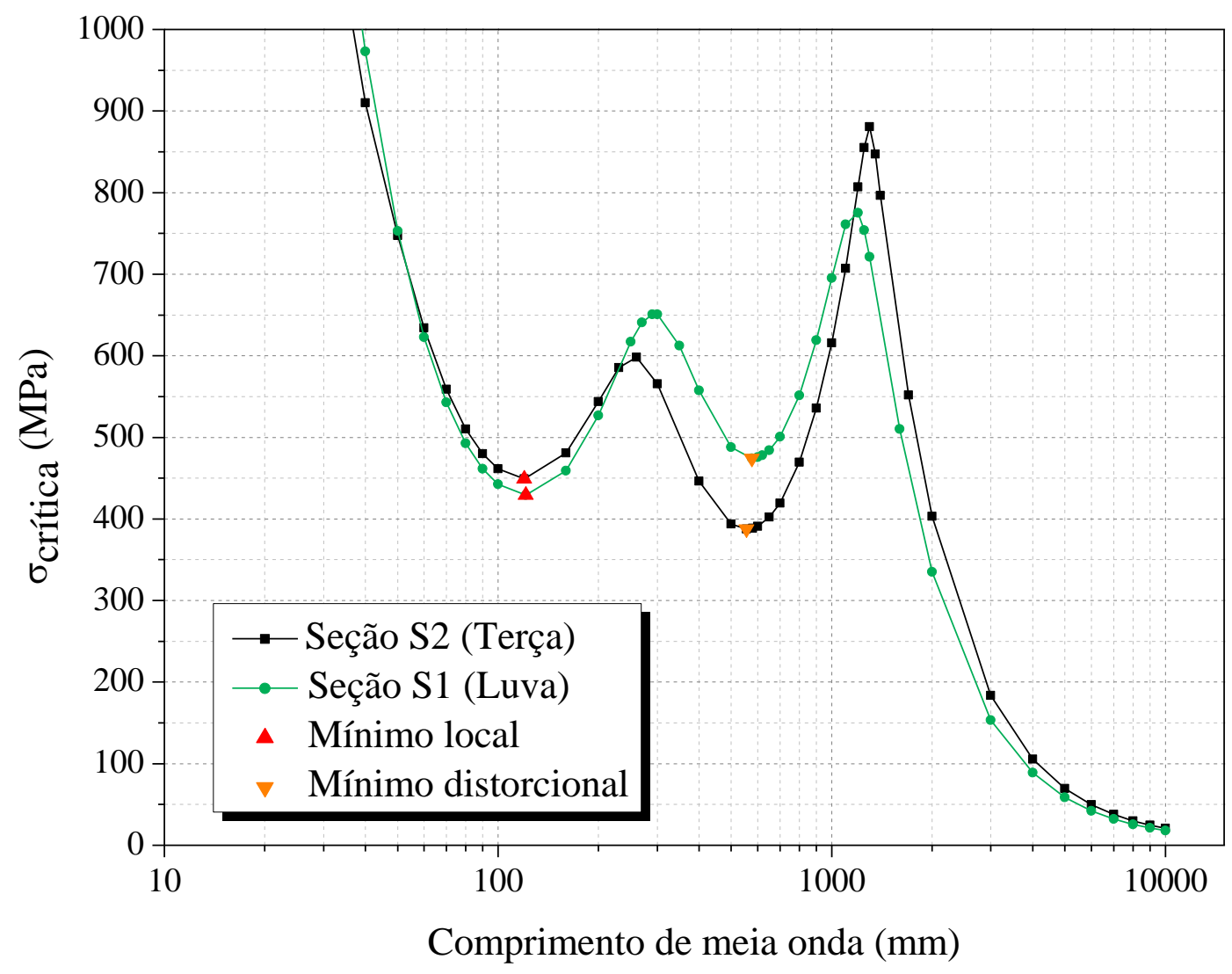

Figura 4.34 - Análise de estabilidade elástica para o protótipo ZA62-L88.

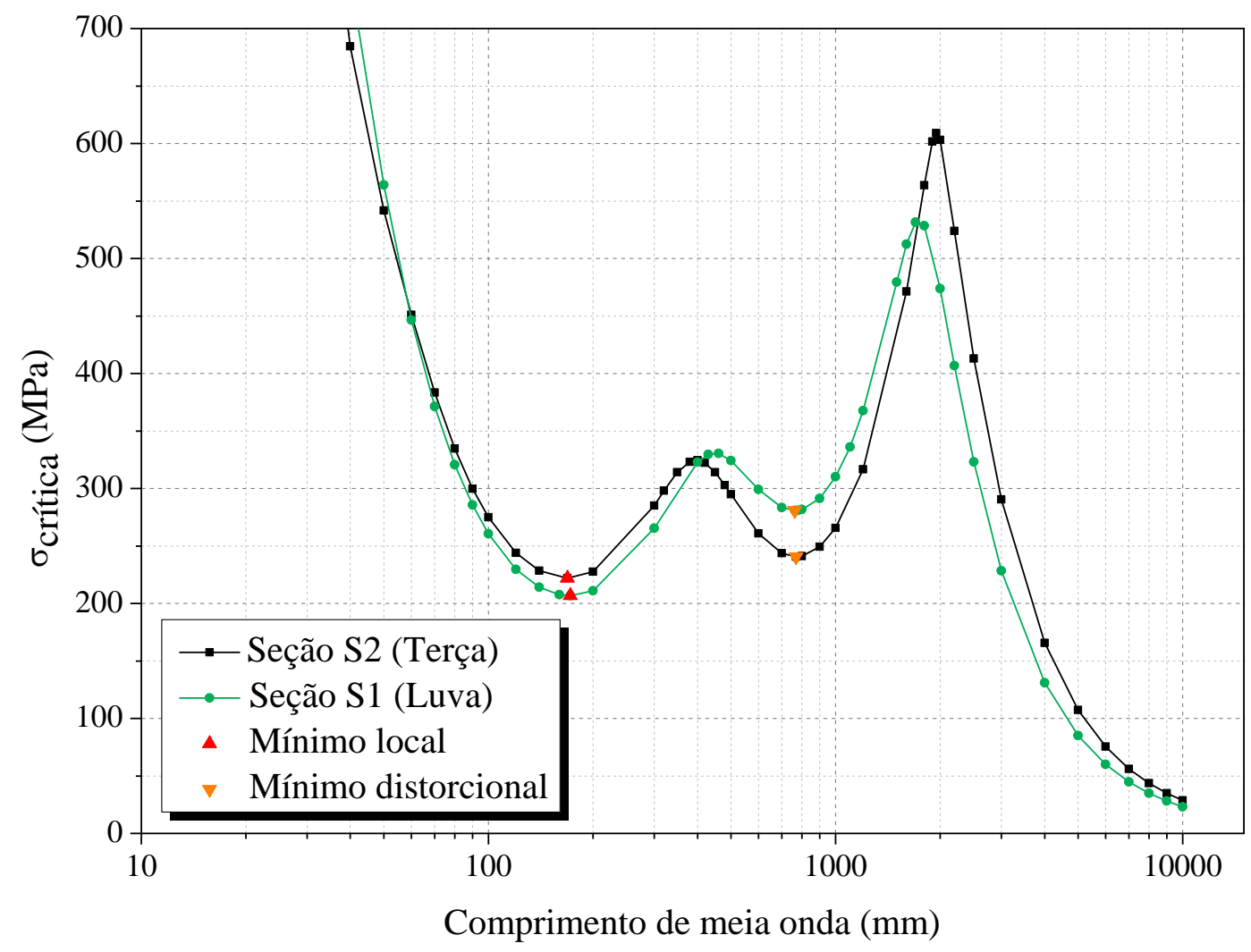

Figura 4.35 - Análise de estabilidade elástica para o protótipo ZB63-L126. 
Na Tabela 4.3 são apresentados os valores teóricos e experimentais da força máxima por terça, desconsiderando a interação entre momento fletor e força cortante. A parcela de força experimental atribuída a cada terça foi determinada com base nos respectivos deslocamentos medidos na fase linear, tomando-se como referência o trecho compreendido entre $0,1 \mathrm{~F}_{\exp } \mathrm{e}$ $0,6 \mathrm{~F}_{\text {exp. }}$

A Tabela 4.4 é similar à Tabela 4.3, porém os valores teóricos da força máxima foram obtidos considerando a interação entre momento fletor e força cortante com base na expressão de interação 4.16. Para facilitar a análise da viabilidade do método empregado neste trabalho, as relações $F_{\text {exp }} / F_{\text {teo }}$ das Tabelas 4.3 e 4.4 foram organizadas na Figura 4.36 para cada comprimento de luva (curta, mediana e longa).

$\mathrm{Na}$ Tabela 4.5 são apresentados os valores experimentais e teóricos resistentes dos esforços, bem como o resultado da interação momento-cortante.

Tabela 4.3 - Valores experimentais e teóricos da força máxima por terça desconsiderando a interação $\mathrm{M}-\mathrm{V}$.

\begin{tabular}{|c|c|c|c|c|c|c|c|}
\hline Série & Protótipo & $\begin{array}{l}F_{\text {exp }}^{a} \\
(\mathbf{k N})\end{array}$ & $\begin{array}{c}\mathbf{F}_{\text {teo }}(\text { Terça) } \\
(\mathbf{k N})\end{array}$ & $\begin{array}{c}\mathbf{F}_{\text {teo }}(\text { Luva) } \\
(\mathbf{k N})\end{array}$ & $F_{\text {exp }}{ }^{a} / F_{\text {teo }}{ }^{b}$ & Falha $_{\text {exp }}$ & Falhat $_{\text {teo }}$ \\
\hline \multirow{4}{*}{ A } & ZA62-L44 & 7,78 & 9,98 & 10,23 & 0,78 & Terça & Terça \\
\hline & ZA62-L88 & 10,17 & 10,84 & 9,93 & 1,02 & Terça & Luva \\
\hline & ZA62-L132 & 11,01 & 11,83 & 9,98 & 1,10 & Terça & Luva \\
\hline & ZA62-C & 11,15 & 9,36 & - & 1,19 & Terça & Terça \\
\hline \multirow{5}{*}{ B } & ZB63-L63 & 12,59 & 15,70 & 14,54 & 0,87 & Terça & Luva \\
\hline & ZB63-L126 & 15,44 & 17,97 & 14,96 & 1,03 & Luva & Luva \\
\hline & ZB63-L126T3 & 17,91 & 18,06 & 28,25 & 0,99 & Terça & Terça \\
\hline & ZB63-L189 & 17,40 & 20,50 & 14,98 & 1,16 & Luva & Luva \\
\hline & ZB63-C & 16,32 & 14,26 & - & 1,14 & Terça & Terça \\
\hline \multirow{5}{*}{$\mathrm{C}$} & ZC83-L63 & 8,83 & 11,73 & 11,25 & 0,78 & Luva & Luva \\
\hline & ZC83-L126 & 11,02 & 12,90 & 11,28 & 0,98 & Luva & Luva \\
\hline & ZC83-L126T3 & 13,15 & 12,71 & 21,19 & 1,03 & Terça & Terça \\
\hline & ZC83-L189 & 11,76 & 15,12 & 11,32 & 1,04 & Luva & Luva \\
\hline & ZC83-C & 12,60 & 10,86 & - & 1,16 & Terça & Terça \\
\hline
\end{tabular}

${ }^{a}$ Valor máximo experimental por terça, com peso próprio considerado.

${ }^{b}$ Menor valor entre $F_{\text {teo }}$ (Terça) e $F_{\text {teo }}$ (Luva). 
Tabela 4.4 -Valores experimentais e teóricos da força máxima por terça considerando a interação $\mathrm{M}-\mathrm{V}$.

\begin{tabular}{|c|c|c|c|c|c|c|c|}
\hline Série & Protótipo & $\begin{array}{l}F_{\text {exp }}^{a} \\
(k N)\end{array}$ & $\begin{array}{c}F_{\text {teo }}(\text { Terça }) \\
(k N)\end{array}$ & $\begin{array}{c}\mathbf{F}_{\text {teo }} \text { (Luva) } \\
(\mathbf{k N})\end{array}$ & $F_{\text {exp }}{ }^{a} / F_{\text {teo }}{ }^{b}$ & Falha $_{\text {exp }}$ & Falha $_{\text {teo }}$ \\
\hline \multirow{4}{*}{ A } & ZA62-L44 & 7,78 & 11,24 & 10,24 & 0,76 & Terça & Luva \\
\hline & ZA62-L88 & 10,17 & 12,14 & 10,27 & 0,99 & Terça & Luva \\
\hline & ZA62-L132 & 11,01 & 13,21 & 10,27 & 1,07 & Terça & Luva \\
\hline & ZA62-C & 11,15 & 10,44 & - & 1,07 & Terça & Terça \\
\hline \multirow{5}{*}{ B } & ZB63-L63 & 12,59 & 15,73 & 13,87 & 0,91 & Terça & Luva \\
\hline & ZB63-L126 & 15,44 & 17,51 & 14,03 & 1,10 & Luva & Luva \\
\hline & ZB63-L126T3 & 17,91 & 17,55 & 30,14 & 1,02 & Terça & Terça \\
\hline & ZB63-L189 & 17,40 & 19,58 & 14,05 & 1,24 & Luva & Luva \\
\hline & ZB63-C & 16,32 & 14,36 & - & 1,14 & Terça & Terça \\
\hline \multirow{5}{*}{$\mathrm{C}$} & ZC83-L63 & 8,83 & 11,98 & 10,84 & 0,81 & Luva & Luva \\
\hline & ZC83-L126 & 11,02 & 13,01 & 10,87 & 1,01 & Luva & Luva \\
\hline & ZC83-L126T3 & 13,15 & 12,99 & 22,79 & 1,01 & Terça & Terça \\
\hline & ZC83-L189 & 11,76 & 14,17 & 10,90 & 1,08 & Luva & Luva \\
\hline & ZC83-C & 12,60 & 11,09 & - & 1,14 & Terça & Terça \\
\hline
\end{tabular}

${ }^{a}$ Valor máximo experimental por terça, com peso próprio considerado.

${ }^{\mathrm{b}}$ Menor valor entre $\mathrm{F}_{\text {teo }}$ (Terça) e $\mathrm{F}_{\text {teo }}$ (Luva).

Tabela 4.5 -Valores experimentais e teóricos resistentes dos esforços e resultados da interação momento-cortante.

\begin{tabular}{|c|c|c|c|c|c|c|c|c|c|c|c|c|c|}
\hline \multirow[b]{2}{*}{ Série } & \multirow[b]{2}{*}{ Protótipo } & \multicolumn{6}{|c|}{ Terça (seção S2) } & \multicolumn{6}{|c|}{ Luva (seção S1) } \\
\hline & & $\begin{array}{c}M_{\text {exp }}^{a} \\
(\mathbf{k N . c m}) \\
\end{array}$ & $\begin{array}{l}M_{R 1, \text { teo }} \\
(\mathbf{k N . c m})\end{array}$ & $\begin{array}{r}M_{\text {Rdist,teo }} \\
\text { (kN.cm) }\end{array}$ & $\begin{array}{l}V_{\text {exp }}^{a} \\
(\mathbf{k N}) \\
\end{array}$ & $\begin{array}{l}\mathbf{V}_{\mathbf{R}, \text { teo }} \\
(\mathbf{k N}) \\
\end{array}$ & $\begin{array}{c}\text { Interação } \\
\text { M-V } \\
\end{array}$ & $\begin{array}{c}M_{\text {exp }}{ }^{a} \\
\text { (kN.cm) }\end{array}$ & $\begin{array}{c}M_{\text {Rl,teo }} \\
(\mathrm{kN.cm})\end{array}$ & $\begin{array}{c}M_{\text {Rdist,teo }} \\
\text { (kN.cm) } \\
\end{array}$ & $\begin{array}{l}V_{\text {exp }}{ }^{a} \\
(\mathbf{k N}) \\
\end{array}$ & $\begin{array}{l}\mathbf{V}_{\mathbf{R}, \text { teo }} \\
(\mathrm{kN}) \\
\end{array}$ & $\begin{array}{c}\text { Interação } \\
\text { M-V }\end{array}$ \\
\hline \multirow{4}{*}{$\mathbf{A}$} & ZA62-L44 & 1082 & 1591 & 1388 & 3,89 & 29,53 & 0,48 & 1168 & 1560 & 1535 & 3,89 & 29,53 & 0,58 \\
\hline & ZA62-L88 & 1302 & 1588 & 1388 & 5,08 & 29,46 & 0,70 & 1525 & 1564 & 1489 & 5,08 & 29,46 & 0,98 \\
\hline & ZA62-L132 & 1289 & 1586 & 1384 & 5,51 & 29,43 & 0,69 & 1652 & 1565 & 1497 & 5,51 & 29,43 & 1,15 \\
\hline & ZA62-C ${ }^{\mathrm{b}}$ & 1673 & 1589 & 1404 & 5,58 & 30,45 & 1,14 & - & - & - & - & - & - \\
\hline \multirow{5}{*}{ B } & ZB63-L63 & 1690 & 2291 & 2108 & 6,30 & 20,27 & 0,64 & 1889 & 2214 & 2180 & 6,30 & 20,27 & 0,82 \\
\hline & ZB63-L126 & 1830 & 2300 & 2130 & 7,72 & 20,27 & 0,78 & 2317 & 2244 & 2261 & 7,72 & 20,27 & 1,21 \\
\hline & ZB63-L126T3 & 2123 & 2307 & 2140 & 8,96 & 20,24 & 1,04 & 2687 & 4607 & 4238 & 8,96 & 78,36 & 0,35 \\
\hline & ZB63-L189 & 1788 & 2299 & 2106 & 8,70 & 20,24 & 0,79 & 2610 & 2248 & 2281 & 8,70 & 20,24 & 1,53 \\
\hline & ZB63-C ${ }^{\mathrm{b}}$ & 2448 & 2302 & 2139 & 8,16 & 20,30 & 1,29 & - & - & - & - & - & - \\
\hline \multirow{5}{*}{ C } & ZC83-L63 & 1626 & 2310 & 2162 & 4,41 & 20,27 & 0,54 & 1765 & 2249 & 2297 & 4,41 & 20,27 & 0,66 \\
\hline & ZC83-L126 & 1857 & 2316 & 2174 & 5,51 & 20,21 & 0,72 & 2204 & 2257 & 2271 & 5,51 & 20,21 & 1,03 \\
\hline & ZC83-L126T3 & 2216 & 2311 & 2142 & 6,58 & 20,25 & 1,02 & 2630 & 4607 & 4238 & 6,58 & 78,36 & 0,33 \\
\hline & ZC83-L189 & 1796 & 2310 & 2133 & 5,88 & 20,26 & 0,69 & 2351 & 2263 & 2281 & 5,88 & 20,26 & 1,16 \\
\hline & ZC83-C & 2521 & 2307 & 2172 & 6,30 & 20,27 & 1,29 & - & - & & - & - & - \\
\hline
\end{tabular}

${ }^{\mathrm{a}}$ Valores máximos, considerando o peso próprio.

${ }^{\text {b}}$ Seção da terça no meio do vão 


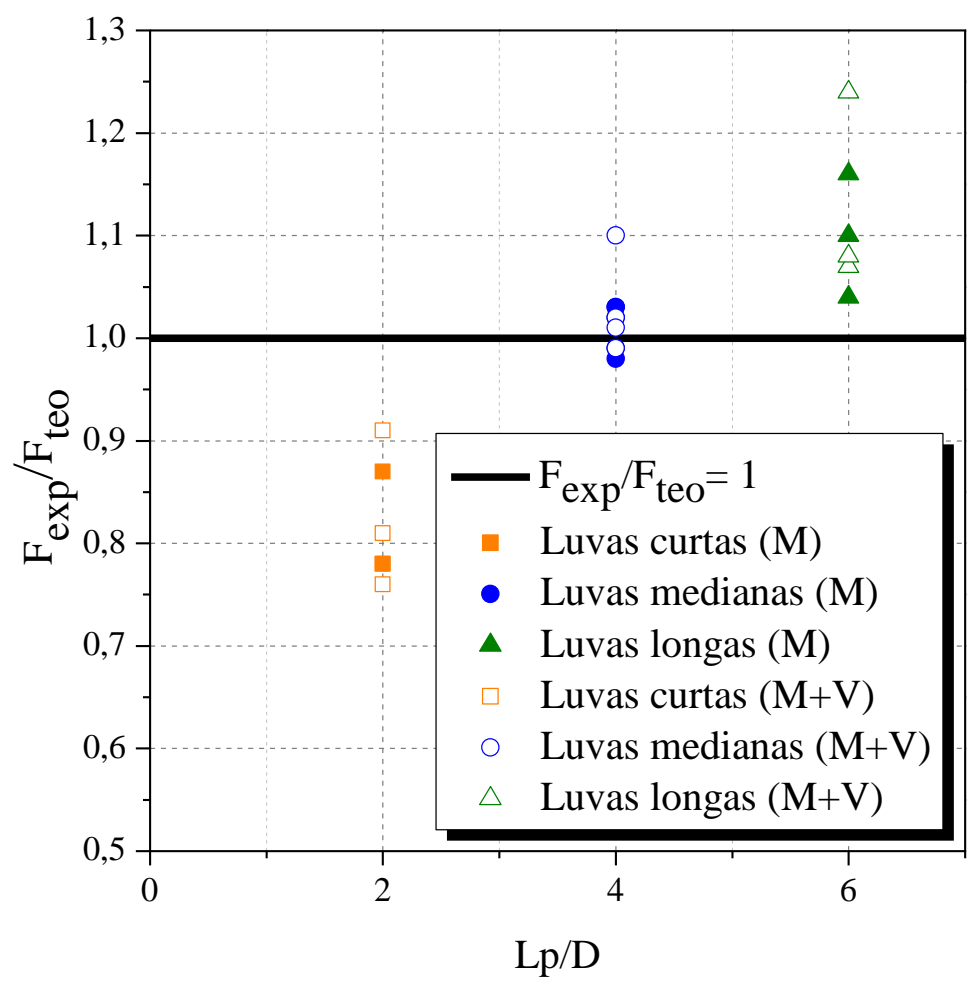

Figura 4.36 - Valores experimentais e teóricos da força máxima para diferentes comprimentos de luva, desconsiderando $(\mathrm{M})$ ou considerando $(\mathrm{M}+\mathrm{V})$ a interação momento-cortante.

Com base nos resultados apresentados nas Tabelas 4.3 e 4.4 e na Figura 4.36, concluise que os protótipos constituídos por luvas curtas $\left(L_{p} / D=2\right)$ apresentaram $\mathrm{F}_{\text {exp }} / \mathrm{F}_{\text {teo }}<1$, indicando que o modelo teórico resulta inseguro. Já os protótipos contínuos fisicamente ou com luvas medianas e longas $\left(L_{p} / D=2\right.$ e $\left(\mathrm{L}_{\mathrm{p}} / \mathrm{D}=4\right)$ apresentaram $\mathrm{F}_{\text {exp }} / \mathrm{F}_{\text {teo }}>1$ ou muito próximos a 1, indicando portanto que o modelo teórico resulta seguro.

Na Figura 4.37 são apresentados os resultados teóricos, juntamente com a curva de interação momento-cortante. Os resultados teóricos correspondem à seção onde ocorreu o mecanismo de falha teórico (Tabela 4.4), podendo ser na região central da luva (seção S1) ou na terça próximo à extremidade da luva (seção S2).

Nota-se claramente que as terças com luvas curtas $\left(\mathrm{L}_{\mathrm{p}} / \mathrm{D}=2\right)$ não atendem ao critério de segurança do modelo de cálculo, o que não acontece nos demais protótipos (terças contínuas e terças com luva mediana e longa). Tal fato pode ser atribuído principalmente a dois fatores: nas luvas curtas os efeitos localizados induzidos pela ligação são mais acentuados e como a ligação ocorre apenas na alma, a hipótese de flexão restringida deixa de ser válida na região da emenda. No anexo E é apresentada uma análise das deformações nas mesas das terças. 


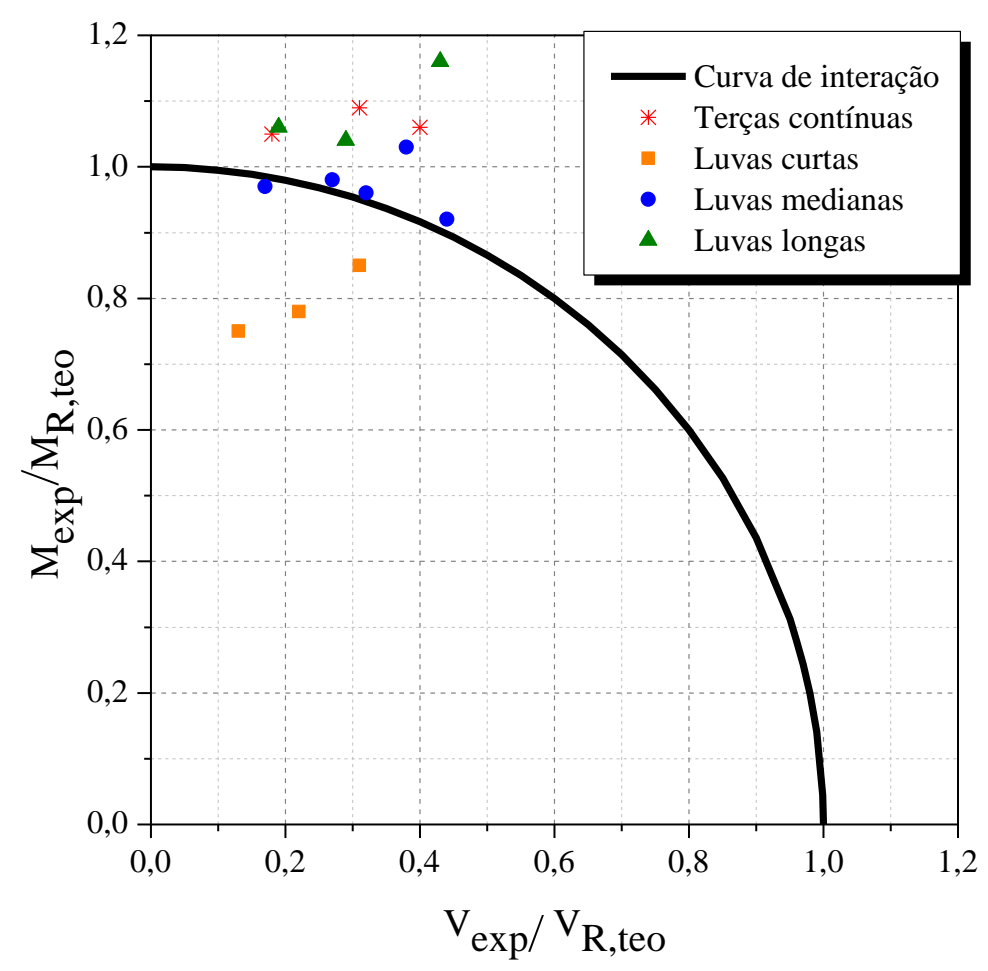

Figura 4.37 - Diagrama de interação momento-cortante e resultados teóricos.

\subsubsection{Modos de falha}

Os modos de falha observados nos ensaios estão apresentados na Figura 4.38. A falha dos protótipos foi observada ora na parte central da luva (seção S1), ora na terça próximo ao final da luva (seção S2).

Da análise de estabilidade elástica (Figuras 4.34 e 4.35) é possível notar que os pontos de mínimo associados aos modos local e distorcional resultam próximos, portanto o mecanismo de falha pode se manifestar como local ou distorcional.

As terças contínuas (sem emenda) falharam a meio vão por instabilidadade distorcional (ZA62-C) e instabilidade local (ZB63-C e ZC83-C), conforme mostrado na Figura 4.38a. Por sua vez, as terças contínuas por meio de luvas falharam predominantemente por instabilidade local nas região central da luva ou na terça próximo ao final da luva (Figura 4.38b e $4.38 \mathrm{c})$.

Nas terças com luvas curtas $\left(L_{p} / D=2\right)$, os esforços solicitantes máximos na luva (seção S1) e na terça (seção S2) resultam próximos. Entretanto, como a luva é enrijecida pelo suporte, a falha ocorreu na terça. O mesmo ocorreu para as terças com luva de espessura maior (Figura $4.38 b)$. 
Nas terças com luvas medianas e longas $\left(L_{p} / D=4\right.$ e $\left.L_{p} / D=6\right)$, a diferença entre os momentos fletores das seções S1 e S2 aumenta. Assim, a seção S1 (luva) resultou consideravelmente mais solicitada que a seção S2 (terça) e o mecanismo de falha ocorreu na parte central da luva. (Figura 4.38c).

Apesar de nenhuma imperfeição inicial ter sido identificada após uma inspeção visual, um atípico mecanismo de falha localizado na extremidade da luva ocorreu no protótipo ZC83L63 (Figura 4.39), refletindo em redução de rigidez quando comparada a dos demais protótipos. 


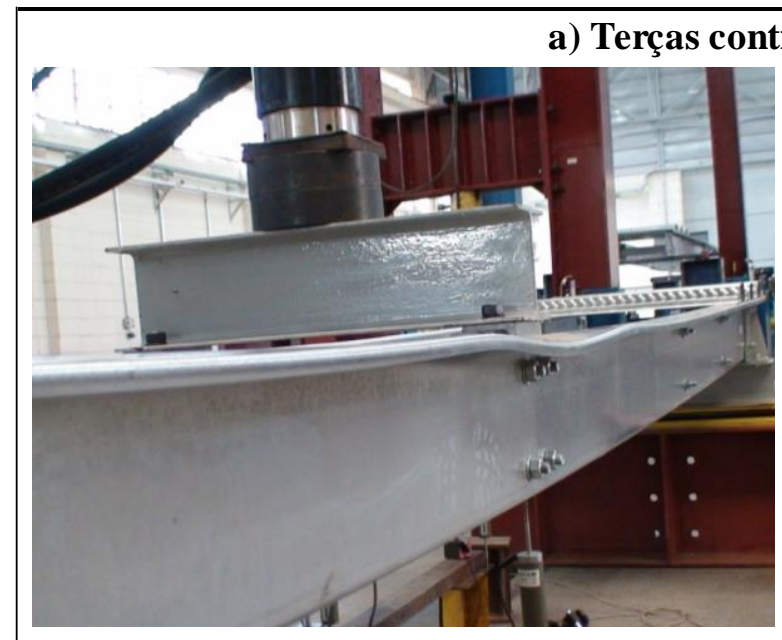

Instabilidade distorcional

Protótipo: ZA62-C

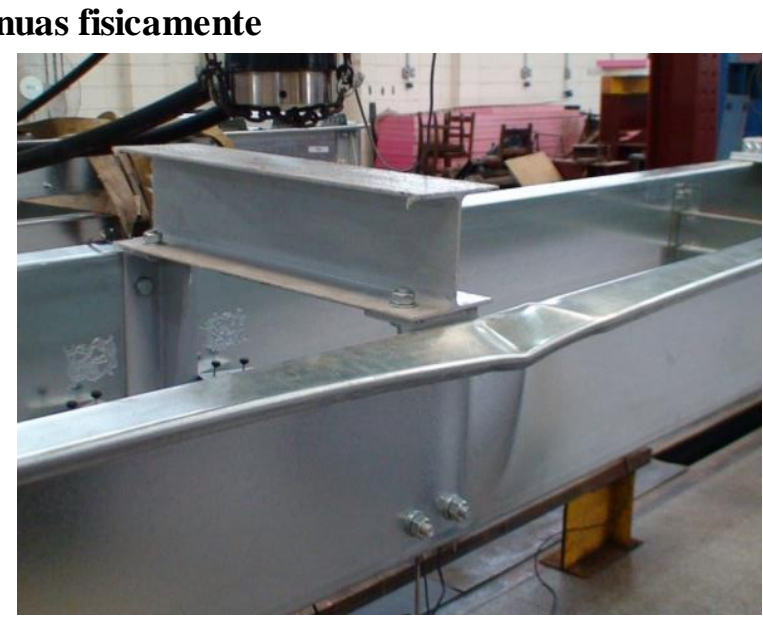

Instabilidade local

Protótipos: ZB63-C e ZC83-C

b) Terças com luva curta $\left(L_{p} / D=2\right)$ e terças com luva de espessura nominal de $3,00 \mathrm{~mm}$
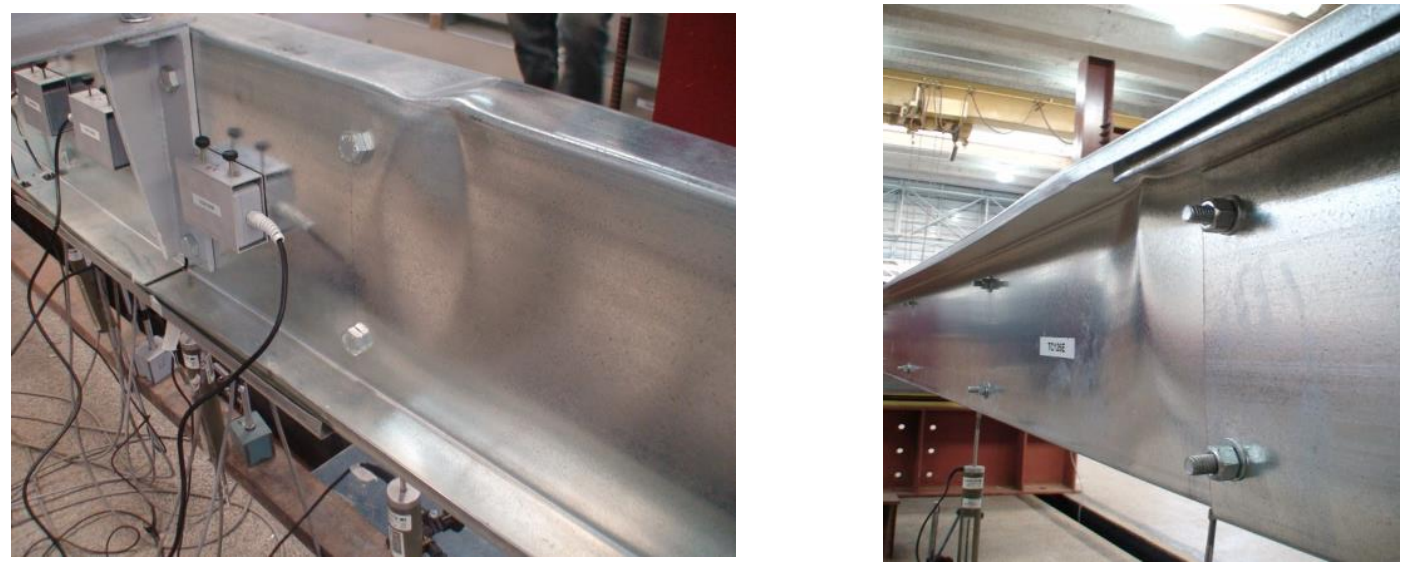

Instabilidade local da terça no fim da ligação

Protótipos: ZA62-L44, ZA62-L88, ZA62-L132, ZB63-L63, ZB63-L126T3 e ZC83-L126T3

c) Terças com luva mediana $\left(L_{p} / D=4\right)$ e luva longa $(L p / D=6)$
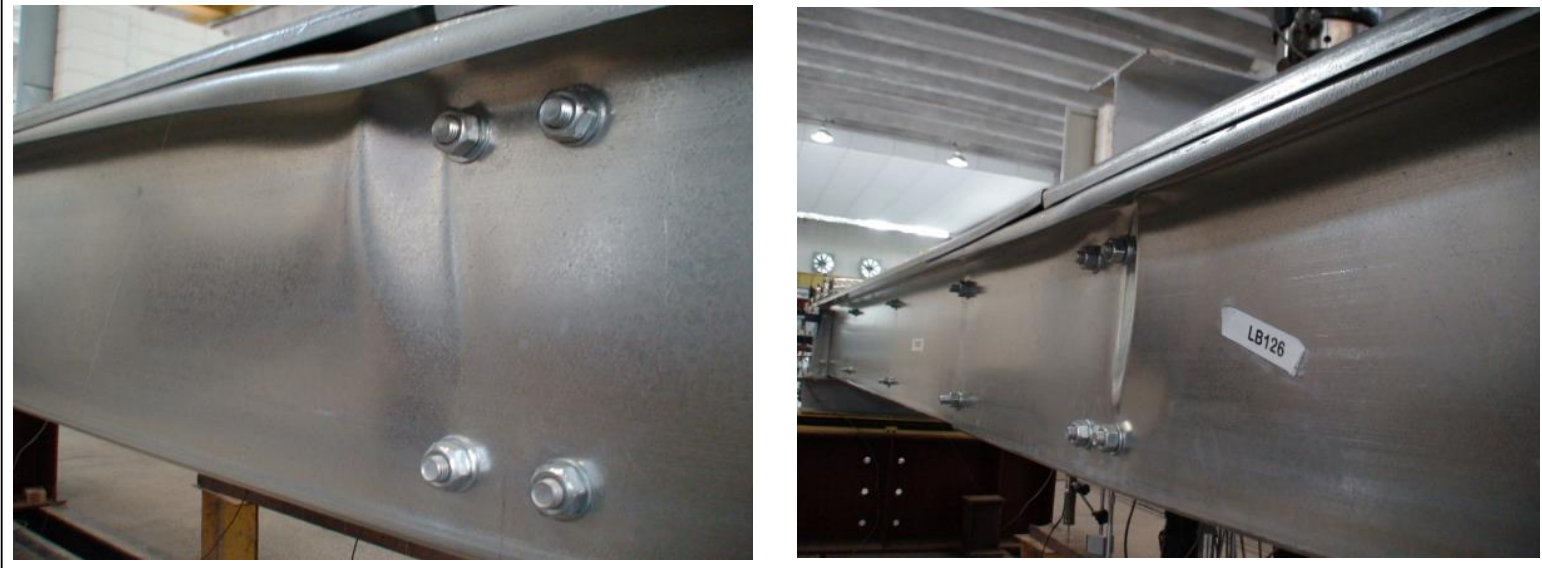

Instabilidade local no meio da luva

Protótipos: ZB63-L126, ZB63-L189, ZC83-L126 e ZC83-L189

Figura 4.38 - Modos de falha observados nos ensaios. 


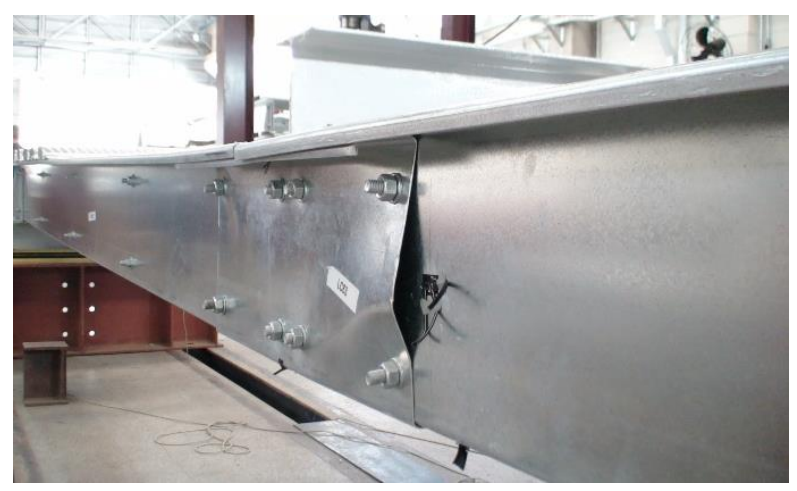

Figura 4.39 - Mecanismo de falha atípico na extremidade da luva do protótipo ZC83-L63. 


\section{CONCLUSÕES}

A análise experimental dos protótipos permitiu avaliar o comportamento estrutural do sistema, considerando a influência da variação do comprimento da luva, da altura do perfil, da espessura da luva e do vão. Pôde-se também analisar a influência da variação da espessura do conjunto terça-luva por meio de ensaios similares feitos por Fávero Neto (2013).

Os resultados obtidos para as terças com luva foram comparados aos obtidos para terças contínuas fisicamente (sem luva), onde concluiu-se que a rigidez do sistema pode resultar consideravelmente inferior à da terça contínua, portanto, torna-se relevante considerar a resposta momento-rotação (M-Ө) da ligação na análise das terças contínuas de múltiplos vãos.

Dessa forma, uma estratégia foi desenvolvida para obtenção das curvas momentorotação (M-Ө) de modo a considerar todas as parcelas de flexibilidade da ligação. Em seguida, tais curvas foram calibradas com base nos resultados experimentais e introduzidas em dois modelos numéricos de barras por meio de molas rotacionais, reproduzindo muito bem os resultados experimentais. O primeiro modelo foi constituído por três molas e o segundo por apenas uma mola representando toda a ligação.

As curvas momento-rotação (M- $\Theta$ ) obtidas resultaram não lineares e dependentes das variáveis investigadas (comprimento efetivo da luva, altura da seção, vão e distância dos parafusos ao centro geométrico da ligação). Para um mesmo perfil e vão, a rigidez da ligação aumenta à medida que aumenta o comprimento da luva. Para um mesmo perfil e comprimento da luva, a variação do vão mostrou-se significativa apenas para as luvas longas $\left(L_{p} / D=6\right)$, havendo redução de rigidez à medida que aumenta o vão.

Com base em análise paramétrica foi determinada uma expressão para avaliação da curva momento-rotação, a qual pode ser inserida como mola não linear na análise estrutural de terças contínuas de múltiplos vãos, possibilitando prever os esforços e deslocamentos de forma mais realista. Tal expressão proposta é válida para terças e luvas com a mesma espessura.

Em relação aos estados-limites últimos, os sistemas contínuos apresentaram como modo de falha a instabilidadade distorcional (ZA62-C) ou a instabilidade local (ZB63-C e ZC83-C), confirmando a previsão teórica via método da resistencia direta. Os protótipos com luva apresentaram mecanismo de falha associado à instabilidade local na parte central da luva (seção $S 1$ ) ou na terça próximo ao final da luva (seção $S 2)$. Para luvas curtas $\left(L_{p} / D=2\right)$, a falha ocorreu na terça, pois o suporte atua como enrijecedor na parte central da luva. Para luvas medianas e longas $\left(L_{p} / D=4\right.$ e $\left.L_{p} / D=6\right)$ a falha ocorreu na luva, pois o momento fletor na terça 
é consideravelmente inferior ao da luva. Para luva de maior espessura que a da terça, o modo de falha ocorreu sempre na terça.

Os esforços resistentes avaliados via método da resistência direta, considerando ou não a interação com a força cortante, resultaram a favor da segurança para as terças com luva mediana e longa $\left(L_{p} / D=4\right.$ e $\left.L_{p} / D=6\right)$, porém contra a segurança para as terças com luva curta $\left(L_{p} / D=2\right)$, devido à maior influência das forças localizadas na alma introduzidas pelos parafusos bem como do afastamento da condição de flexão restringida assumida na análise de estabilidade elástica. Portanto, o método da resistência direta para terças com luva deve ser aplicado com cautela, ficando restrito aos casos de luvas medianas e longas.

A análise comparativa de modelos numéricos de terças de múltiplos vãos, assumindo molas nos apoios com base na expressão M- $\Theta$ proposta neste trabalho, bem como nos trabalhos de outros autores, permitiu confirmar que a expressão aqui proposta conduz a bons resultados e, portanto, pode ser satisfatoriamente empregada na determinação de esforços solicitantes e deslocamentos. Entretanto, como o estudo experimental foi conduzido em protótipos biapoiados, torna-se relevante prosseguir a investigação em protótipos com múltiplos vãos. 


\section{REFERÊNCIAS BIBLIOGRÁFICAS}

ALBION SECTIONS. Catálogo técnico. Disponível em :<

http://www.albionsections.co.uk/doc/52.pdf >. Acesso em: 20 Fev. 2016.

AMERICAN IRON AND STEEL INSTITUTE. (2012). ANSI/AISI S100-2012: North American Specification for the Design of Cold-Formed Steel Structural Members.

Washington, DC, 2012.

AMERICAN IRON AND STEEL INSTITUTE. (2009). Design Guide D111-09: Design Guide for Cold-Formed Steel Purlin Roof Framing Systems. Washington, DC, 2009.

AMERICAN IRON AND STEEL INSTITUTE. (1996). ANSI/AISI: Test Procedures for use with the 1996 AISI Cold-Formed Steel Specification. Washington, DC, 1996.

AMERICAN INSTITUTE OF STEEL CONSTRUCTION. (2010). ANSI/AISC 360-10:

Specification for Structural Steel Buildings. Chicago, IL, 2010.

AMERICAN SOCIETY FOR TESTING AND MATERIALS. (2014). ASTM A370:

Standard Test Methods and Definitions for Mechanical Testing of Steel Products. West

Conshohocken, PA, 2014.

AMERICAN SOCIETY FOR TESTING AND MATERIALS. (2013). ASTM A325:

Standard Specification for Structural Bolts, Steel, Heat Treated 830 MPa Minimum Tensile

Strength (Metric). West Conshohocken, PA, 2013.

AMERICAN SOCIETY FOR TESTING AND MATERIALS. (2012). ASTM A307:

Standard Specification for Carbon Steel Bolts, Studs, and Threaded Rod 60000 PSI Tensile

Strength. West Conshohocken, PA, 2012.

ASSOCIAÇÃO BRASILEIRA DE NORMAS TÉCNICAS. (2010). NBR 14762:

Dimensionamento de estruturas de aço constituídas por perfis formados a frio. Rio de Janeiro, 2010.

ASSOCIAÇÃO BRASILEIRA DE NORMAS TÉCNICAS . (2012). NBR 7008-3: Chapas e bobinas de aço revestidas com zinco ou liga zinco-ferro pelo processo contínuo de imersão a quente Parte 3: Aços estruturais. Rio de Janeiro, 2012.

BASAGLIA, C. D. (2004). Sobre o comportamento estrutural de terças de aço considerando a interação com as telhas. Dissertação (Mestrado) - Escola de Engenharia de São Carlos, Universidade de São Paulo, São Carlos, 2004.

BRYAN, E.R. (1993). The design of bolted joints in cold-formed steel sections. Thin-Walled Structures, v.16, p.239-262, 1993. 
BW INDUSTRIES. Catálogo técnico. Disponível em :< http://www.bwindustries.co.uk/images/admin_images/documents/BW\%20Purlins\%202015.pdf >. Acesso em: 20 Fev. 2016.

CHUNG, K.F.; HO H.C. (2005). Analyses and design of lapped connections between coldformed steel Z sections. Thin-Walled Structures, v.43, p.1071-1090, 2005.

DUBINA, D.; UNGUREANU, V. (2010). Behaviour of multi-span cold-formed Z-purlins with bolted lapped connections. Thin-Walled Structures, v.48, p.866-871, 2010.

FÁVERO NETO, A. H. Terças de aço formadas a frio com continuidade nos apoios: ênfase ao estudo das ligações de alma parafusadas com transpasse ou luva. 2013. $93 \mathrm{f}$. Dissertação (Mestrado) - Escola de Engenharia de São Carlos, Universidade de São Paulo, São Carlos, 2013.

FÁVERO NETO, A.H.; VIEIRA JR., L.C.M.; MALITE, M. (2013). Strength and Stiffness of cold formed steel purlins with sleeved and overlapped bolted connections. In: Proceedings of the 2013 SSRC Annual Stability Conference. St. Louis, MO, 2013.

GHOSN, A.A.; SINNO, R.R. (1995). Governing stresses in Z-purlin lap joints. Journal of Structural Engineering, v.121, n.12, p.1735-1741, 1995.

GHOSN, A.A.; SINNO, R.R. (1996). Load capacity of nested, laterally braced, cold-formed steel Z-section beams. Journal of Structural Engineering, v.122, n.8, p.968-971, 1996.

GUTIERREZ, R.; LOUREIRO, A.; LOPEZ, M.; MORENO, A. (2011). Analysis of coldformed purlins with slotted sleeve connections. Thin-Walled Structures, v.49, p.833-841, 2011.

GUTIERREZ, R.; LOUREIRO, A.; REINOSA, J. M.; LOPEZ, M. (2015). Numerical study of purlin joints with sleeve connections. Thin-Walled Structures, v.94, p.214-224, 2015.

HO H.C.; CHUNG, K.F. (2004). Experimental investigation into the structural behaviour of lapped connections between cold-formed steel Z sections. Thin-Walled Structures, v.42, p.1013-1033, 2004.

HO H.C.; CHUNG, K.F. (2006a). Analytical prediction on deformation characteristics of lapped connections between cold-formed steel Z sections. Thin-Walled Structures, v.44, p.115-130, 2006.

HO H.C.; CHUNG, K.F. (2006b). Structural behaviour of lapped cold-formed steel Z sections with generic bolted configurations. Thin-Walled Structures, v.44, p.466-480, 2006. 
JAVARONI, C. E. (1999). Perfis de aço conformados a frio submetidos à flexão: Análise teórico-experimental. São Carlos. 255p. Tese (Doutorado) - Escola de Engenharia de São Carlos, Universidade de São Paulo, 1999.

LIU, J.; XU, L.; FOX, S. (2015a). Lapped cold-formed steel Z-shaped purlin connections with vertical slotted holes. Journal of Constructional Steel Research, v.107 p.150-161, 2015.

LIU, Q.; YANG, J.; WANG, F. (2015b). Numerical simulation of sleeve connections for cold formed steel sigma sections. Engineering Structures, v.100, p.686-695, 2015.

MODULAR SISTEMA CONSTRUTIVO. Catálogo técnico. Disponível em :< http://www.modularsc.com.br/catalogo/catalogo_modular_sistema_construtivo.pdf $>$. Acesso em: 20 Fev. 2016.

MOORE, D.B. (1990). Moment-rotation characteristics of purlin connections. In:

International Specialty Conference on Cold-formed Steel Structures, 10., Saint Louis. Proceeding University of Missouri-Rolla. p.525-544, 1990.

PHAM, C. H.; DAVIS, A. F.; EMMETT, B. R. (2012). Experimental and numerical investigations of high strength cold-formed lapped $\mathrm{Z}$ purlins under combined bending and shear. In: Proceedings of 21st International Specialty Conference on Cold-Formed Steel Structures. Saint Louis, p.391-406, 2012.

PHAM, C. H.; DAVIS, A. F.; EMMETT, B. R. (2014). Numerical investigation of coldformed lapped $\mathrm{Z}$ purlins under combined bending and shear. Journal of Constructional Steel Research, v.95 p.116-125, 2014.

ROBERTSON, G. W.; KURT, C. E. (1986). Behavior of nested Z-Shaped purlins. In: Proceedings of 8st International Specialty Conference on Cold-Formed Steel Structures. Saint Louis, 1986.

SALMON, C.G.; JOHNSON, J.E.; MALHAS, F.A. (2008). Steel Structures: Design and Behavior. 5.ed. New Jersey: Prentice Hall, 2008.

SCHAFER, B.W.; ADANY, S. (2006). Buckling analysis of cold-formed steel members using CUFSM: Conventional and constrained finite strip methods. In: Proceedings of 18th International Specialty Conference on Cold-Formed Steel Structures. Orlando, FL. p.3954, 2006.

TAN, S.H.; SEAH, L.K.; LI, Y. (2002). Connections of sleeve joint purlin system. Structural Engineering and Mechanics, v.13, n.1, p.1-16, 2002.

VIEIRA, R. C. (2009). Estudo comparativo entre terças de aço, convencionais em vigas, treliças planas e treliças multiplanares. Dissertação (Mestrado) - Faculdade de engenharia civil, Arquitetura e Urbanismo, Universidade Estadual de Campinas, Campinas, 2009. 
WANG, C.J.; MYNORS, D.J.; MORGAN, T.; CARTWRIGHT, B. (2012). Deflection analysis of sleeve jointed purlin systems with non-linear rotational stiffness. Applied Mechanics and Materials, v.147, p.66-69, 2012.

WIBBERNMEYER, K. D. (2010). Determining the R values for 12 inch deep Z-purlins and girts with through-fastened panels under suction loading. $60 \mathrm{p}$. Thesis (Master) Faculty of the Graduate School, Missouri University of Science and Technology. 2010.

WINTER, G. (1956). Test on bolted connections in light gage steel. Journal Structural Division. v.82, n.ST2, March 1956

YANG, J.; LIU, Q. (2012). Sleeve connections of cold-formed steel sigma purlins. Engineering Structures, v.43, p.245-258, 2012.

YE, W.; WANG, C. J.; MYNORS, D. J.; KIBBLE, K. A.; MORGAN, T.; CARTWRIGHT,B. (2013). Load-deflection behavior of sleeved joints in modified Z purlin system. Thin-Walled Structures, v.73, p.318-328, 2013.

YU, W.W.; LABOUBE, R.A. (2010). Cold-formed Steel Design. 4.ed. New York: John Wiley, 2010.

ZHANG, L.; TONG, G. (2008). Moment resistance and flexural rigidity of lapped connections in multi-span cold-formed Z purlin systems. Thin-Walled Structures, v.46, p.551$560,2008$.

ZADANFARROKH, F.; BRYAN, E. R. (1992). Testing and design of bolted connections in cold formed steel sections. In: Proceedings of 11st International Specialty Conference on Cold-Formed Steel Structures. Saint Louis, 1992. 


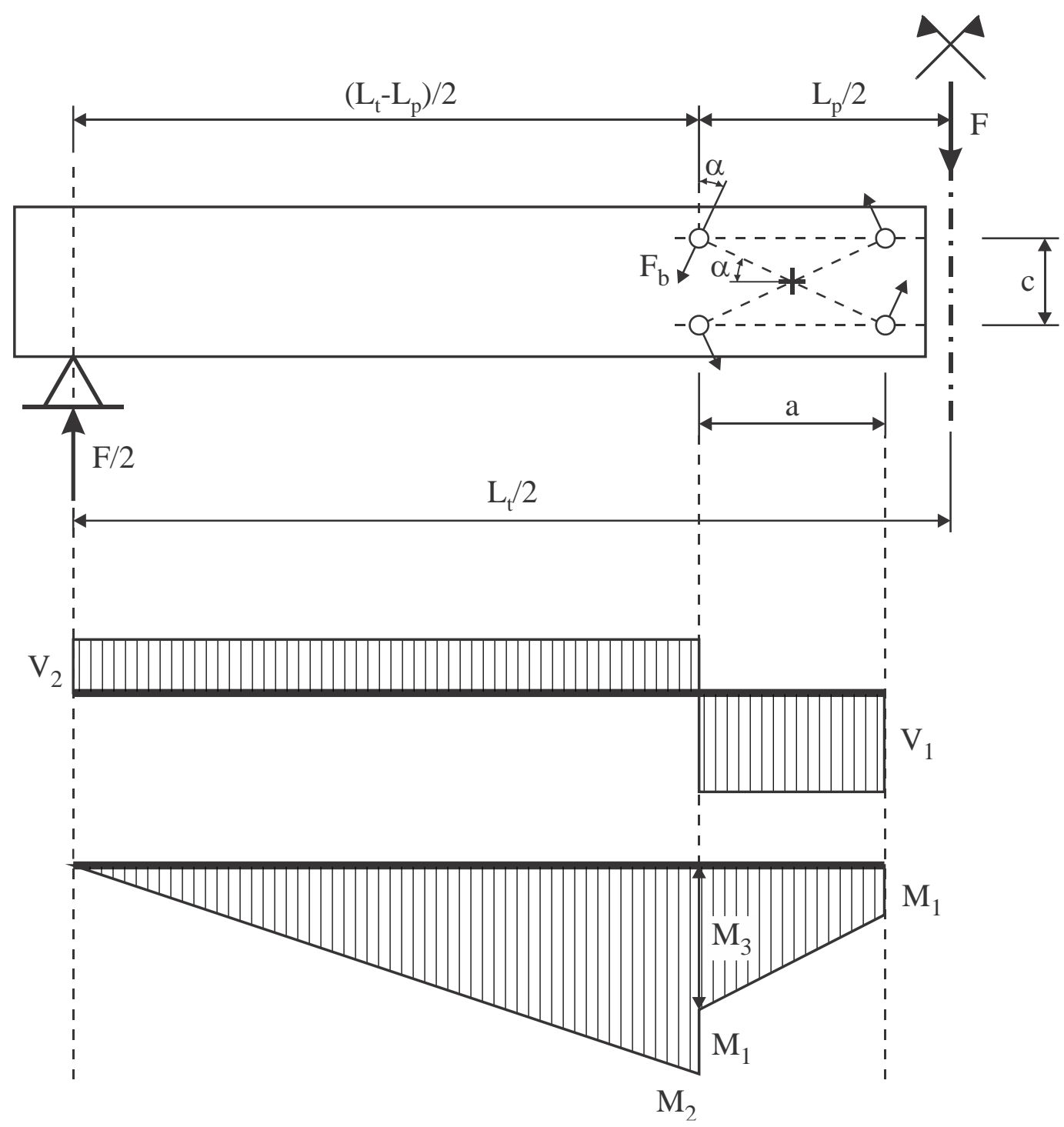

Figura A.1 - Diagramas de esforços solicitantes na terça. 


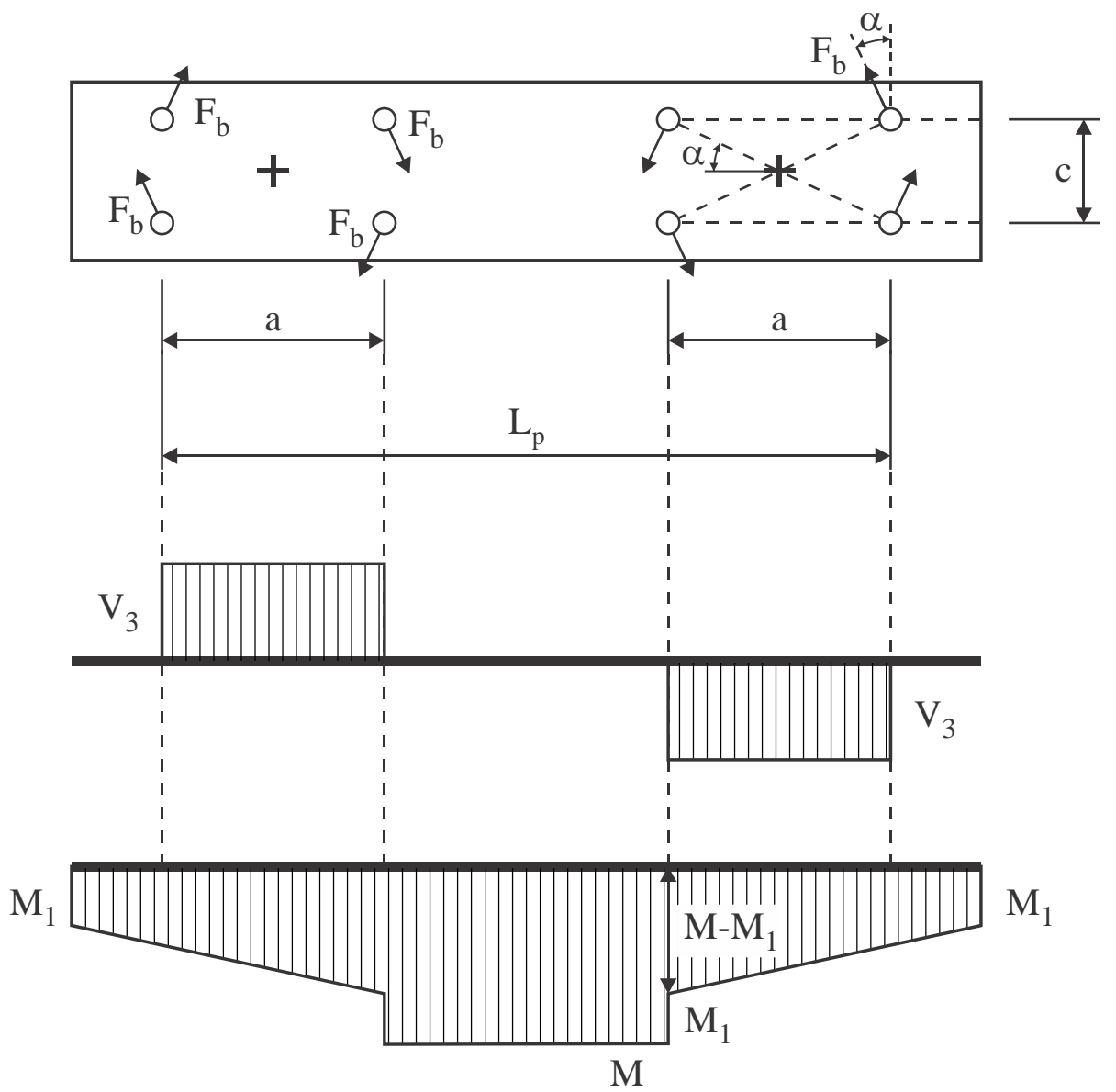

Figura A.2 - Diagramas de esforços solicitantes na luva.

Tabela A.1 - Expressões para cálculo dos esforços solicitantes e força nos parafusos.

\begin{tabular}{|c|c|}
\hline a) Momento fletor & b) Força cortante \\
\hline$M=\frac{F L}{4}$ & $V_{1}=\frac{F}{2}-2 F_{b} \cos \alpha$ \\
$M_{1}=\left(F_{b} \operatorname{sen} \alpha\right) c$ & $V_{2}=\frac{F}{2}$ \\
$M_{2}=\frac{F}{4}\left(L-2 L_{t}\right)$ & $V_{3}=2 F_{b} \cos \alpha$ \\
$M_{3}=\frac{F}{4}\left(L-2 L_{t}\right)-\left(F_{b} \operatorname{sen} \alpha\right) c$ & d) $\hat{\text { Angulo } \alpha}$ \\
\hline c) Força concentrada & $\alpha=\operatorname{arctg}\left(\frac{c}{a}\right)$ \\
\hline$F_{b}=\frac{F L}{8 \sqrt{a^{2}+c^{2}}}$ & \\
\hline
\end{tabular}




\section{APÊNDICE B - DIMENSÕES DOS PROTÓTIPOS}

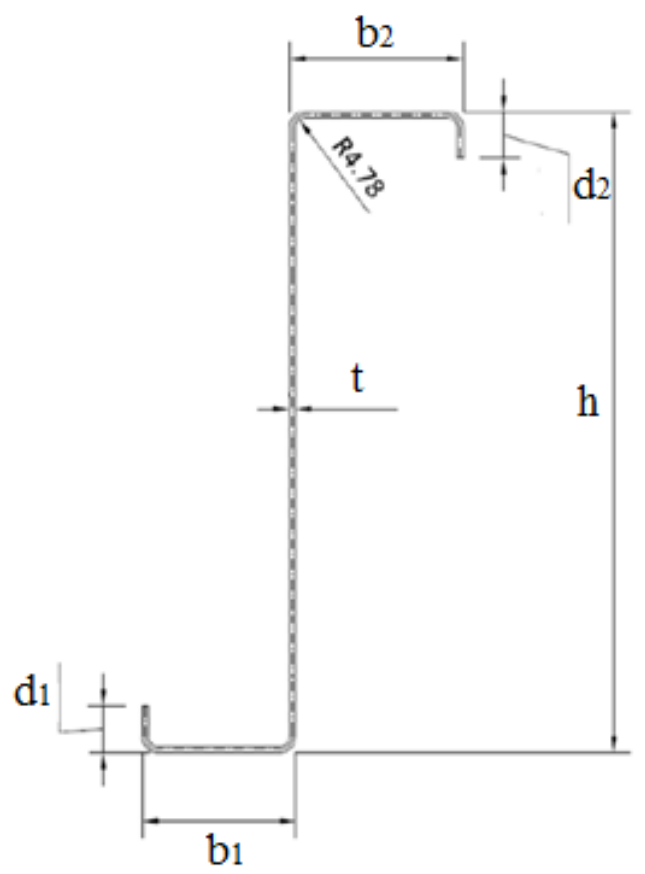

Figura B.1 - Seção transversal dos protótipos.

Tabela B.1 - Dimensões dos protótipos.

\begin{tabular}{|c|c|c|c|c|c|c|c|c|}
\hline Série & Protótipo & $\begin{array}{c}\text { Alma } \\
\text { h }(\mathbf{m m}) \\
\end{array}$ & $\begin{array}{c}\text { Mesa menor } \\
\mathbf{b}_{1}(\mathrm{~mm})\end{array}$ & $\begin{array}{c}\text { Mesa maior } \\
\mathbf{b}_{2}(\mathrm{~mm})\end{array}$ & $\begin{array}{c}\text { Enrijecedor } \\
d_{1}(\mathrm{~mm})\end{array}$ & $\begin{array}{c}\text { Enrijecedor } \\
\mathbf{d}_{2}(\mathrm{~mm})\end{array}$ & $\begin{array}{c}\text { Espessura } \\
\text { t }(\mathbf{m m})\end{array}$ & $\begin{array}{c}\text { Raio interno } \\
\mathbf{r}_{\mathbf{i}}(\mathbf{m m})\end{array}$ \\
\hline \multirow{5}{*}{ A } & Dimensões nominais & 220,00 & 59,00 & 67,00 & 22,00 & 21,00 & 1,95 & 4,78 \\
\hline & ZA62-L44 & 220,25 & 59,52 & 68,90 & 21,74 & 18,14 & \multirow{4}{*}{1,95} & \multirow{4}{*}{4,78} \\
\hline & ZA62-L88 & 220,75 & 60,11 & 68,39 & 21,71 & 17,95 & & \\
\hline & ZA62-L132 & 221,00 & 59,80 & 68,29 & 22,16 & 17,76 & & \\
\hline & ZA62-C & 220,50 & 60,38 & 67,96 & 21,88 & 18,61 & & \\
\hline \multirow{7}{*}{ B } & Dimensões nominais & 315,00 & 76,00 & 86,00 & 23,00 & 23,00 & 1,95 & \multirow{7}{*}{4,78} \\
\hline & ZB63-L63 & 314,75 & 75,65 & 87,35 & 20,87 & 20,01 & & \\
\hline & ZB63-L126 & 314,75 & 76,28 & 87,39 & 23,40 & 20,35 & 1,93 & \\
\hline & ZB63-L126T3 (Terça) & 315,50 & 76,30 & 87,52 & 23,77 & 20,43 & & \\
\hline & ZB63-L126T3 (Luva) ${ }^{\mathrm{a}}$ & 315,00 & 76,00 & 86,00 & 25,00 & 24,00 & 3,00 & \\
\hline & ZB63-L189 & 315,25 & 75,83 & 87,84 & 23,97 & 19,71 & \multirow{2}{*}{1,93} & \\
\hline & ZB63-C & 314,25 & 76,86 & 87,59 & 23,39 & 20,63 & & \\
\hline \multirow{7}{*}{$\mathrm{C}$} & Dimensões nominais & 315,00 & 76,00 & 86,00 & 23,00 & 23,00 & 1,95 & 4,78 \\
\hline & ZC83-L63 & 314,88 & 76,74 & 87,39 & 23,22 & 21,10 & \multirow{3}{*}{1,93} & \multirow{6}{*}{4,78} \\
\hline & ZC83-L126 & 315,75 & 76,90 & 87,43 & 23,33 & 21,22 & & \\
\hline & ZC83-L126T3 (Terça) & 315,25 & 76,03 & 87,84 & 23,67 & 20,55 & & \\
\hline & ZC83-L126T3 (Luva) ${ }^{\mathrm{a}}$ & 315,00 & 76,00 & 86,00 & 25,00 & 24,00 & 3,00 & \\
\hline & ZC83-L189 & 315,00 & 77,56 & 88,00 & 23,73 & 20,28 & \multirow{2}{*}{1,93} & \\
\hline & ZC83-C & 314,75 & 76,44 & 87,00 & 23,27 & 21,42 & & \\
\hline
\end{tabular}

${ }^{\mathrm{a} D}$ Dimensões nominais 


\section{APÊNDICE C - CARACTERIZAÇÃO MECÂNICA DO AÇO DOS PROTÓTIPOS}

De acordo com as dimensões da seção transversal (altura e espessura), as terças e luvas foram divididas em três lotes de fabricação. Foram usinados nove corpos de prova (Figura C.1) extraídos dos perfis correspondentes à bobina de aço utilizada na fabricação de cada lote (Figuras C.2, C.3 e C.4):

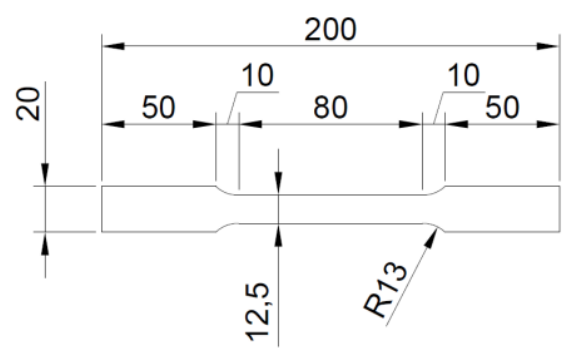

Figura C.1 - Corpos de prova para ensaio de tração conforme ASTM A370:2014.

- Lote 1 (código da bobina: RM 1640.2);

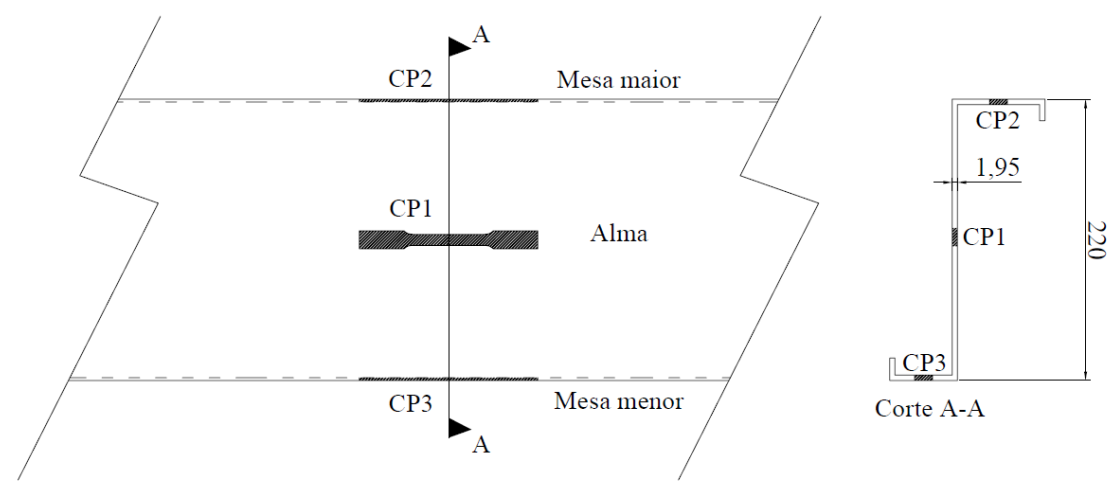

Figura C.2 - Corpos de prova extraídos do perfil Z com altura de $220 \mathrm{~mm}$ e espessura de $1,95 \mathrm{~mm}$. 
- $\quad$ Lote 2 (código da bobina: RM 1660.1);

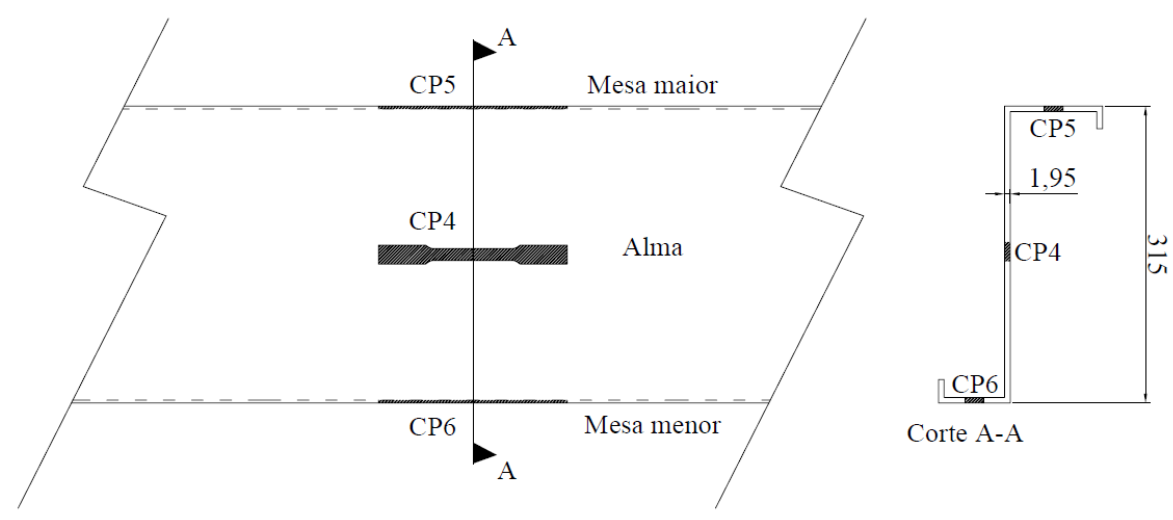

Figura C.3 - Corpos de prova extraídos do perfil Z com altura de $315 \mathrm{~mm}$ e espessura de $1,95 \mathrm{~mm}$.

- Lote 3 (código da bobina: RM 17441.1).

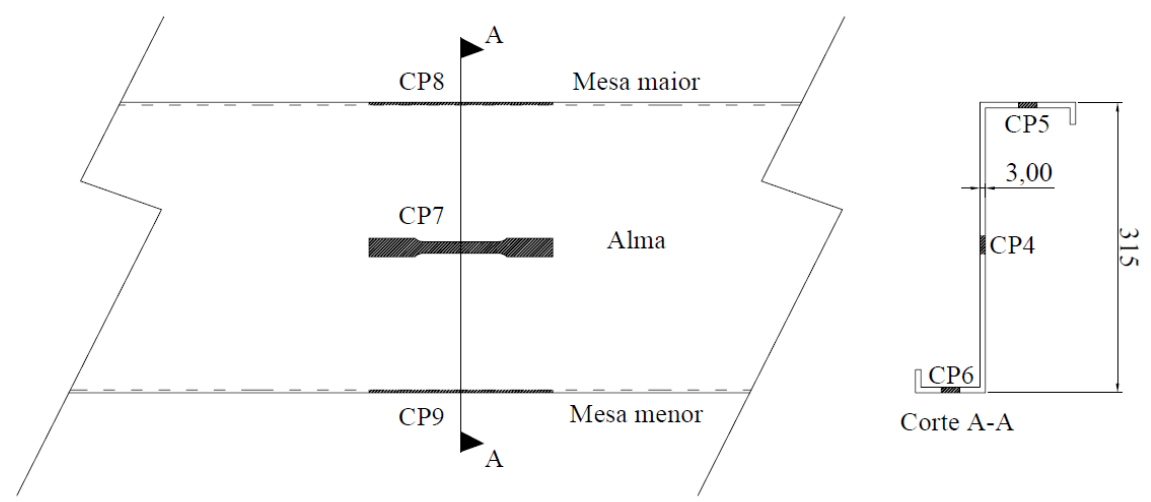

Figura C.4 - Corpos de prova extraídos do perfil Z com altura de $315 \mathrm{~mm}$ e espessura de $3,00 \mathrm{~mm}$.

Na Tabela C.1 são apresentados os resultados experimentais da caracterização mecânica do aço. Uma queda de energia no laboratório comprometeu a determinação da resistência ao escoamento $\left(f_{y}\right)$ e resistência à ruptura $\left(f_{u}\right)$ do corpo de prova 6 . 
Tabela C.1 - Propriedades mecânicas do aço ${ }^{\mathrm{a}}$.

\begin{tabular}{|c|c|c|c|c|c|}
\hline $\mathbf{C P}$ & Altura/espessura do perfil $(\mathbf{m m})^{b}$ & Local de extração do CP & $\mathbf{f}_{\mathbf{y}}(\mathbf{M P a})$ & $\mathbf{f}_{\mathrm{u}}(\mathbf{M P a})$ & $A(\%)^{c}$ \\
\hline 1 & & Alma & 397,4 & 484,0 & 24 \\
\hline 2 & $220 / 1,95$ & Mesa maior & 391,3 & 475,4 & 26 \\
\hline \multirow[t]{2}{*}{3} & & Mesa menor & 399,3 & 495,4 & 26 \\
\hline & & Média $=$ & 396,0 & 484,9 & 25 \\
\hline 4 & & Alma & 374,8 & 467,6 & 26 \\
\hline 5 & $315 / 1,95$ & Mesa maior & 387,4 & 479,8 & 26 \\
\hline \multirow[t]{2}{*}{6} & & Mesa menor & - & - & 30 \\
\hline & & Média $=$ & 381,1 & 473,7 & 27 \\
\hline 7 & & Alma & 375,9 & 462,7 & 32 \\
\hline 8 & $315 / 3,00$ & Mesa maior & 375,3 & 465,9 & 30 \\
\hline \multirow[t]{2}{*}{9} & & Mesa menor & 368,0 & 458,3 & 34 \\
\hline & & Média = & 373,1 & 462,3 & 32 \\
\hline
\end{tabular}

${ }^{\mathrm{a}}$ Valores mínimos conforme NBR 7008 - grau ZAR-345: fy = $345 \mathrm{MPa} ; \mathrm{fu}=430 \mathrm{MPa} ; \mathrm{A}=12 \%$.

${ }^{\mathrm{b}}$ Valores nominais

${ }^{\mathrm{c}}$ Base de medida igual a $50 \mathrm{~mm}$. 


\section{APÊNDICE D - INSTRUMENTAÇÃO DOS PROTÓTIPOS}
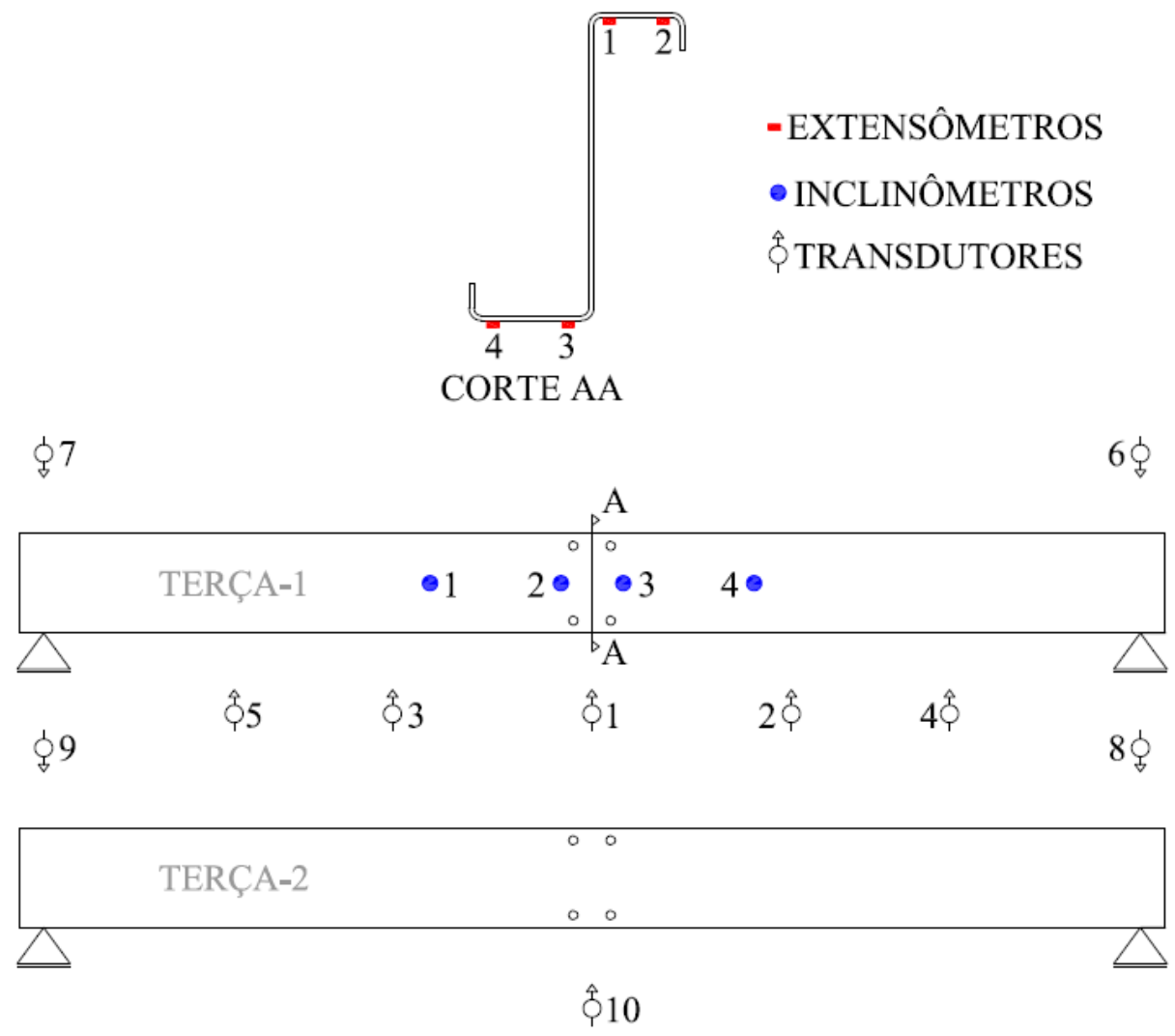

Figura D.1 - Instrumentação dos protótipos contínuos (sem emenda). 

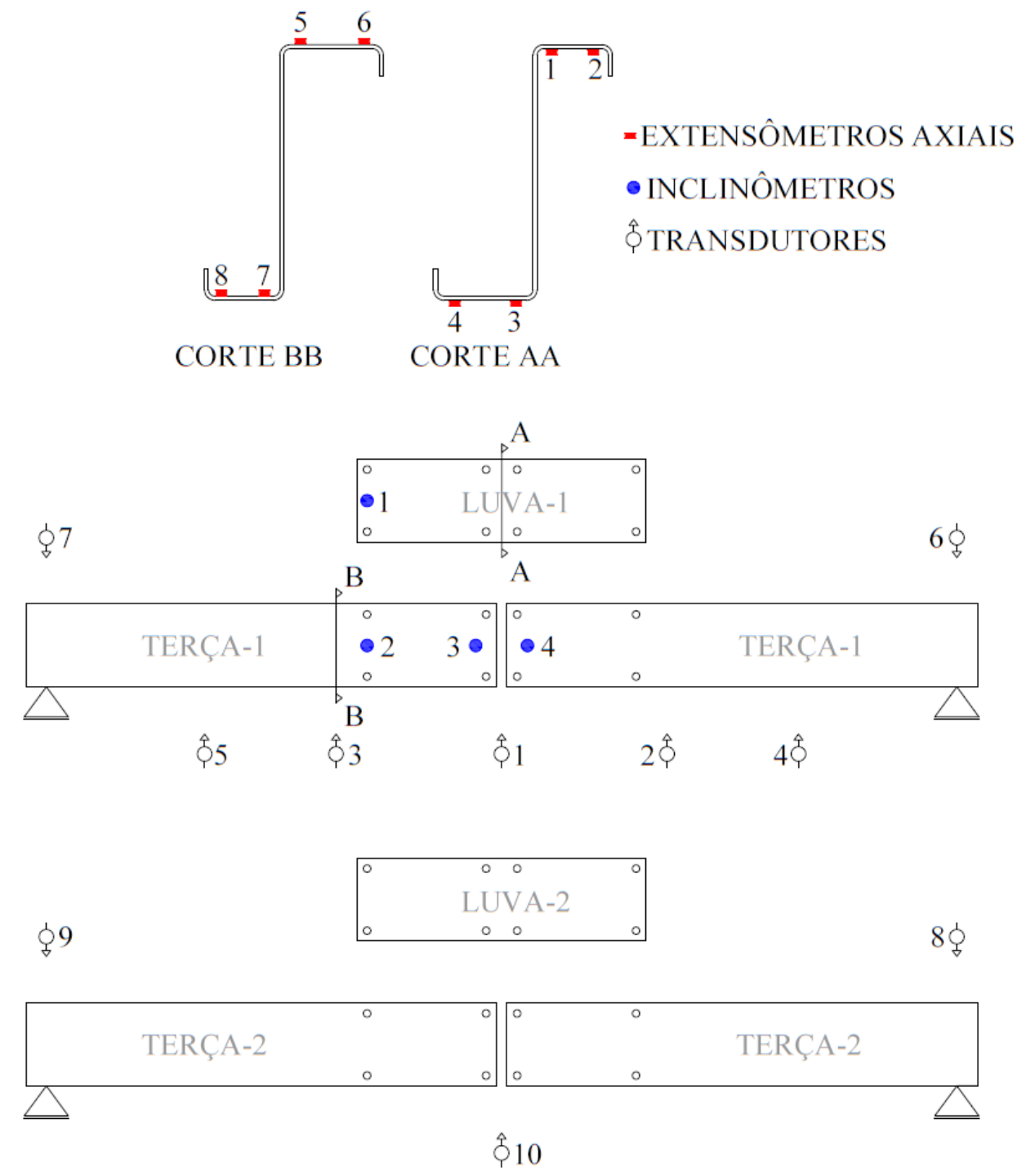

Figura D.2 - Instrumentação dos protótipos com luvas. 
- INCLINÔMETROS

$\hat{\text { TेTRANSDUTORES }}$

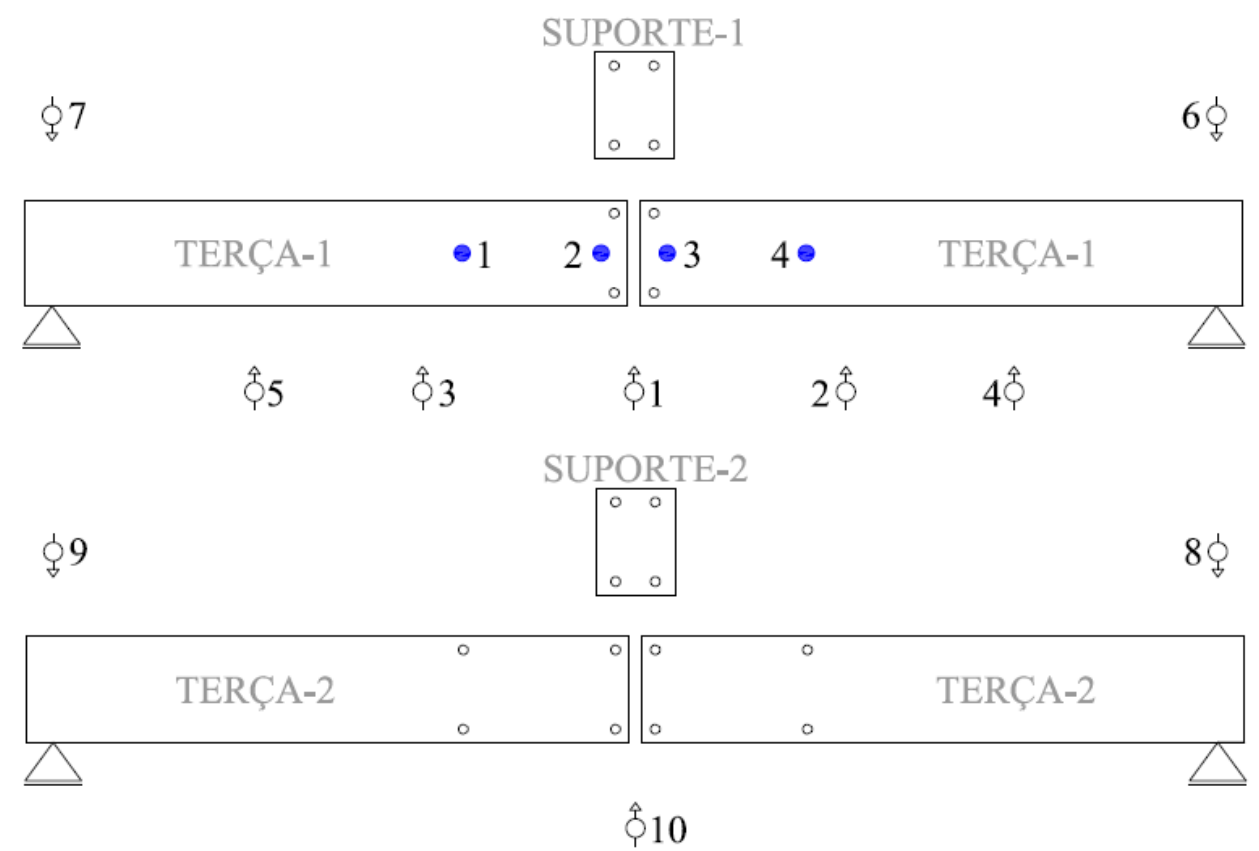

Figura D.3 - Instrumentação do protótipo conectado apenas no suporte 


\section{APÊNDICE E - ANÁLISE DE DEFORMAÇÕES NAS MESAS DAS TERÇAS}

$\mathrm{Na}$ flexão restringida (reta), a distribuição de deformações na mesa é admitida uniforme. Tal hipótese foi considerada nas análises de estabilidade elástica associadas à determinação do momento fletor.

$\mathrm{Na}$ montagem dos protótipos, as terças foram travadas lateralmente a intervalos regulares ao longo do vão, de modo a configurar uma condição de flexão restringida, isto é, flexão em torno do eixo perpendicular à alma. Para confirmar tal condição, os protótipos da série B foram instrumentados com dois extensômetros axiais posicionados nas extremidades das mesas superior e inferior de duas seções transversais (cortes A-A e B-B), conforme apresentado nas Figuras E.1 e E.2.

As deformações na mesa, próximo à alma, foram aqui denominadas $\varepsilon_{\text {MESA-ALMA }} \mathrm{e}$ as deformações na mesa próximas ao enrijecedor de borda foram denominadas $\varepsilon_{\text {ENR-MESA. }}$
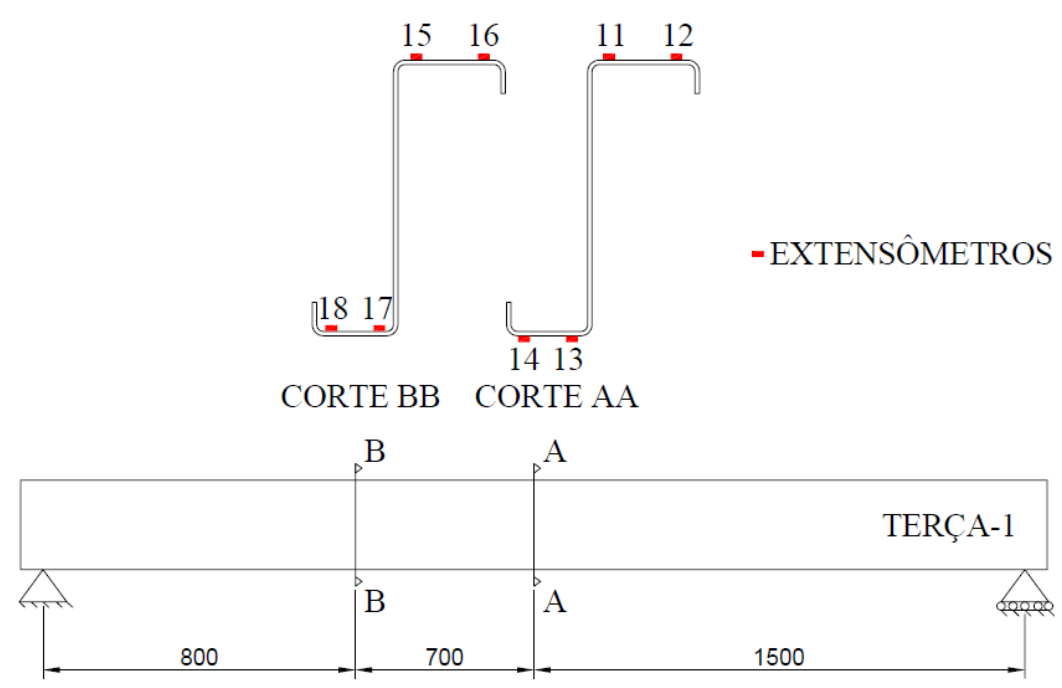

Figura E.1 - Posições dos extensômetros nas seções analisadas: protótipo ZB-63C. 


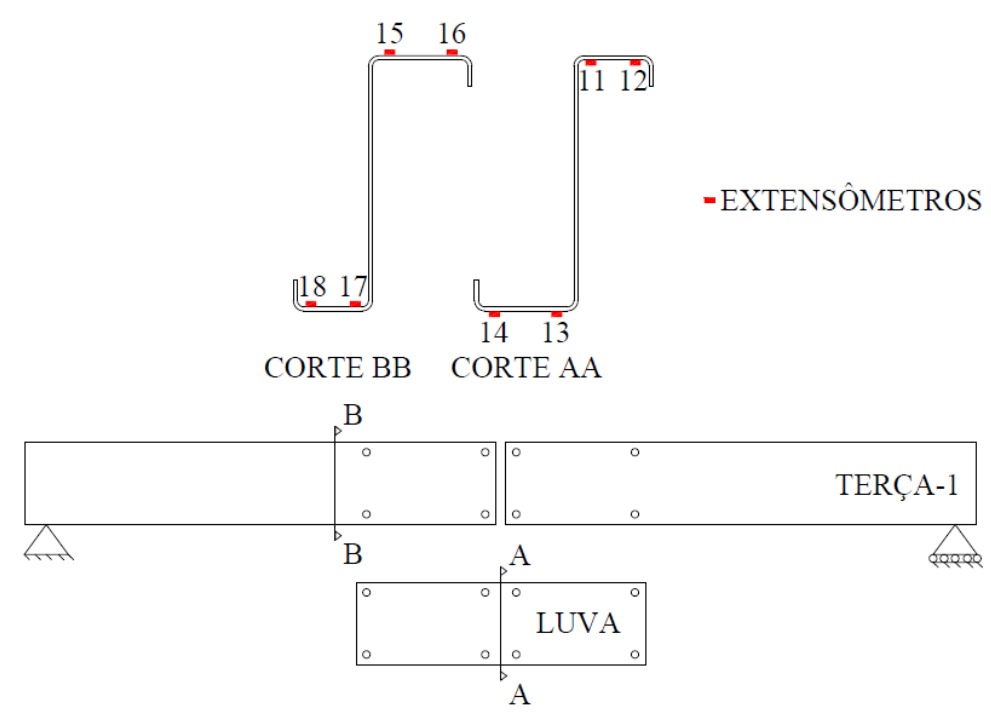

Figura E.2 - Posições dos extensômetros nas seções analisadas: protótipos com luvas.

Para a terça contínua, a evolução das deformações específicas em função da força é mostrada para as duas seções indicadas pelo corte A-A (Figura E.3a) e pelo corte B-B (Figura E.3b). Valores teóricos elástico-lineares (curva teórica) foram calculados com base na teoria de vigas e introduzidos como referência para efeito de comparação com as deformações experimentais.

Os resultados obtidos para o protótipo com terças contínuas fisicamente (ZB63-C) confirmam o comportamento esperado de flexão restringida, uma vez que as deformações nas extremidades das mesas apresentaram valores muito próximos.

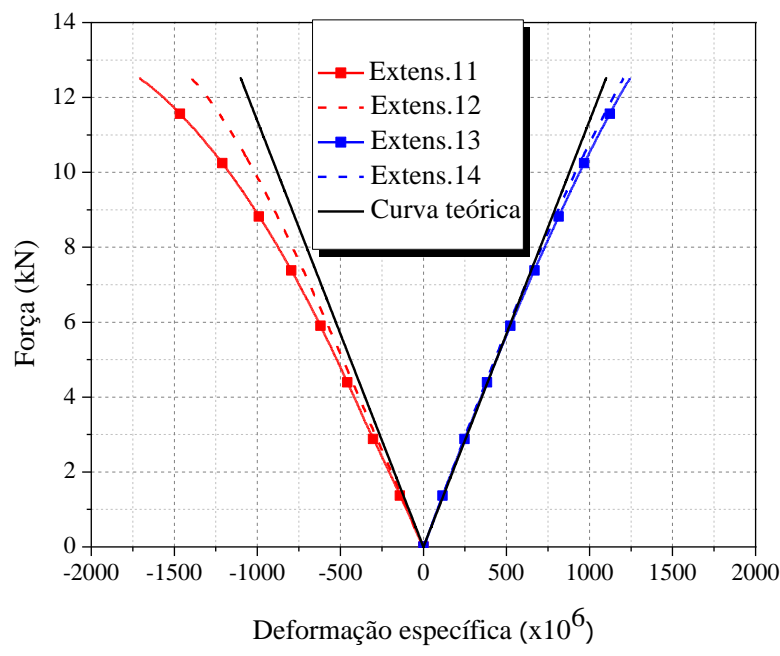

a) Seção A-A

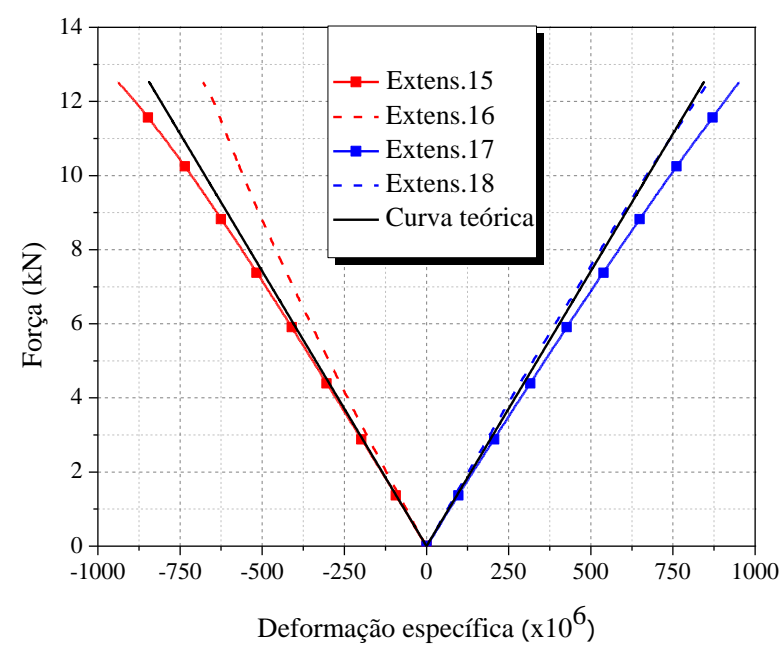

b) Seção B-B

Figura E.3 - Curvas força versus deformação especifica para o protótipo ZB63-C. 
Nas Figuras E.4 (seção S1) e E.5 (seção S2) são apresentadas as razões entre deformações experimentais ( $\left.\varepsilon_{\text {ENR-MESA }} / \varepsilon_{\text {MESA-ALMA }}\right)$ em função da relação entre o momento fletor solicitante e momento fletor máximo $\left(\mathrm{M} / \mathrm{M}_{\max }\right)$. Pela acentuada diferença entre as deformações na mesa, é possível observar que as terças com luvas, na região instrumentada (região da emenda) não ficaram submetidas à condição de flexão restringida, distanciando-se mais dessa condição quanto menor o comprimento da luva.

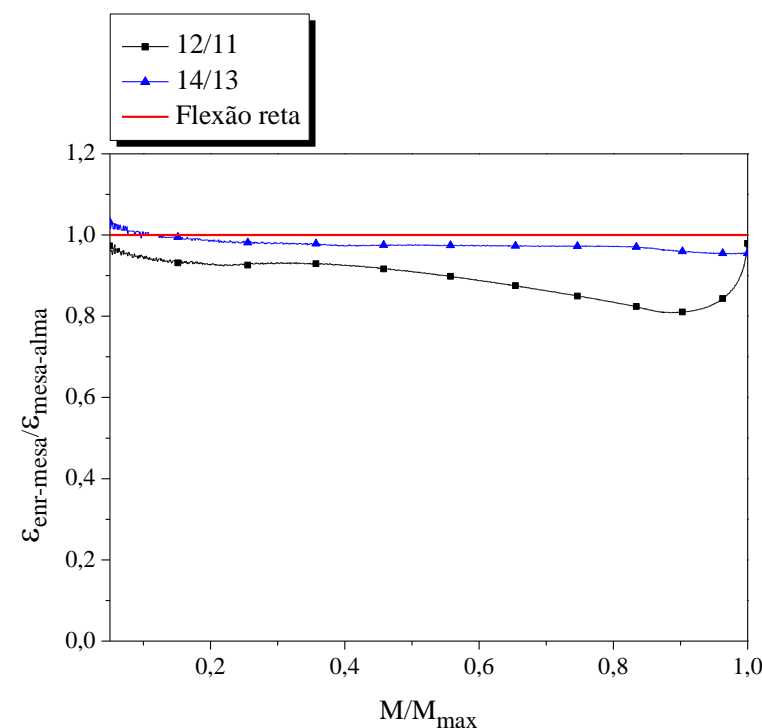

a) Protótipo ZB63-C

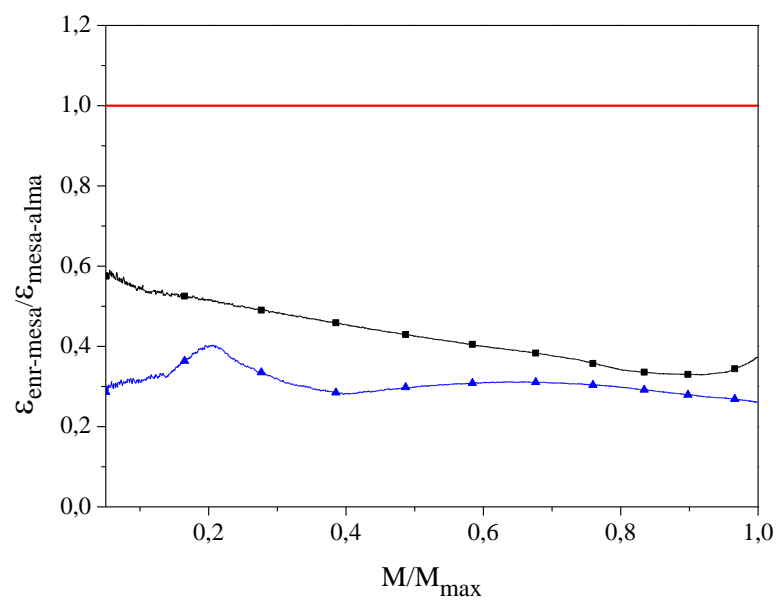

c) Protótipo ZB63-L126

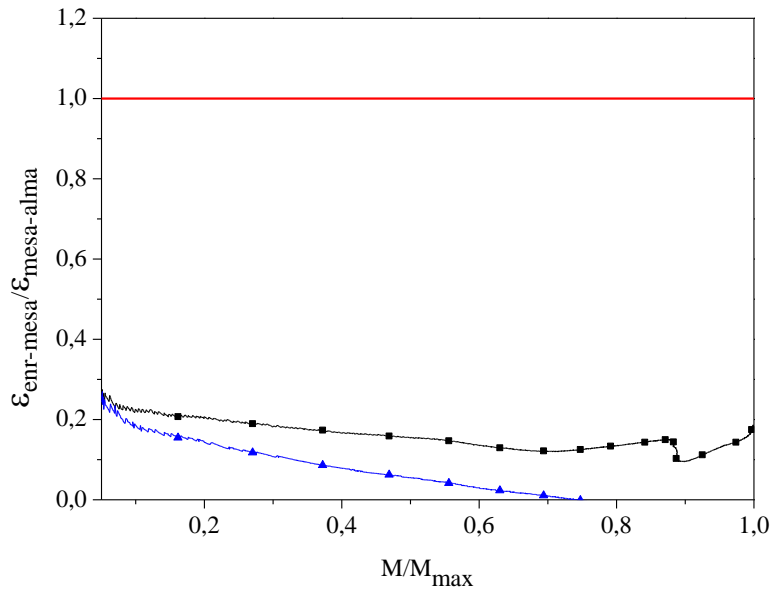

b) Protótipo ZB63-L63

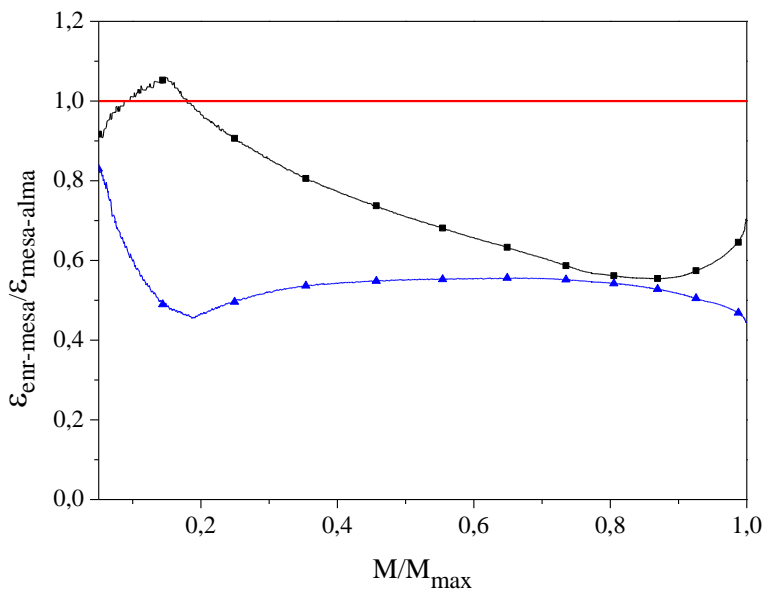

d) Protótipo ZB63-L189

Figura E.4 - Razão entre as deformações específicas nos extensômetros na seção S1. 


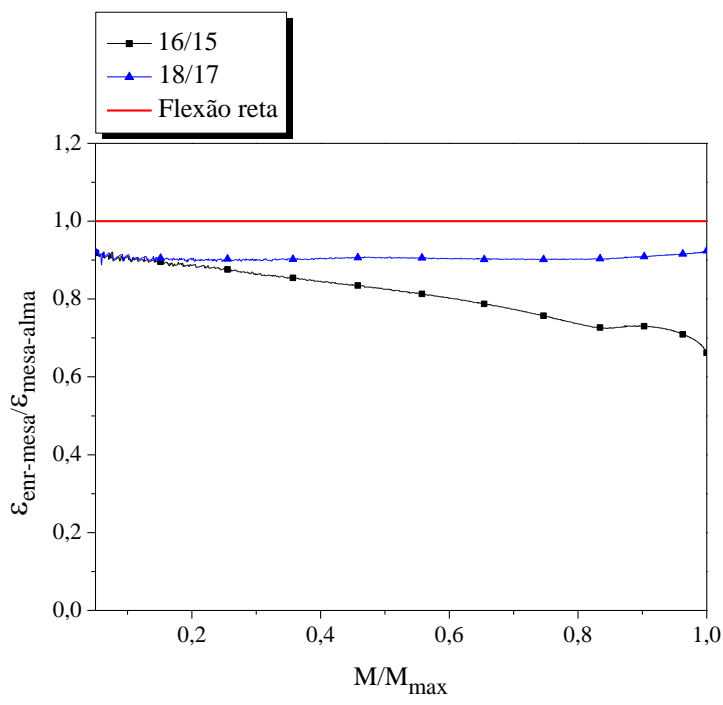

a) Protótipo ZB63-C

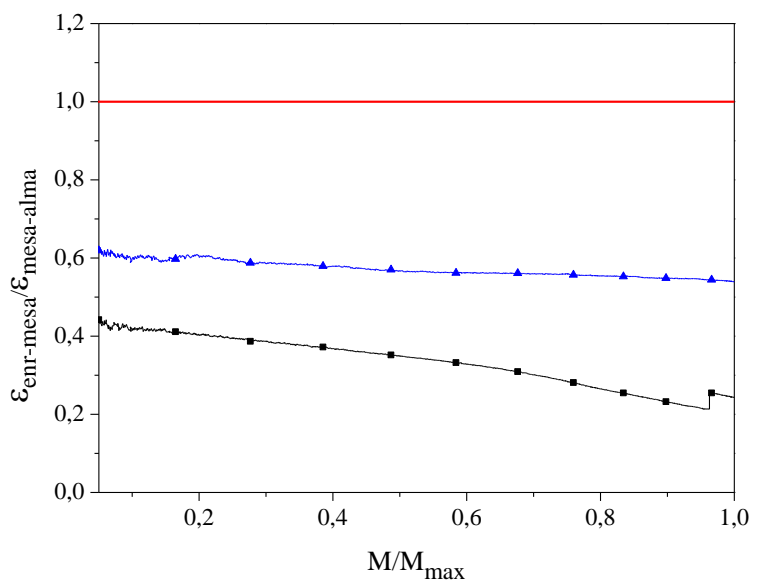

c) Protótipo ZB63-L126

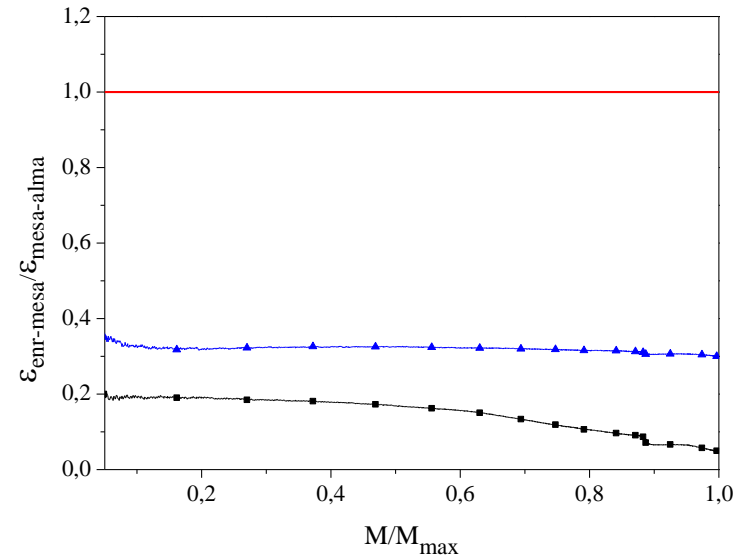

b) Protótipo ZB63-L63

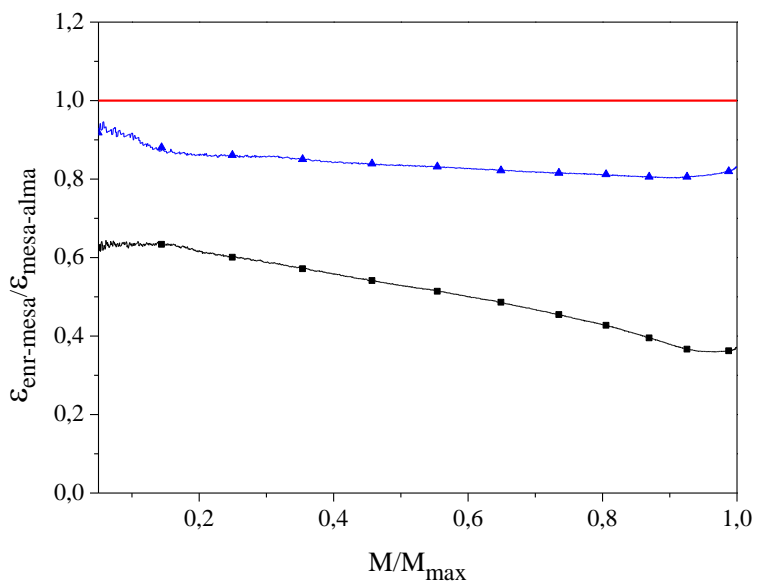

d) Protótipo ZB63-L189

Figura E.5 - Razão entre as deformações específicas nos extensômetros da seção S2. 